University of Rhode Island

DigitalCommons@URI

Open Access Master's Theses

1978

\title{
An Experimental Investigation of the Nearfield Pressures of Ultrasonic Transducers and Arrays
}

George Anthony Fisher

University of Rhode Island

Follow this and additional works at: https://digitalcommons.uri.edu/theses

\section{Recommended Citation}

Fisher, George Anthony, "An Experimental Investigation of the Nearfield Pressures of Ultrasonic Transducers and Arrays" (1978). Open Access Master's Theses. Paper 878.

https://digitalcommons.uri.edu/theses/878

This Thesis is brought to you for free and open access by DigitalCommons@URI. It has been accepted for inclusion in Open Access Master's Theses by an authorized administrator of DigitalCommons@URI. For more information, please contact digitalcommons-group@uri.edu. 
AN EXPERIHENTAL INVESTIGATION OF TEE NEABFIELD PEESSURES OF JITRASONIC TBAHSDUCERS

AND ARBAIS

BI

GEORGE ANTHON I FISBZR

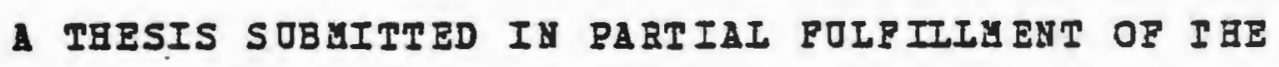
REQUIREE ENTS OF THE DEGREE OF

GASTER OF SCIENCE

I

OCEAN ENGINEERING

OHIVERSITI OF BEODE ISLAND 


\section{vASTER OF SCIENCE THESIS}

OF

GEORGE ANTHONY FISHER

Approved:

Thesis Comittee

Major Professor-.- Te tei fltandonn

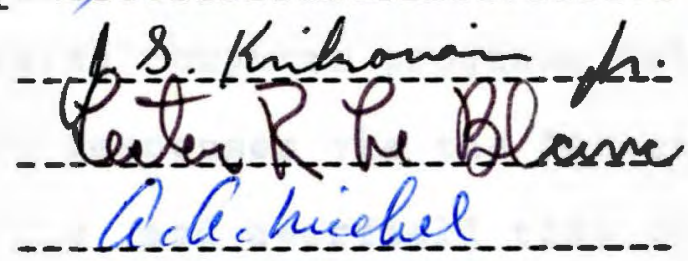

Dean of the Graduate School

UNIVERSITY OF BHODE ISLAND 
This thesis describes the procedures and results of research conducted on palsed ultrasonic piezoceramic transancers and arrays which operate in the megahertz range. These transducers and arrays are typical of the types employed currently in biomedical diagnostic systems. Two areas vere addressed: The rerification of the Impulse Besponse Approach as a method to predict the spatial and tenforal characteristics of the acoustic field pressures of nltrasonic transucers of general shapes and excitations, and the infestigation of the element interaction and spatial resolution of field pressures of arrays of piezoceramic elements.

In antomated computer controlled high frequency acoustic measuring system was constructed. Sereral high frequency transducers were built to obtain acoustic nearfield data vith this system. The data vere subsequently processed using computer programs which were created to obtain impulse responses via the deconrolution of the far field on axis and nearfield time dependent pressures. The acoustic fields of an array driven under focussed and unfocussed conditions were also extensively nap ped.

The experimentally derired impulse responses vere in good agreement with the theoretical responses and thus provided important new verification of the Impulse aesponse approach. The results of the experiment also indicated that extraneous modes of pibration of piezoceramic discs ii1: 
vere, in this case, insignificant. A multi-element transducer array was constructed and operated in such a manner as to focus the acoustic energy, confining it to a narrow region as opposed to a continuous beam. The element to element interaction effects caused by electrical and acoostic coupling vere found to be of significant importance in the single driren elenent case. The effects of interaction were not great enough to cause a perturbation from the expected field pressure pattern when the array was driven for focussing. 
Grateful Acknowledgment for the support of this work

is made to:

THE NATIONAI INSTITUTE OF HEAITH

$$
\text { and }
$$

TERE UNIVERSITY OF RHODE ISIAND

ACADEMIC COMPUTER CENTER 


\section{TABLE of CONTENTS}

I. INTRODDCTION 1

II. MEASOREYENT STSTEM 6 .

a/D Con verter 9

Positioning System 19

analog Signal source 21

Beceive Amplifiers and Probes 22

III. TEEORY of the IYPOLSE RESPONSE APPBOACE 27

IV. MATHEYATCAI TECENIQJES fOI DECO\&VOLOTION 40

Evaluation Criteria 43

Specific Techniques 45

Description of Implenented Method 53

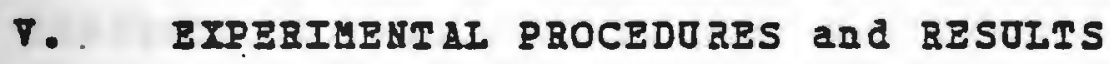

POE SINGLE TBANSDUCBRS

Transacer Construction 64

beasarements and Besults 67

VI. EIPERIYENT AL PROCEDURES and RESULTS fOI ARRATS 87

Introduction $\quad 87$

Array Construction : 89

Measurement Procedures 90

yeasurements and lesults 92

VII. CORCIUSIOHS 108

IIST Of REFERENCES 111

APPENDIX A - COHPOTER PROGRAM IISTINGS 113 
Block Diagran of leasurement system 8

Positioning Carriage 10

A/D Converter: Timing Diagram 12

M/D Converter: Block Diagram 16

Geometry of General Integral Equation 28

GeometIy of Impolse Response Punction 32

Geometry of Coordinate Transformation 33

Theoretical Impulse Besponse: On axis 36

Theoretical Impulse Response: Inside Disc ' 37

Theoretical Impulse Response: Outside Disc 38

Theoretical Impulse Response: Par Field outside Diss 39

Box yodel of Typical yeasurement systell 42

Test Result of Frequency Dirision Technigue 49

Test Result of Time Domain Approach 52

Test desult of Iteratire Technigue: No Dypamics 59

Test.Result of Iterative Technique: Rith Dpramics 61

Convolution Check of Iterative Technique 63

Experimental Impulse Response: Insufficient Range $\quad 69$

Experimental Impulse Besponse: Steel and Poan Baffle 71

Experimental Impulse Besponses: Lead Metaniobate on

Lluninam Bar, Outside Disc 74

Lead Eetaniobate on Tungsten Backing, outside Dise 75

Iithium Sulphate on Tungsten Backing, outside Disc 76 
Recontolution Check, Outside Disc

Lead पetaniobate on Tuggten Backing, Inside Disc

Iithing Sulphate on Tungsten Backing, Inside Disc

Beconvolution Check, Inside DisC

Lead Jetaniobate on Aluminam Bar, On aris

Lead Betaniobate on Tungsten Backing, On Aris

Iithium Sulphate on Tungsten Backing, on axis

Reconvolution Check, on Aris

Circuit Diagral of Digital Delay polser

91

Field of array: One Element, Others open

Fleld of array: One Element, Others Open

Pield of array: End Element, Others Clamped

Field of array: 11 Elements

Pressure Time Bistory: Hot Pocussed

Pressure Time Eistory: Pocal point

Geometry for Delap Calculation

Pleld of Array: Pocussed at $B=0 \quad 2=20$

Field of arIay: Focussed at $\mathrm{R}=10 \quad \mathrm{z}=30$ 
This thesis describes procedures and results of research carried out at the Oniversity of Rhode Island, under a grant from the National Institute of Bealth, G 23104. The objectires of this study are: The investigation of the nearfield characteristics of certain nltrasonic transducers and arrays which operate in the negahertz range, and the verification, of the impulse response approach to evaluate the spatial and temporal characteristics of the acoustic field which results from the pulsed vide bandyidth excitation of ultrasonic transducers and arrays. Oltimately the implementation of this knowledge will be used to design and construct an nltrasonic bionedical diagnostic systen which operates in real time, with a higher order of resolution than previonsly attained. .

Reports generated by the lational Science Foundation have summarized the present state of the art in the use of medical ultrasonic devices for diagnostic purposes. These reports have also made explicit recommendations concerning the tyge of research wich is required in order to advance this area. [ see references (1) through (5) ], In particular, the need for research on eraluating the 
operating characteristics and limitations of pulsed ultrasonic systems which atilize two-dimensional transducer arrays, is indicated. It is expected that, as the state of the art adrances, new uses for these ultrasonic diagnostic systems will be found.

It was intended that the work performed under this grant produce significant advances in the area of pulsed acoustic radiators and arrays. To this end, the project proceeded in three distinct stages. First a collection of equipment was assembled and constructed to form a Measurement systen capable of making the neccessary altrasonic field measurements in the megahertz range. secondly. computer programs to process this data were uritten and evaluated. Finally, measurements vere made on several single element transaucers, and also multi-element arrays. These measurements were then used to verify the Inpulse Response vethod of evaluating the characteristics of pulsed acoustic fields from single transducers and arrays.

an erperimental verification of the impulse response approach to evaluate the spatial and temporal characteristics of pulsed acoustic fields fron ultrasonic transducers and arrays bad not been previously performed. 1 few investigators bave measured time dependent pressures of palsed baffled pistons, comparing them to those predicted by theory; howerer, rafious difficulties in obtaining measurements have appeared. These experimental 
difficulties, as explained below, have provided stumbling blocks to verifying anp analytical method of predicting acoustic fields for pulsed ercitations of transducers and arrays.

In a recent experimental investigation of the transient acoustic field which resalts from an inpulsive electrical excitation of a piezoceramic cylinder, Carome (6) used a fairly large piezoceramic element, in the form of a crlinder tyo or three centimeters in diameter, 2.54 or 5.08 centimeters thick. The motivation for this large length was based on the observation that compressional wares propagate from both the front and the rear faces of the element when the transducer is electrically pulsed. The ware of interest is that propagating from the front of the disc into the medium. Howerer, a short time later the vare from the rear face has travelled through the element and arrives at the front face, making the face relocity hard to predict. A large length was used to increase the time separation between the front and rear waves, hopefully to the point where they were non-orerlapping. Also, a large diameter was chosen to create a similar separation of edge pulses in the pressure time history.

Sereral other Iesearchers [ (7) and (8) ] hare mounted elements on materials chosen to match the acoustic infedance of the element, thereby minimizing the back face pulses. Also, backing materials having a high loss factor, such as mirtures of epory and Tungsten, have often been 
employed, yielding transducers of significantly wider bandwidth. Rossoff (7) extensively documented the electrical and mechanical properties of piezoceramic transducers, for cases with and without the use of lossy backing materials. The properties of the lossy backing materials were also described in detail as functions of the relative concentration and size of the rungsten particles. Redwood (8) treated the use of such backings as an approximate resistive load in his electrical analog model of pulsed transducers.

since the dynamics of the probe become critically important in ang wideband acoustic experiment, neight and Bayman, (9), constructed their oun probes for these reasons, and used then to inrestigate the field of faicly small (5-8 mm.) diameter pistons, which were also backed uith loaded epoxy. Using a schlieren visualization system, the pulses travelling from the face and the edges of the projector were clearly seen. These results are in general agreement with those predicted via the use of the impulse response approach, (11) .

In studies comparing experimental results to theoretical predictions of acoustic transient fields, both the drnamics of the projector and probe are important. In particular it should be noted that the behavior of the radiating face of the piston is critically important. Bither assumptions must be made that the face is moring vith a uniforl relocity distribution, or this relocity 
distribution mast be measured. In regard to the probe it is noted that its directivity and dyamic response can greatly affect the videband measurements.

There is considerable conjecture presently as to the importance of vibrations other than the simple thickness expansion of the elements which results in the aniform velocity distribution on the radiating face. Elasticity theory predicts that radial modes of vibration are possible, and actually probable. The excitation of these modes can of course be expected due to the wideband electrical excitation and the non-uniform loading presented to the faces of the element by the fluid and the backing material. Bowerer their importance relative to the thickness mode is presently undefined.

This study presents experimental procedures which are used to give new verification to the Impulse Besponse Approach. The acoustic field which results from the pulsed excitation of several transducers is investigated, and the results are shown to shed some light on the accuracl of the uniform velocity distribution. Pinally, a multi-element array of small piezoceramic transaucers is constructed and analysed, and the resultant acoustic pressure fields for pulsed excitation are presented. The subject of interaction between different elements of the array is addressed, as are the differences betyeen nearfield beall focussing and far field beall forming. 


\section{UEASUREMENT SYSTEH}

as put forth in the grant proposal, the work was to start with an investigation of the pulsed ultrasonic field of single element high frequency piezoceramic transducers. a verification was sought of the Impulse Response Approach as a method of acoustic field prediction, which is elegantly simple in its mathematics, yet able to prodict time dependent pressures not only in the far or near field but at all points with equal ease. The Iesearch was to continue with a study of multi-elenent electronically steerable phased arrays.

In the early stages of planning of this research, it vias forseen that a prereguisite to performing the types of measurements needed was the construction of a complete measurement systeu. Early experiments made obvious these needs by their absence.

In rier of the high frequencies in rolved, and the precise physical relationships required to obtain the beam patterns and field behariors which yere sought, two areas of equipment were lacking. These vere: First; a high. speed analog to digital converter to be used to digitize pressure time histories; and second, a precision positioning system to maintain and control tbe physical relationships desired between the projecting transducer(s) and field pressure measuring probe.

The above requirements should not be taken to indicate 
that the research tean was completely deroid of resources; indeed, quite a collection of test equipment which was partially or completely suited to acoustic research had already been amassed at the Dniversity of Rhode Island Department of Ocean Engineering's South Lab. This included a Data General Mova 1200 minicomputer which was Iichly endoved with peripherals, including a 9-track magnetic tape drive, a dot matrix plotter, a dual floppy disk, and a BODEl data link to the academic computer center. [ see figure (1) ] . Also arailable were a large tank vith morable carriages for acoustic test vork; several low frequency oscilloscopes; and the existing technical services and personel of the department.

It was therefore decided to expand upon the existing data processing capabilities of the Mova, at least as far as was practical. This expansion took the form of the construction of a high speed analog to digital converter, configured to the rova as a dedicated I/O derice; and the construction of a microprocessor-based computer with capability to interface to the Nora. Hhere processing exceeded the capabilities of the Nova, the data would be transferred to the academic computer center system for processing on a large mainframe computer.

Dhile it was fortunate that such equipment existed to be expanded upon for data acquisition and processing needs, the teal was less fortunate as to the positioning spsten. although the large scale acoustic tank was available, it 


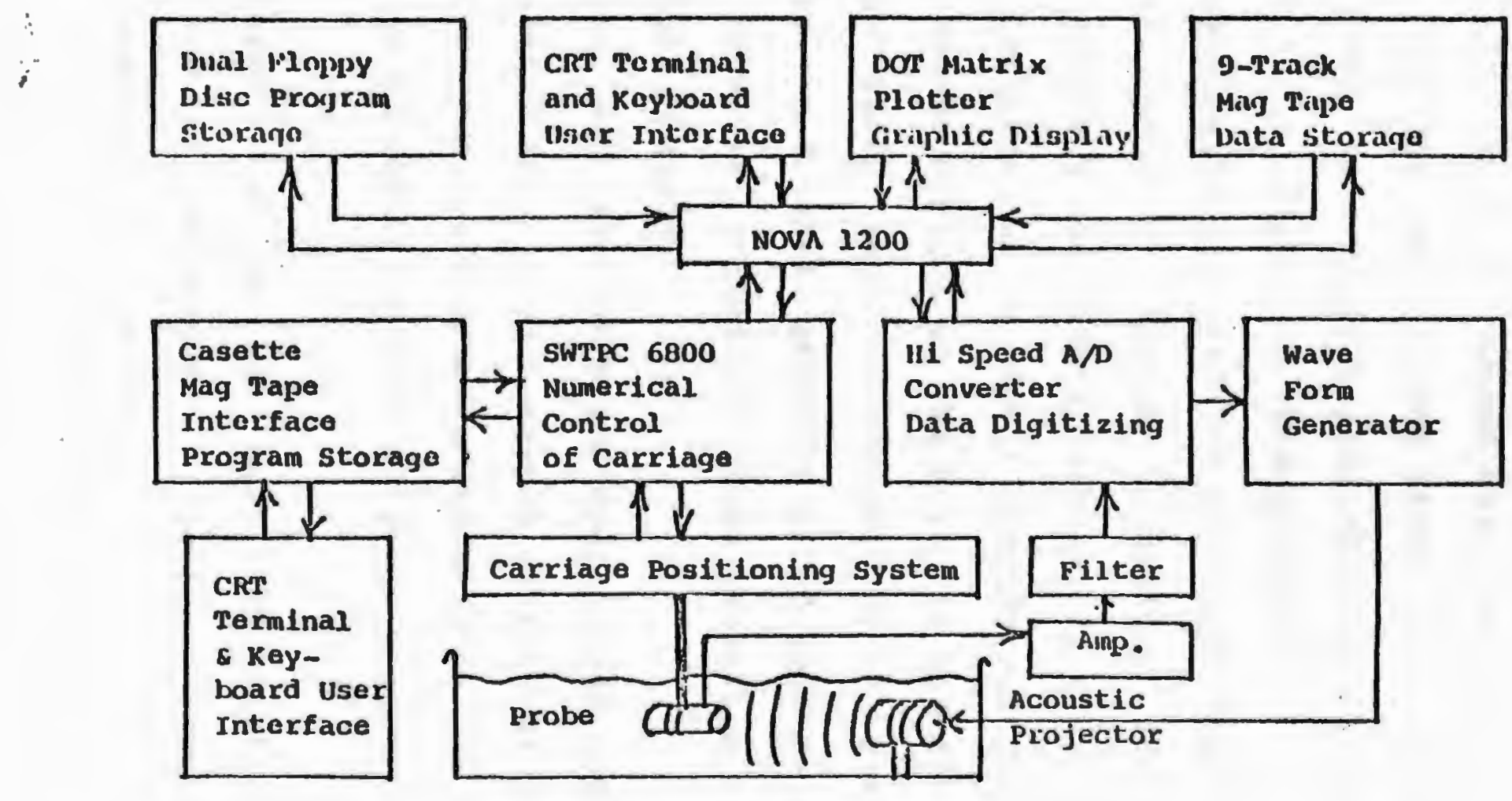

- Figure 1. Data Acquisition System 
vas felt that, in view of the suall distances and high precision necessary, and due to the high frequencl nature of the work, the system would prove too large and nnvieldI. As it later turned out, certain measurements had to be carried out in the large tank. Bowerer, all measurements vere made using a precision positioning systen designed and built as part of this research.

The positioning systen, in its final configuration, was a fully a utomatic derice consisting of a computer controlled carriage positioning systen, as shown in figure (2). The position of a small staging was placed under complete computer control of the Nora via the use of small D.C. motors, which vere controlled by a slare nicrocomputer, and shaft position and direction encoders. This made possible extensive field mappings containing several thousand points.

Nith the addition of these specialized derices, the Mota was transformed in to a system capable of performing automated acoustic measurements and storing the resultant data for later processing on the dcademic Computer center's Systex.

a discussion of the abore mentioned additions to the MOT a will now be described in greater detail in the following subsections.

AYALOG tO DIGITAL CONVERTER

For some of the beampattern measurements needed, a 


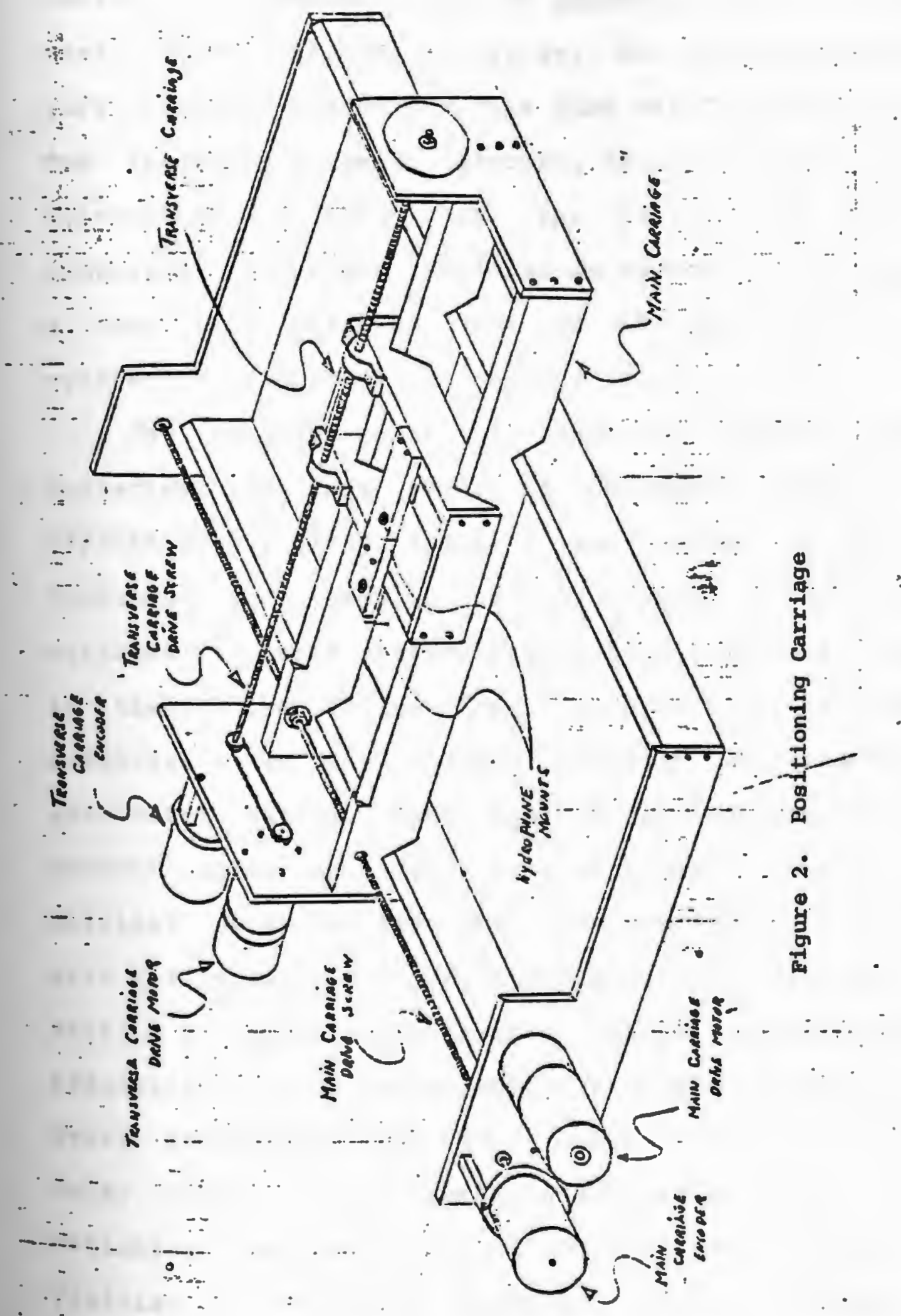


peak detector and relatively slow analog to digital converter (referred to as $a / D$ henceforth for convenience) vould have sufficed. Hoverer, for the Impulse Response york, accurate pressure versus time waveforms were desired. The frequency range of interest, in view of the biomedical orientation of this work, was between 1 to $10 \mathrm{Hzz}$. To accurately reproduce wareforms as opposed to just spectra, a very high samfling rate of at least several tens of megahertz and preferably $100 \mathrm{kHz}$. was indicated.

The present state of technology does not offer $A / D$ converters of this speed at reasonable cost, so a repetitive sapling approach ras adopted. Borrowing a technique from sampling oscilloscopes, a slower a/D was atilized to make conversions on triggered analog signals. In theory the analog event is repetitive, and hence the sampling times are shifted slightly relative to the successive erents. These samples are then rearranged into correct order to field a time sampled record with a sampling rate corresponding to the frequency associated with the small time shift, [see figure (3)]. To control this shift, a reliable fitter-free timer vitb binarg input and resolution of 10 nanoseconds was purchased as a unit froll Evans Associates, and is referred to as the Interleave Delay Timer. Jsing readily arailable logic derices, a reliable time shift of 10 manoseconds was obtainable, rielding an effective sampling rate of $100 \mathrm{Mz}$, which proved to be more than sufficient. 


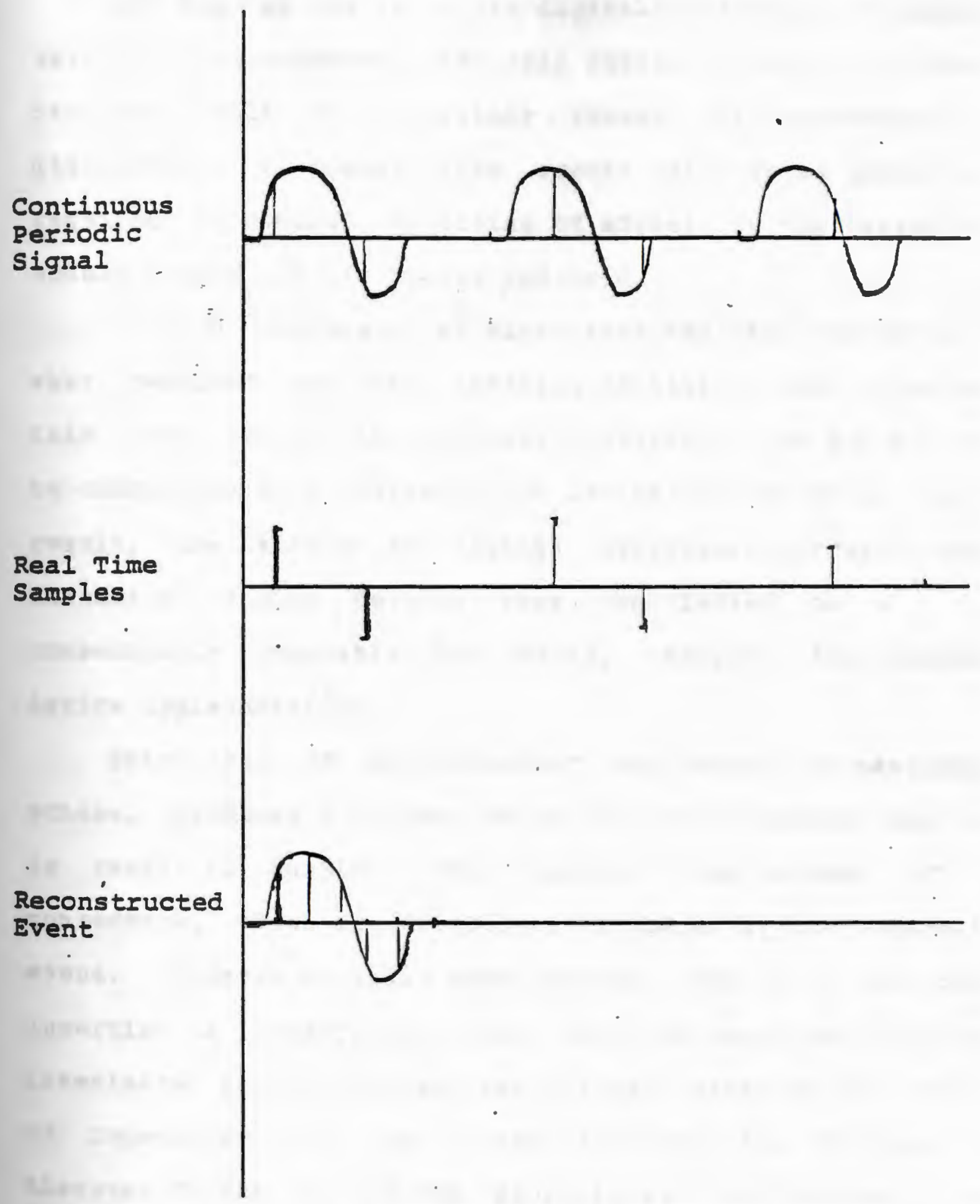

Figure 3. Analog to Digital Converter riming Diagram 
as far as the analog to digital conversion of analog waveforms was concerned, the only remaining need yas a fast sample-and-Eold to accurately freeze the waveforms for digitizing. a considerable amount of digital logic was reguired to control the timing of signals to the converter nodule itself and the sanple-and-gold.

$1 / D$ conversion at high Iates was half the battle; wat remained was the handing of digital data input at this high speed. As previously mentioned, the a/D ras to be configured as a dedicated I/O device for the MOVA. As a result, the analog to digital conversion circuitry and associated timing devices were constructed on a commercially arailable I/O board, designed for custom derice implementation.

This type of a/D converter, because of its sampling scheme, produces a trigger pulse from the computer when it is ready to sample. This differs from slower $M / D$ converters, which are themselves triggered by the external event. Because of this, some provision had to be made for Inserting a propagation delay, which is separate from the interleave delay, between the trigger pulse and the start of repetitive sampling. This accounts for varying tines-of-flight of pulses propagating from projector to receiving probe. A 16-bit binary programmable counter was installed with the A/D, Sample-and-Hold, and Interleare Tiner modules, as vell as other control logic, on the uire-wrap section of the I/O board. 
The A/D converter chosen was a Datel G3BC 8-bit unit with a conrersion time of 800 nanoseconds. Although sanpling could be as fast as $1.25 \mathrm{MHz}$. in real time, the fastest continuous rate of entering data into the rova's nemory is one 16-bit word erery 1.2 microseconds. This is not a programmed I/O transfer; rather this. speed is available only with the use of direct memory access.

The rova Cpo interrogates every I/O device after each progran instruction. This interrogation is to determine if an devices are requesting interrupt service or direct memory access (termed " Data Channel " by Data General, manufacturer of the rora , - This interrogation takes the form of two digital signals, INTP and DCEP, that pass 'dais chain. Eashion from the CPU, sequentially through the I/O derices, then back to the CPO. If these signals Ieturn to the CPO, no derice has made a Ieguest. If any derice does make a request, it inhibits the signal corresponding to the type of reguest from passing through it. The first derice along the chain to stop the signal is the one which will receive service. This means that there is a different priority for each device, depending apon its electrical location on the bus. The high speed $A / D$ was Installed to have the highest priority in the machine, so Do other derice would be able to disrupt its operation.

Because the CPO must see the interrogation signals Ieturn to it (no requests being made) before it continues with the next progran instruction, it is possible for the 
I/O devices to inbibit normal program execution continually.

This interruption of program flow is the technique by which timing between the $A / D$ converter and the $C P D$ is accomplished. The program controlling the converter sends certain control words to the device, programming its behavior. Then a start pulse is sent, which triggers the $\mathbf{A} \mathbf{D}$ to go into operation. Immediately the converter makes a Data Channel request, and continues to do so until it has finished its assigned task. Refer to figure (4) for a block diagram of the system.

The pre-programming of the high speed a/D consists of writing four data words to internal registers. One of these words is written to the addess Counter Register, which is read by the $C P J$ each time a Data Chandel transfer takes place; it contains the address of memory where the current data is to be stored. Another register to be vitten is the nord zero Detect counter. This counter is programmed with the negative of the number of words to be stored in memory, and is incremented with each ralid Data Channel transfer, as is the previous counter. In this maner, consecutive transfers are stored in successive memory locations. Then the rord zero Detect Counter has been increnented up to one more than its maximum count, (1.e. up to zero) it sends signals to the rest of the device to relinquish control to the cpo. A third data yord from the CPO sets ap the Interleave Delay Timer, which 


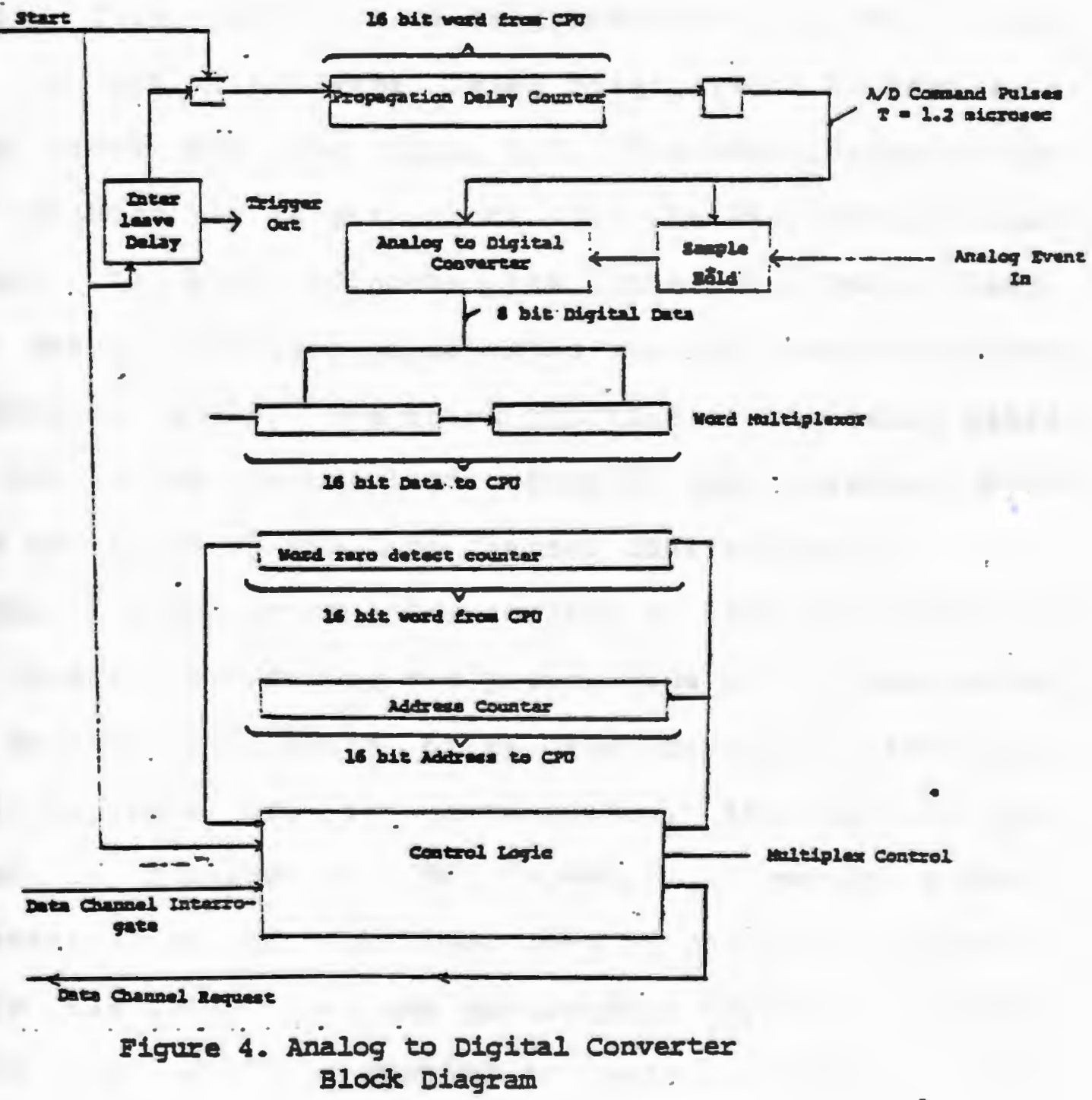


programs the correct number of sample delay time increments between the start pulse and the trigger output. The fourth data rord is directed to the propagation delay counter. This number represents the integer number of tenths of alcroseconds of delay between the start pulse and the start of repetitive sampling.

Pollowing the setup of these Iegisters, the CPO sends a start pulse to the $N D$ converter. This triggers three erents. This start pulse is spnchronized to the $10 \mathrm{uEz}$. clock of the Interleave Delay Timer, which is used as a master clock for the wole $\mathrm{a} / \mathrm{D}$. The spmchronized start pulse enables the $10 \mathrm{HHz}$. Clock into the Propagation Delay Counter. It also triggers the Interleave Delay Timer, which sends a trigger pulse after its programmed delay to the outside world. The third function of the start pulse is to set ap the control logic vich in turn presets a byte packer and picks up the Data Channel continuously.

The $1 / D$ converter holds control at this point ria the Data Channel, but anring the propagation delay, because no data samples are being taken, the address and rord zero Detect counters are not incremented. Although the Data Channel is Iunning at full speed, it merely stores irfelevant data in the first word of the memory block to receive the data. When the propagation delay has elapsed, the $10 \mathrm{H}$. clock is divided by twelve to give an actual sampling rate of $833 \mathrm{KBz}$. or one sample every 1.2 aicroseconds. These sampling commands are sent to the 
Sanfle-and-Bold, a Datel model sBu-OB. This unit bas an acquisition time of 35 nanoseconds and a 200 picosecond aperture time. The sample commands to the $\mathrm{A} / \mathrm{D}$ module are delayed by 80 nanoseconds to allow the Sample-and-Bold time to acquire the analog signal.

Then the contersion is complete, the $A / D$ module sends a signal to load the data appearing on its outputs into one side of a 16-bit register. Which side is determined by a brte multiplerer in such a way that the odd numbered samples are stored in the left eight bits, while the eren numbered samples are sent to the right eight bits. A set of latches and gates determine when both sides of the 16-bit Iegister contain new data, and at this time they increment the Adress and pord counters, which results in the data being stored in nemory via the Data Channel.

This sampling continues until the rord zero Detect Counter signals the control logic to drop the Data Channel. Other logic in the I/O board is set so that when the derice is done, an interrupt is generated to restart progran execution. The resident program must then re-order the new data with data from other pings in such a way that the analog wareform is reconstructed. Because the actual sapling rate is once every 1.2 microseconds, while the effective sampling rate is $100 \mathrm{~Hz}$, a slight calculation shows that 120 identical analog pings must be sampled to rield one reconstructed wareform. 
POSITIONIRG STSTEH

The precision positioning carriage system constructed for this work was a two-aris unit of suitable size to be used with a common aquarina. The area of coverage was 41 by 80 centimeters. A main carriage which travels on ree shaped rails itself supported a smaller transterse carriage whose direction of motion was at right angles to that of the main carriage. Both rere mored and beld in position by metric leadscreus, chosen such that one turn resulted in a translation of $1.5 \mathrm{~mm} .$. as seen in figure (2). This odd amount was desired to match an economical type of shaft encoder arailable having an output of 150 digital pulses per revolution, thereby resulting in an output of one aigital pulse per each .01 mil. of translation.

Direction indicators were constructed and installad on each shaft, so that cumulative position data could be had after morements in both directions. The leadscrews were operable by hand cranks, and also chain driren by small D.C. motors. These control and feedback signals yere Interfaced to a Southwest Technical Products' 6800 nicrocomputer. The SRTPC 6800 was in tarn interfaced to the rova. A short program was written for the SHTPC 6800 to control the carriage according to commands received from the wOVA.

The shaft encoders were interfacad to the SNTPC 6800 in such a val that an interrupt was generated for each pulse from either encoder. Onder program control, a 
destination count receired fron the sora is compared to a current location counter maintained in memory of the SRTPC 6800. If a difference erists, the corresponding drive notor is turned on. The direction of rotation is determined by the sign of the difference between the destination counter and the current position counter. As the motor runs, pulses from the shaft encoders generate interrupts to the main program, which is waiting in a ccmparison step. At each interrupt, the 6800's CpO examines the input interface to determine which encoder generated the interrupt, and which direction is indicated for its shaft. Based on this information, one count is added or subtracted fron the current position counter. lote that interrupts frcm either shaft are processed, so the shafts could move simultaneously vithout interference.

Following the correction to the current position conter, the interrupt routine ends with a return to the comparison step of the main progran. Is the interrupt service routine is transparent to the counter comparison Iontine, when the current location counter matches the destination counter, the motoris shut off. The motors have internal locking brakes which engage guickli when the notors stop, resulting in negligible coast which has been determined to be 3 counts or .03mm. Also, because Lterrupts are allowed eren after the motors are shut off, this coast does not accumulate. The exact accuracy and precision of the carriage was not measured as it vas 
obviously sufficient for our vork. It has been estimated to be better than $1 / 4 \mathrm{~mm}$.

\section{ABALOG SIGNAL SOORCE and CONDITIONIMG}

The remainder of the system includes some sort of waveforil generator to drive the transducer under investigation, and the necessary aplifiers to tailor the received signal to the dynamic range of the $\mathrm{A} / \mathrm{D}$. Because the focns of the study was on transient phenomena, the ideal input wareform yould have been an impulse which yould have provided an infinitely wide bandwidth. Such is not realizable in actual practice, and the compromise made ras a pulse of very short duration as noted below.

Two pulsers were used, both manufactured by uetrotek Inc. They vere essentially identical on the output side, differing only in that one was a more elaborate unit with extra controls for pulse amplitude; damping, width, and rep rate - The first was a model P-105a module implemented vith a 300 volt power supply of our own construction. The second was designed to fit as a plug-in for a Tektronix power rack model Tr 506. The model number of the second pulser was up 215. While these units were not identical the $I$ both produced polses of up to 300 rolt magnitude with a Iise time of approrimately 10 manoseconds. Pulse width was influenced greatly by the type of transucer, the length of interconnecting cable, and the amount of damping or termination employed. Generally the polse was narrower 
than 200 nanoseconds, with several oscillations of 30 to 50 nanosecond period, superimposed on the palse. While not the ultimate in bandwidth, this proved to be more than sufficient excitạtion.

\section{RECEIVE AMPIPIERS and OLTRASONIC PROBES}

Two different receive amflifiers were used for this study. The first was a solid state device of our own construction, which ras modified to provide greater gain and bandwidth. Later, a commercial amplifier, also a plug-in design frow thetrotek, vas purchased. Haring many more conveniences, this proved to be a valuable addition to our instrumentation. This amp, a model uB101, initially provided a bandwidth having a high pass characteristic with adjustable cutoff frequencr. Then the unit vas received. the lowest frequency to pass through the unit was $500 \mathrm{kBz}$.; howerer, this was lowered to $100 \mathrm{kgz}$. to provide better low frequency Iesponse. The input impedance of the commercial unit was surpisingly 10\%, approzimately 3000 ohms, considering it vas designed expressly for ultrasonic work. Because of this, the final set up used a combination of the two amplifiers. The first stage of the 'bome-brew' unit was used with as short a cable as possible between it and the receiring probe, to present a high input impedance ( approximately 10 Eegohns, to the probe. The output of this first stage then drove the lower impedance input of 
the commercial unit, which was extrenely convenient in view of its db attenuator pad.

The description of the measurement system yould not be complete vithout a thorough discussion of the receiving probe which were used in the systen. Bere again, the objective vas wide bandvidth. also desirable vas a probe which was as close to omni-directional as possible. These two constraints result in the conclusion that the size of the element used must be very small compared to a wavelength of sound in water at the highest frequency contemplated. This constraint on size resolts in a very low receiving roltage response. These considerations prompted the use of probes having element diameters of less than $1 \mathrm{~mm}$.

Two commercial probes were used successfully. The lirst probe to be tested was actually manufactured as a blast transducer, arailable at surprisingly low cost. This transducer is called a "Pinducer" by its manufacturer, Valpey - Bisher .. The construction is a 1 mm. diameter disc of PZT ( Lead Zirconate Titante), mounted in the end of a tube of similar inner diameter. The back electrode lead is brought out through the tube, which is used as the other connection ria gold plating to the front face. Despite its intended use, the pinducer has an extremely good receiving roltage response. The frequency response starts at less than $200 \mathrm{kBz}$. and peaks at about $2 \mathrm{KHz}$.. starting to drop sharply at 4 urz. Our pinducers performed 
excellently and gave us good results.

at one point in the research, which yill be detailed in the later sections, it vas thought that the directionality of the pinducers at higher frequencies was having too great an effect to tolerate. Por this reason, a verl high frequencl small size probe was borrowed from Battelle Dorthwest. This is termed a " Microprobe ", because of its extremely small physical size. The construction is identical to the pinducers, apart from the reduction in size. Again, a small disc element is inserted in the end of a tube, the tube resembling a hypodermic needle. A rerl short $\left(6^{n}\right)$ cable is attached, to prevent capacitive division and frequency limiting. This probe exhibited much higher frequency behavior, having its peak at five to sir uBz., and a lod frequency cutoff of greater than $500 \mathrm{KEz}$. The receiving roltage response was nuch lower, and this unit yas much more affected by input impedance than the pinducers. Also, the directivity was moch less noticeable. This probe gave us good results rhen sufficient signal level was arailable, but the pinducers had the edge in terms of gain and low freguency response. Some probes were constructed as part of the research, and dimensions vere chosen as a compromise betreen the Pinducer and the licroprobe. Tro methods of construction vere used. One attempt was to solder a small chip of $\mathrm{PZT}$ about 250 wicrons thick to the end of a brass rod, then File the assembly carefully antil the chip vas circular, 
vith a diameter of about 600 nicrons. The other connection consisted of a thin wire soldered to the front electrode. The second method consisted of attaching a similar chip to the center conductor of winiature coaxial cable with conductive epory. The chip vas then filed to size as before, and the remaining electrode was connected to the shield of the cable with a piece of fine wire and conductive epoxy. The conductive epoxy was used to aroid heating the element in soldering, which could result in depolarization due to exceeding the curie temperature. These probes seemed quite rafiable frou unit to unit because of differences in construction.

In conclusion to this section describing the measurement system, it can be seen that, at a nominal investment of funds, and a sizeable investment of time, an excellent automated high irequency acoustic measurement system was constructed. Hopefully, as more research continues, the system will be expanded and tuned. Possible additions would include the following: A third axis on the Carriage would be extremely convenient, this taking the form of a vertical displacement capability, and also perhaps a rotational capability on the sane axis. This vould allo the generation of beam patterns with out fear of the directirity_of the receiring probe becoming a source of error. Also, three dimensional beam patterns could be generated, yhich would provide a better measure of kransucer directivity. Another addition would be a larger 
aguarium. The present tank in use allows a maximan distance of about 80 centimeters between projector and probe, less if either has appreciable length. In some cases, this is not in the far field of the projectors. While the carriage itself is only 1 meter in length, a larger (longer) tank would allow measurements in the far fleld, eren if under some restriction of morement. 
III THEORY of the IHPUISE RESPONSE APPROACH

The acoustic pressures which are radiated into a fluid frol a circular piston are well known for points in the far field and for harnonic piston velocities. Ontil recently, the pressure response in the near field and for non-harmonic excitations had not been adequately described. The exact integral expression (1) for the field of a circular piston radiator having a uniform relocity across its face can be expressed as follows $(10)$ :

$$
\left.p\left(x_{y}+\right)=\operatorname{Re}\left[\tilde{p}(x) \theta^{j \Delta t}\right], \tilde{p}(x)=\frac{j p c k}{2 \pi} U_{0} \int_{0}^{a} \sigma d \sigma\right]_{0}^{2 \pi} \frac{e^{-j k r}}{r^{\prime}} d \phi(a)
$$

\section{were}

$$
r^{\prime}=\left(r^{2}+\sigma^{2}-2 r \sigma \sin \theta \cos \phi\right)^{2 / 2}
$$

In the above expressions and those that follow, pc is the specific acoustic impedance of the fluid, $k$ is the ware numer, Do is the peak relocity of the piston, o is the radius from the center of the piston to the differential element,do; $\psi$ is the angle between this radius and a reference aris, and $\theta$ is the angle between the axis of the transducer and the position vector $\vec{B}$, whose length is I. The geometrical variables of interest are shown for clarification in figure (5).

The usual far field approrimation applied to (1. b), 
28.

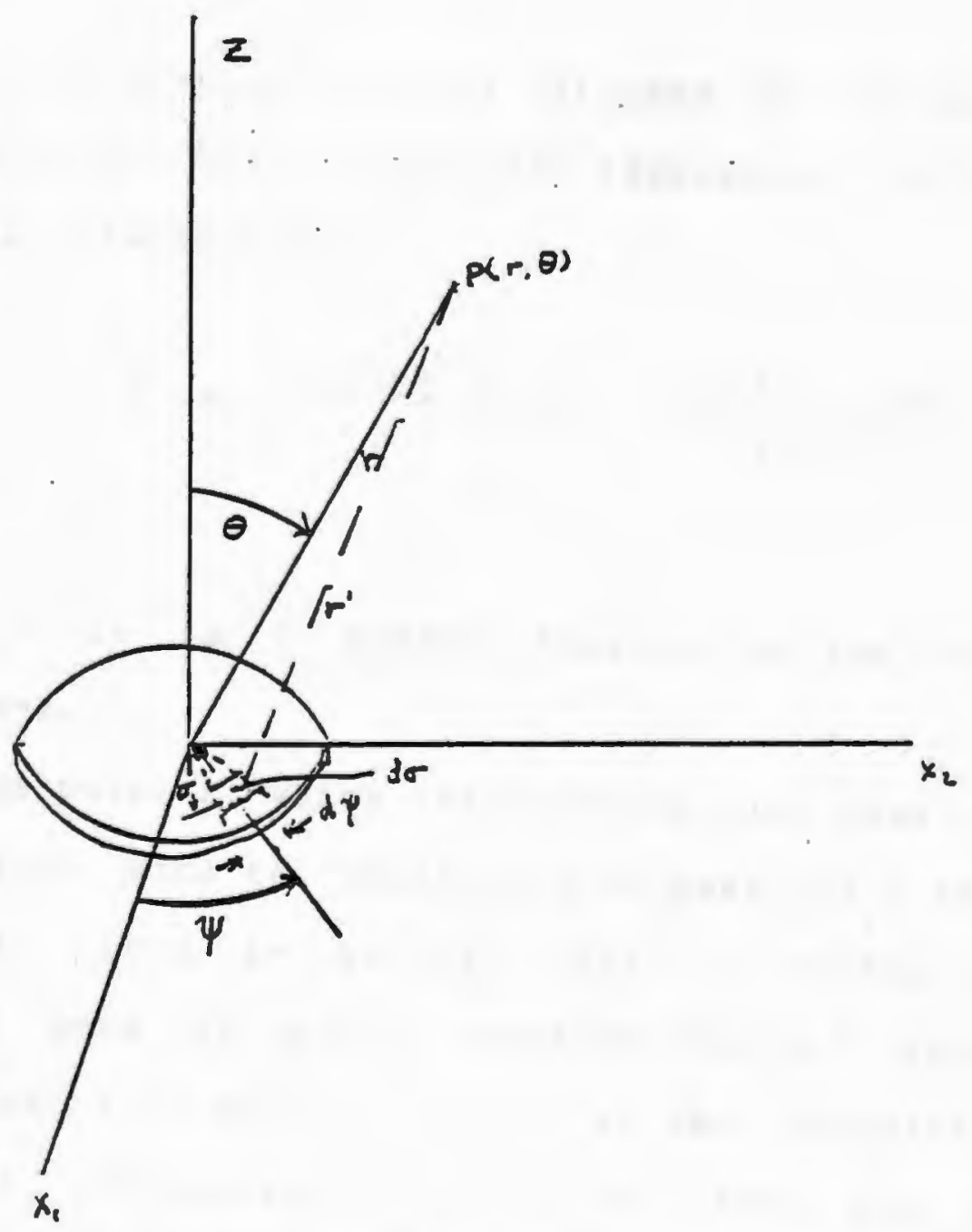

Figure 5. Geometry of General Integral Equation 
and valid if $I \gg$ a $>\sigma$ is:

$$
r^{\prime}=r-\sigma \sin \theta \cos \psi
$$

After substituting equation (2) into (1) and performing the integration, the closed form expression for the far field harmonic pressure is:

$$
p(r, \theta)=\frac{j \rho c k a^{2} U_{0}}{2 r} e^{-j k r}\left[\frac{2 \mu(k) \sin \theta)}{k a \sin \theta}\right]
$$

where $J 1(x)$ is a Bessel function of the first kind and order one.

The point at which the approximation loses validity is associated with the separation of near field and far field regions. This is usually taken to be the zone where a Iegular beam of sond pressure starts to form. Zemanek (10) evaluated equation (1. a) vithout approximation using computer techniques, for regions froll the face of the transducer out into the near field far field transition area, where the pressure magnitude for an harmonic excitation exhibits a highly undulatory behavior. These results can be carried orer to excitations consisting of nany cycles of a sine vare with some success; howerer, if the duration of the excitation becones less than the trarel time of sound across the face of the piston, the 
expressions lose validity.

The next development in the description of the pressure field of pulsed piston radiators was a time domain approach using a transformation of coordinates applied to the Green's function integral solution for the pressure tine historl of a pulsed radiator, see Stepanishen, (11). This resulted in the following convolution integral for the tine dependent pressures in the field:

$$
p\left\{x_{1}+1=\rho \frac{\partial}{\partial t} \int_{\tau=0}^{t} h\left(x_{1}+\tau\right) \operatorname{lev}(\tau) d_{\tau}\right.
$$

where $p(x, t)$ is the time dependent pressure at the spatial point $x, p$ is the density of the medium, $h(x, t)$ is the inpulse Iesponse of the piston to the spatial point, and $\nabla(t)$ is the velocity time history of the piston face. Bquation (4) can be vritten as:

$$
p(x, t)=\operatorname{sh}(x, t)+a s+)
$$

where * denotes contolution.

The impulse response, $h(x, t)$. for a planar radiator of any shape, was also given in the same reference as follovs:

$$
h(x, t)=\frac{\text { Ls } x, c t)}{2 \pi t \sin \theta(x, c t)}
$$

Bere $I(x, c t)$ is the length of the arc formed by the intersection of the radiating piston and a sphere centered 


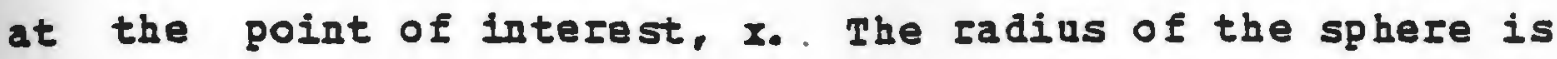
B=ct. $\theta(x, c t)$ is the angle between the radius of the sphere extending to the arc and the perpendicular of the plane passing through the center of the sphere. [ see figure (6) ] . Of particular importance is the fact that the above expressions are valid for anI aniform relocity input and for any point in the half space abore the piston. The evaluation of equation (5) for a circular piston of radius a is simplified if a substitution is made for $t$, $\tau=c t / a$, and for $x, x^{\prime}=x / a$, and if $x$ is resolved into two coordinates of cylindrical geometry. [ see figure (7) ] . Depending on the field point of interest, the resulting function is described in either three or four sections. If the point is inside the right cylinder formed by the projection of the edge of the piston into the half space above, as characterized by the relation a/I>1, the impulse response can be expressed as follows:

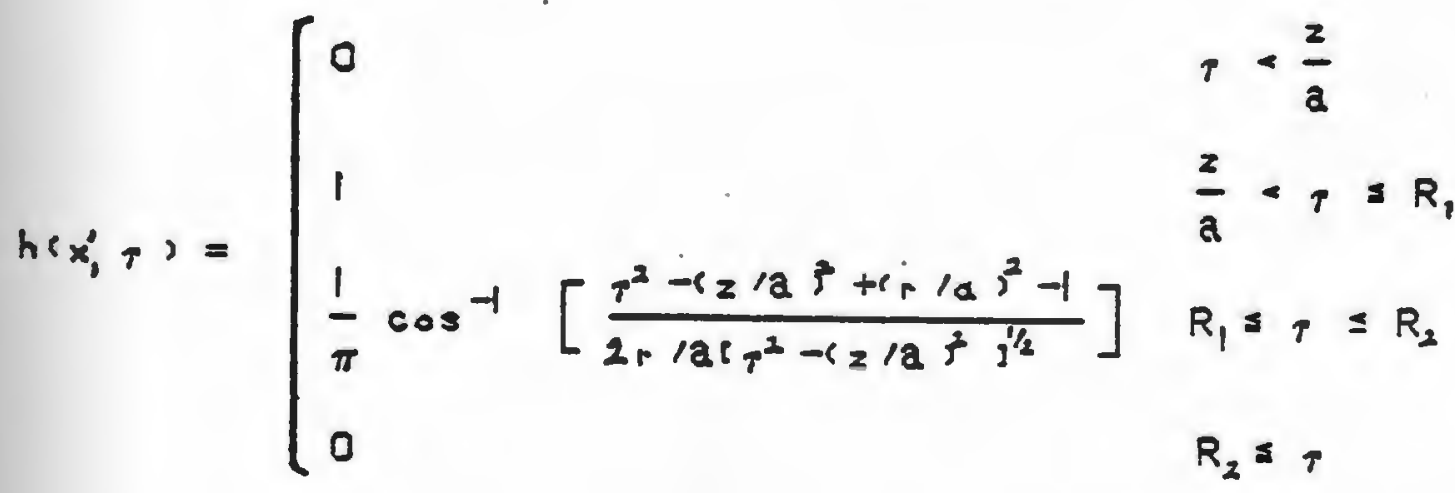




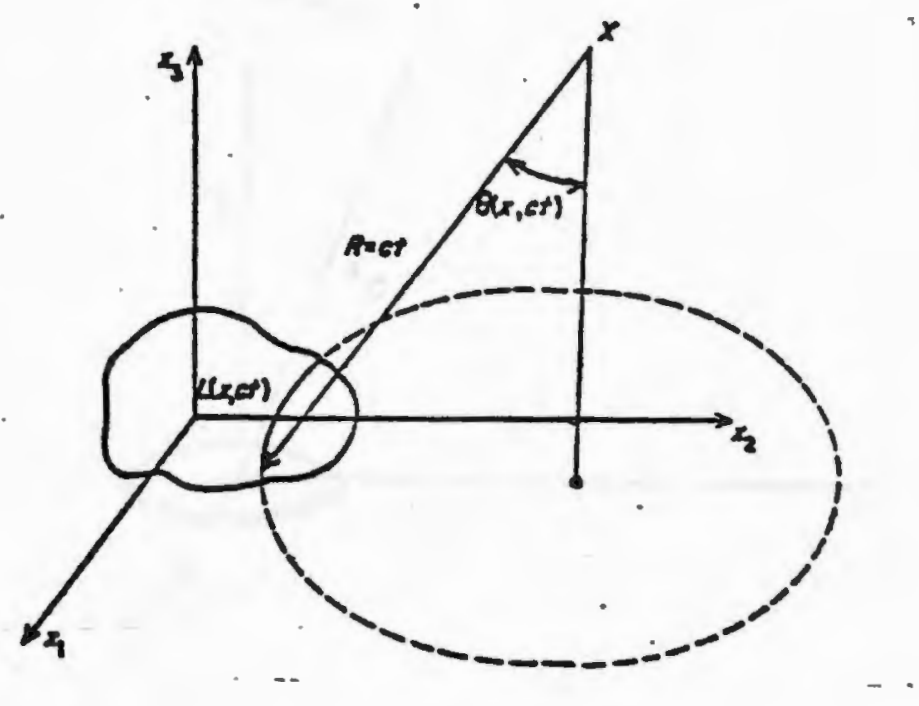

Figure 6. Geometry of Impulse Response Function 


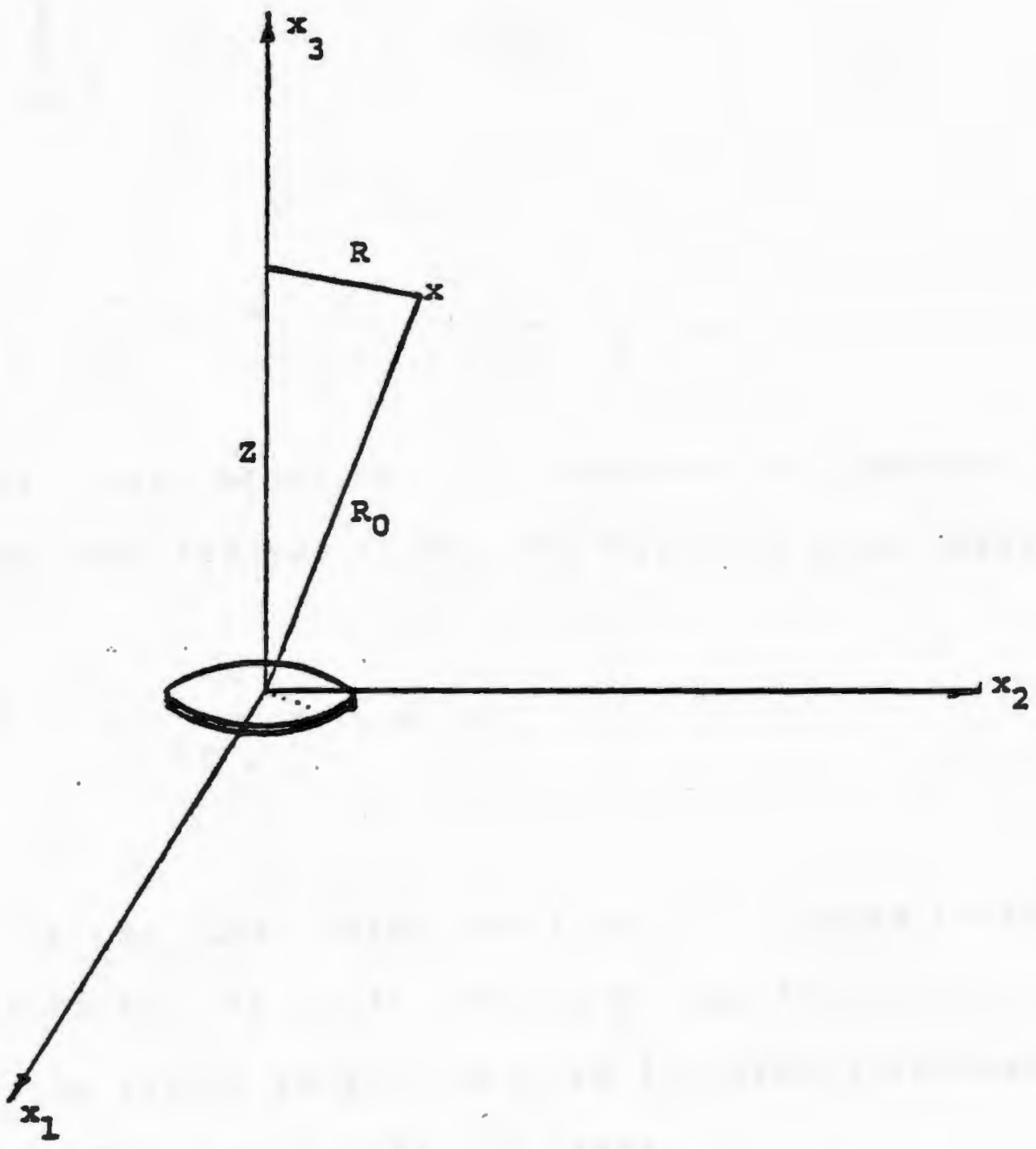

Figure 7. Geometry of coordinate Transformation 
If I/a>1, the inpolse response can be expressed as follows:

$$
h\left(x, \tau^{2}\right)=\left[\begin{array}{ll}
0 & \tau \leq R_{1} \\
\frac{1}{\pi} \cos ^{-1}\left[\frac{\tau^{2}-(2 / a)^{2}+(p / a)^{2}-1}{2 r\left(a t \tau^{2}-(z / a)^{2} j^{1 / 2}\right.}\right] & R_{1} \leq \tau \leq R_{2} \\
0 & R_{2} \leq \tau
\end{array}\right.
$$

where

$$
\left.\left.\left.R_{1}=\left(c \frac{z}{a}\right)^{2}+\left(\frac{r}{a}\right)-1\right)^{2}\right)^{1 / 2} \quad R_{2}=\left(c\left(\frac{z}{a}\right)^{2}+\left(e \frac{r}{a}\right)+1\right)^{2}\right)^{1 / 2}
$$

Also note that equation (7) reduces to the following expression when applied to the far field on axis case:

$$
h\left(R_{0}(a, O, \tau)=\frac{A^{\prime}}{2 \pi R_{0}} \cdot\left(\tau-R_{0} / a\right)\right.
$$

Here $\delta$ is the Dirac delta function. Thus it follows froll equations (5) and (9) that the far field on aris pressure is simply proportional to the piston acceleration veighted by the piston area and range.

Some theoretical impulse responses are presented in Ilgures (8) through (11). The figures show that there are three basic shapes for the impalse response of a circular piston which are depenent on the location of the field point. The on aris impulse response is a rectangle, whose amplitude is unity and time duration is equal to the 
difference in time of propogation of sound from the center and from the edges of the piston. This pulse duration is thus a maximum for a point at the surface of the piston and nonotonically decreases as arial range of the field point increases, [ see figure (8) ] . At points lying inside the projection of the circle of the transducer, the impulse response starts off with a step discontinuity as indicated in figure (9). The response is then constant until the arc depicted in figure (6) has arrived at the edge at its closest point. From this time on, the impulse response decreases monotonically, until it goes to zero at the time the arc has arrived at the opposite edge. Pigure (9) shows this. The third family of impulse responses is the case where the weasuring point is outside the cylinder of projection. Bere, the curre takes on the shape of a non-symmetrical hemisphere, yhose amlitude decreases uth Increasing angle from the aris as indicated in figure (10). The degree of non-symmetry is dictated by the radial distance of the point from the center of the piston. As the radial distance increases, the inpulse response becomes are symmetric as indicated by a comparison of the results in figures (10) and (11). 


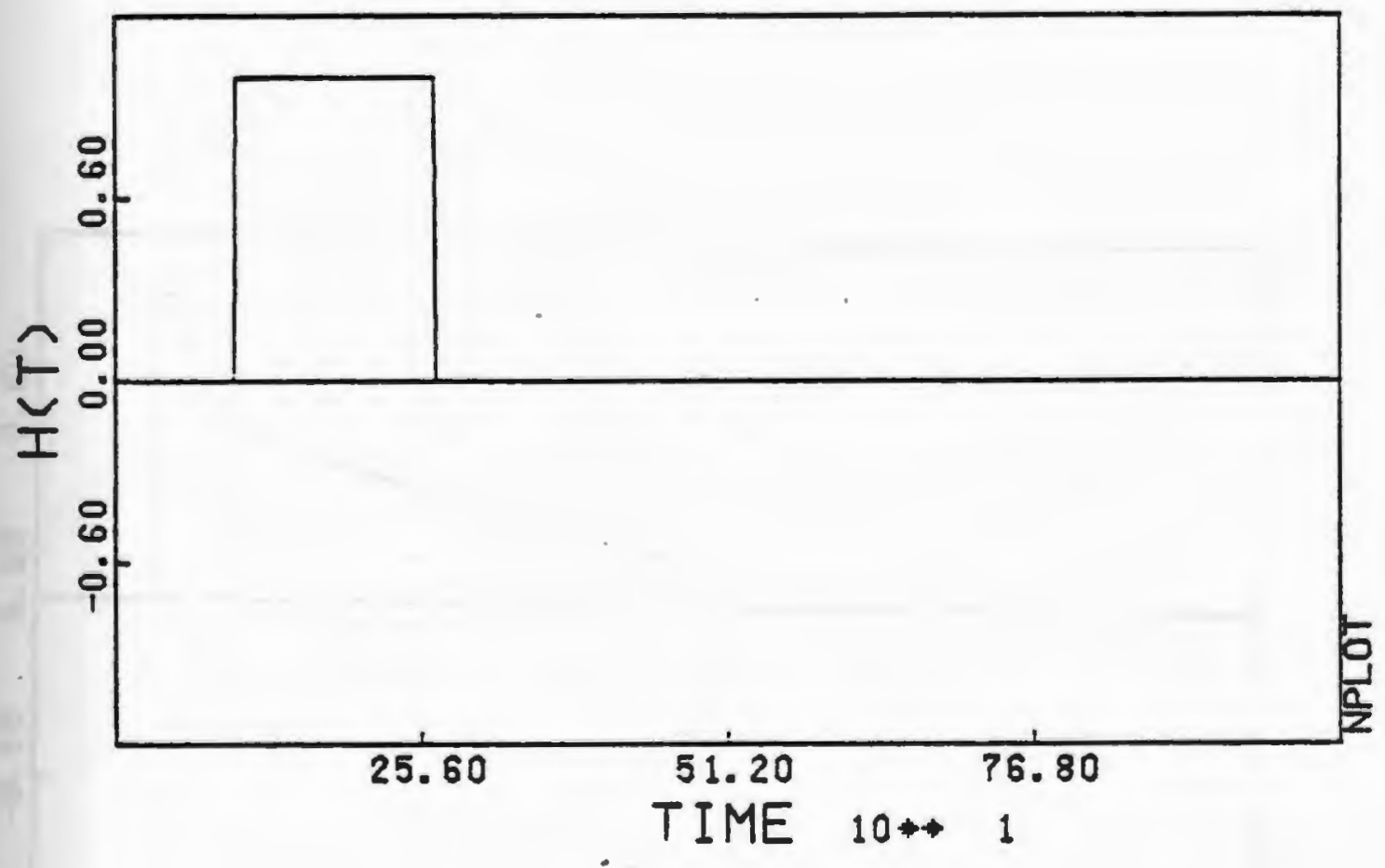

Figure 8. Theoretical Impulse Response: On Axis 


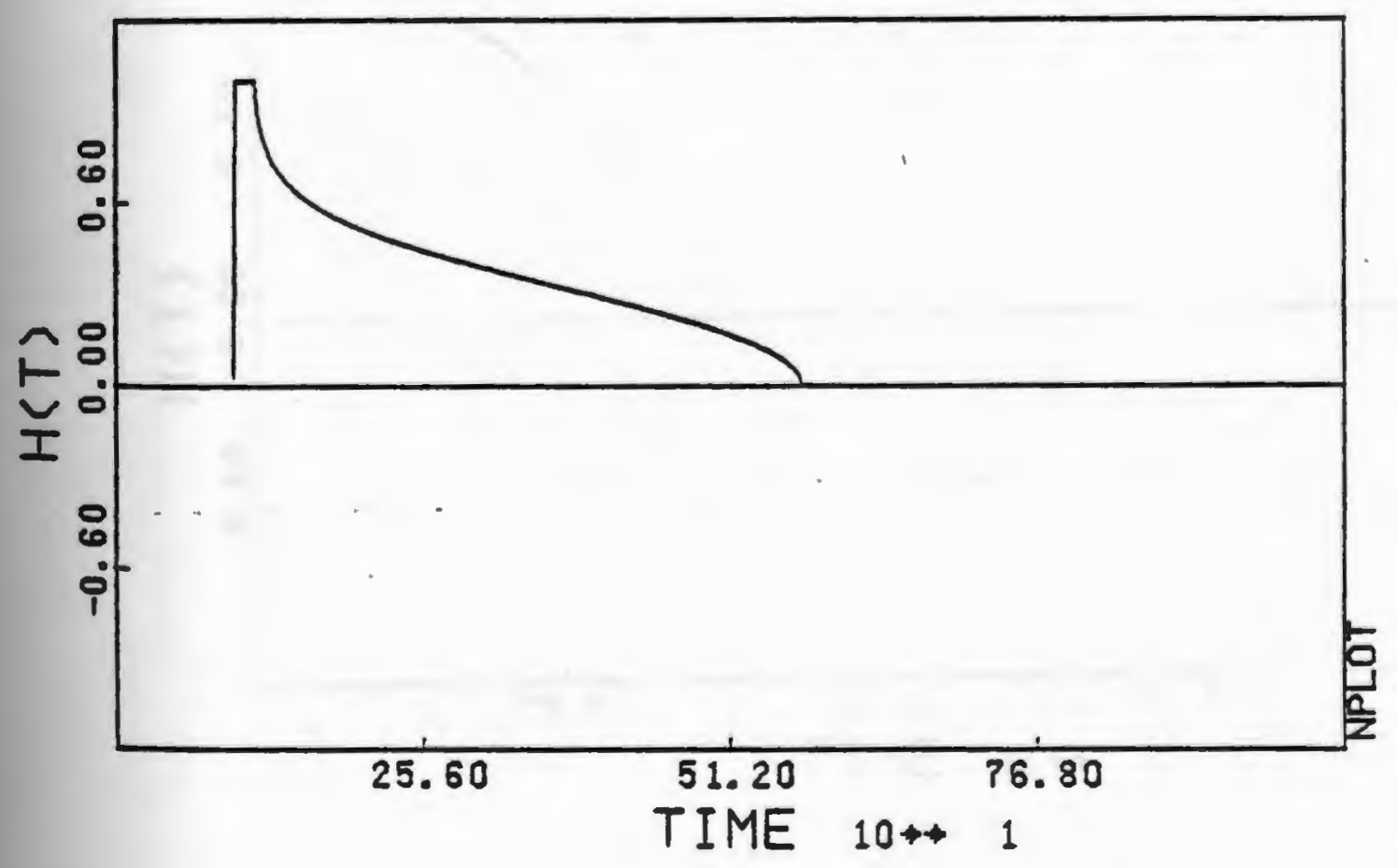

FIgure 9. Theoretical Impulse Response: Inside Disc 


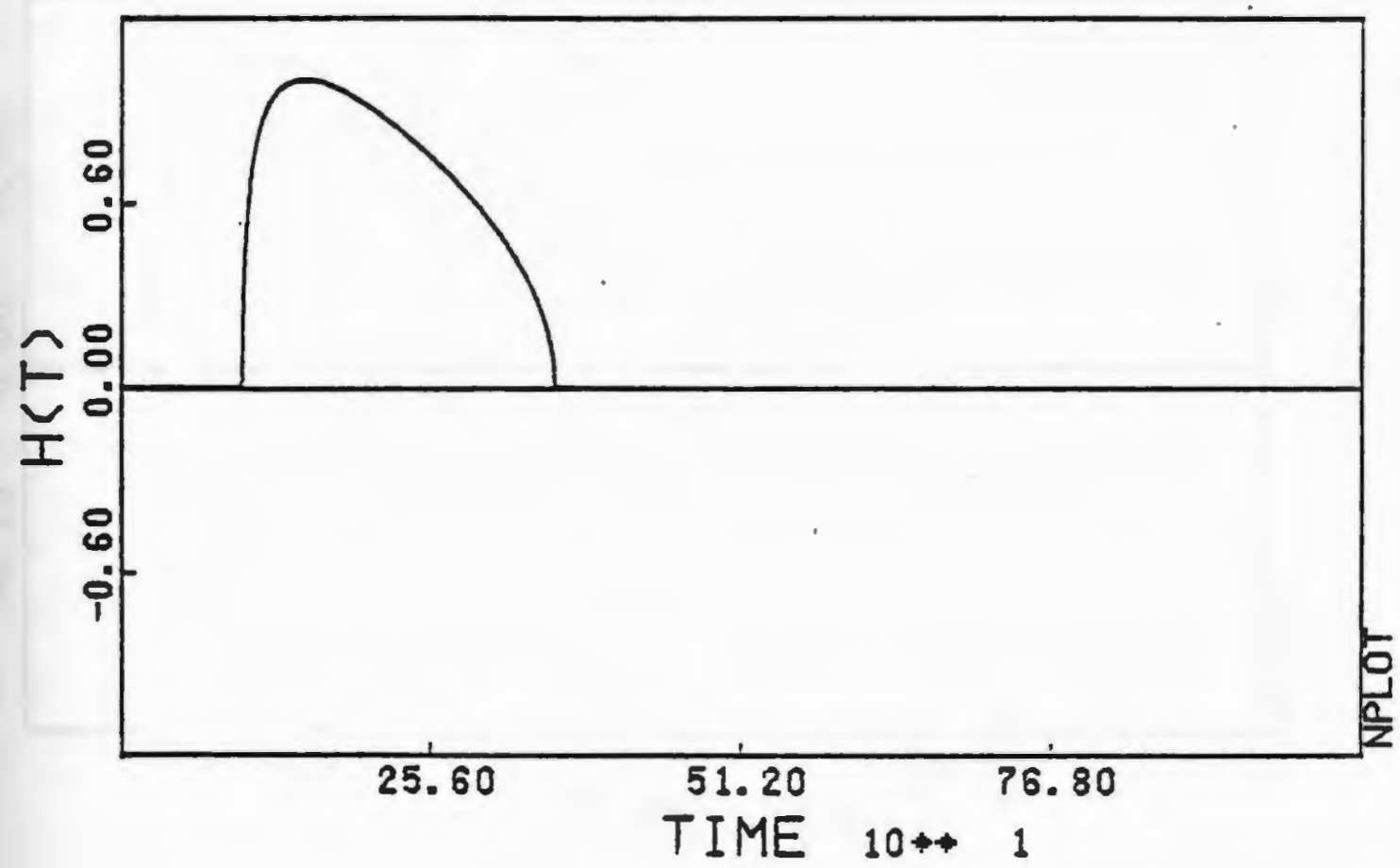

Figure 10. Theoretical Impulse Response: Outside Disc 


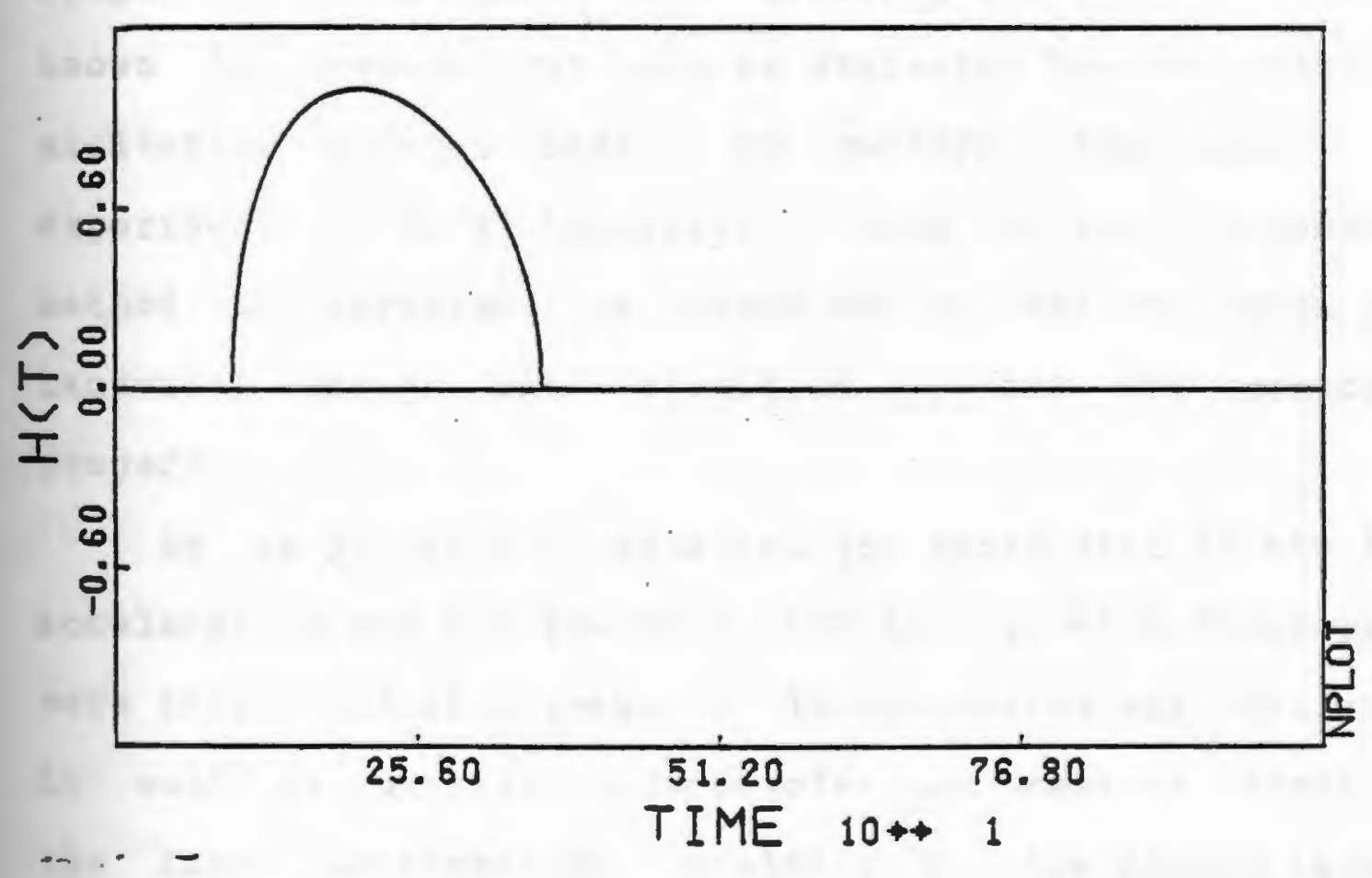

Figure 11. Theoretical Impulse Response: Far Field Outside Disc 


\section{GATEEGATCAL TECBRIQOES fOr DECONPOLOTION}

The key difference between our research and that mentioned previously is that this experiment attempts to start at the end and vork back. That is, Iather than attempt to compare resultant pressures vith.theoretical predictions, we wish to work backwards from experimental pressures to rield the impulse response. Once the impulse response for a particular geometry and spatial point is known the pressure can then be evaluated for any arbitraII excitation without having to perform aditional experiments. Hore importantly once the impulse response method is rerified, the nethod can be used to design vide bandwidth arrays with specified spatial and tenporal properties.

In examination of equation (5) shors that if the face acceleration and the pressure time history at a field point rere known, and if a method of deconvolution was available, it rould be possible to deconvolve the pressure historl by the input acceleration. Fielding a time domain inpulse Iesponse. There are two difficulties associated with this netbod: First, some method of measuring piston velocity or acceleration is required. Second, a method of deccnrolution is necessary.

In view of the first reguirement, consider again equation (9):

$$
h\left(R_{0} / a_{,}, T,=\frac{A}{2 \pi R_{0}} ;\left(T R_{0} / a\right)\right.
$$


as mentioned before, this implies that the far field on axis pressure is proportional to piston acceleration. Therefore, information about the face velocity is arailable from far field on axis pressure measurements.

Consider the black box or systen model of the typical experinental setup in figure (12). As can be seen froll the uodel, the signal passing through the typical measurement system is not solely a function of face relocity and impulse response. Other factors which ultimately affect the received roltage are electrical input, traniducer dynamics, receiving probe dynamics, and dynamics associated with the received signal processing. The beatl of this new experimental approach is that if the on axis far field pressure and the nearfield pressure at the point of interest are taken with the same system, as outlined abore, When the deconvolution is performed, ang effects which are due to common factors will be cancelled out. The deccnrolution gives information only about the difference of the two measurements.

The experimental impulse responses vere developed using an approach based on the preceeding observations. Experimental pressure histories were taken at two points, an on axis field point at large range, and at another field point where the impulse response was desired. These two Mea surements were then processed using computer techniques 


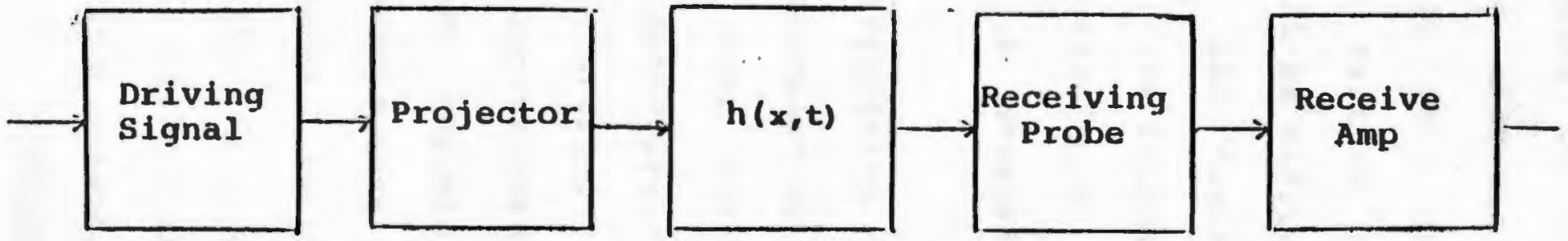

Figure 12. Box Model of Typical Measurement System 
to generate an experimental impulse response.

The preceeding sections indicate that the time-domain Impolse Response can be experimentally derived from field pressure time histories if a method of deconvolution is arailable. To this end, considerable time was spent investigating rarious approaches to deconvolntion. Those not chosen will be outlined in the order in which ther were investigated, and their reasons for failure will be discussed in the following subsections. The method which was finally dereloped to perform deconvolution is then presented in a separate subsection in light of its 1aportance.

EVALUATION CRITERIA and PROCBDURES

Each deconvolution method vhich was investigated was first tested with arbitrary boxcar, i.e., rectangular pulse, time histories. Two borcar functions vere analytically conrolred to obtain a function which vas subsequently decontolved using the following programs. If these indicated success, the program was run using stmulated acoustic data generated by another program. The nodelling program, pUISECEO, was written by a previous student inrolved in this research, Glenn Andrex. Its purgose was to produce theoretical pressure time histories at various field points, based on the theoretical Inpulse Resfonse. [ see equations (7) and (8). ] One of sereral sinfle electrical inputs could be specified, as could the presence or absence of transducer dynamics. 
The program proceeded stepwise, as follows: First, the theoretical Inpalse Response was calculated fiom the expressions cited above. Mext this was transformed to the Irequency domain, were convolution can be performed as a sinple multiplication. This frequency representation vas next multiplied by the transform of the chosen electrical input, and the transform of the transducer dynanics, if included. At this point an inverse Pourler Transform was calculated, yielding the pressure time historl for the point specified in the calculation of the impulse response.

is originally written, the program would treat this signal as if it had been Ieflected by a perfect point reflector. Then the aforementioned process would continue in reverse to field the electrical output of the transducer. Plots were generated after each stage in order as follows: Electrical input, transmit velocity,transmit pressure, receive pressure, receive force response, and receive roltage response.

This program was modified for our purposes as follows: Onl the transmitting section was retained. This portion was executed twice, once for the long range on axis pressure history, and again, calculating the theoretical pressure response for a nearfield point of interest. In adition to plots, permanent disk data sets vere made of the field pressure time histories. These records were accessed by the deconrolution programs under test.

In the initial phases of testing, no transucer 
dynamics were included. This meant that the piston face relccity was identical to the electrical input. onder these conditions, the simulated pressure wareform was simple enough that the theoretical impulse response was apparent in the data. This alloved conclusions to be drawn as to what was happening in the deconvolution program relatively easily.

If the deconvolution process under study shored promise, transducer dynamics would be introduced into the input data. At this point, the input date bore a closer resemblance to real pressure time histories, but the theoretical impulse response us no longer visible in the data. This was considered the hardest artificial test of a deconvolation program: Could it perform in the presence of other transfer functions applied to the two input signals? This was absolutely mecessary in viev of the experimental setup, which rould include transfer functions for the receiving probe and receive amplifier.

SPECIFIC TECANIQOES

Many different approaches to perform deconvolution vere tried, working both in the time domain and in the Erequency domain. The time domain expression for the convolution of the spatially dependent impulse response and the acceleration of the piston may be expressed as follows:

$$
p(x, t)=\rho c \int_{0}^{g} h(x, t-\alpha) \cdot a(\alpha) d \alpha
$$


after normalizing the pressure $p(x, t)$ by the specific acoustic impedance of the fluid, the normalized pressure can then be expressed as follows:

$$
\left.p\left(x_{1}+\right)=h\left(x_{1} t\right)+\text { ast }\right)
$$

where the asterisk * denotes the convolution operation and $\tau$ has been replaced by $t$. The convolution integral of equation (11) is reduced to a much simpler expression if the Ponrier Transform is taken of both sides, noting that the spatial dependence has been dropped from this point on for clarity:

$$
\text { P\&os = HeO,. Asos }
$$

Decontolution, as ve wish to perform it, is the processing of two time functions which are the input and output of a linear system, to gield the time domain inpulse response of the system. The most obvious approach is to start with equation (12) and divide both sides by $\mathbf{A}(1)$, Yielding:

$$
\text { He⿻) }=\frac{P(\omega)}{A(\omega)}
$$


Then an inverse transform should result in the impalse response, $b(\tau)$.

The most obvious flay here is that if a(v) ever goes to zero, $\mathrm{B}(\mathrm{w})$ is undefined. Intuition is satisfied in this case, as it is seen that for this requency $w^{\prime}$, no information about the linear system can be determined if no input is supplied. Theoretically, as long as $\mathbf{l}(w)$ does not go to zero, equation (13) followed by an inverse pourier transform should still rield a correct inpulse response. In practice, any noise present in $P(w)$ is eraggeratsd greatly as $\mathbf{A}(w)$ goes to zero.

An approach which was based on extending the abore technigue was implemented on the Acadenic computer Center's system, and studied at length with little success. The approach consisted of the controlled areraging in the Erequency domain of the quotients of output and input data frequency ralues. Part of the reasoning bebind using such a technique was that although any given signal input vould probably display nulls in their spectra, by using sereral different inputs and processing in parallel, information needed at a noll of one signal would be supplied by another signal not having a coincident null.

The division in the frequency domain was performed for each discrete frequency value of input and output. The guotients vere averaged vith those from other input and output pairs of the same frequency. If ang input contained a null at this frequency, its quotient was omitted from the 
average. An example of the results is presented as figure (13). This should resemble a rectangular pulse, but does not. This approach vas finally abandoned in faror of other more promising techniques. The cause of the distortion was not determined exactly: however, it is a likely probability that the cause was truncation error resulting in cumulative phase errors incurred while the data was transforned back and forth.

The second method which was considered proceeded as follows: The numerator and denominator of equation were multiplied by the conjugate of $A(w)$ :

$$
\left.H^{(} \omega\right)=\frac{\left.A^{(}()\right) A^{+}(\omega)}{\left.\rho_{(}\right) \cdot A^{+}(\omega)}
$$

This technigue is recommended in Bendat and Piersol, reference (12). This formulation could be handed in matrix algebra form, noting that $a(w)$ multiplied by its confugate is simply the frequency transform of the autocorrelation of a(t). Likewise, the multiplication of $P(v)$ and the conjugate of $\mathbf{A}(w)$ is the frequency transform of the cross correlation of a(t) and $p(t)$. After inverse transforming both sides of the frequency domain expressions, the resulting integral equation in the time domain can be converted into the following matrix equation:

$$
[a][h]=[R]
$$




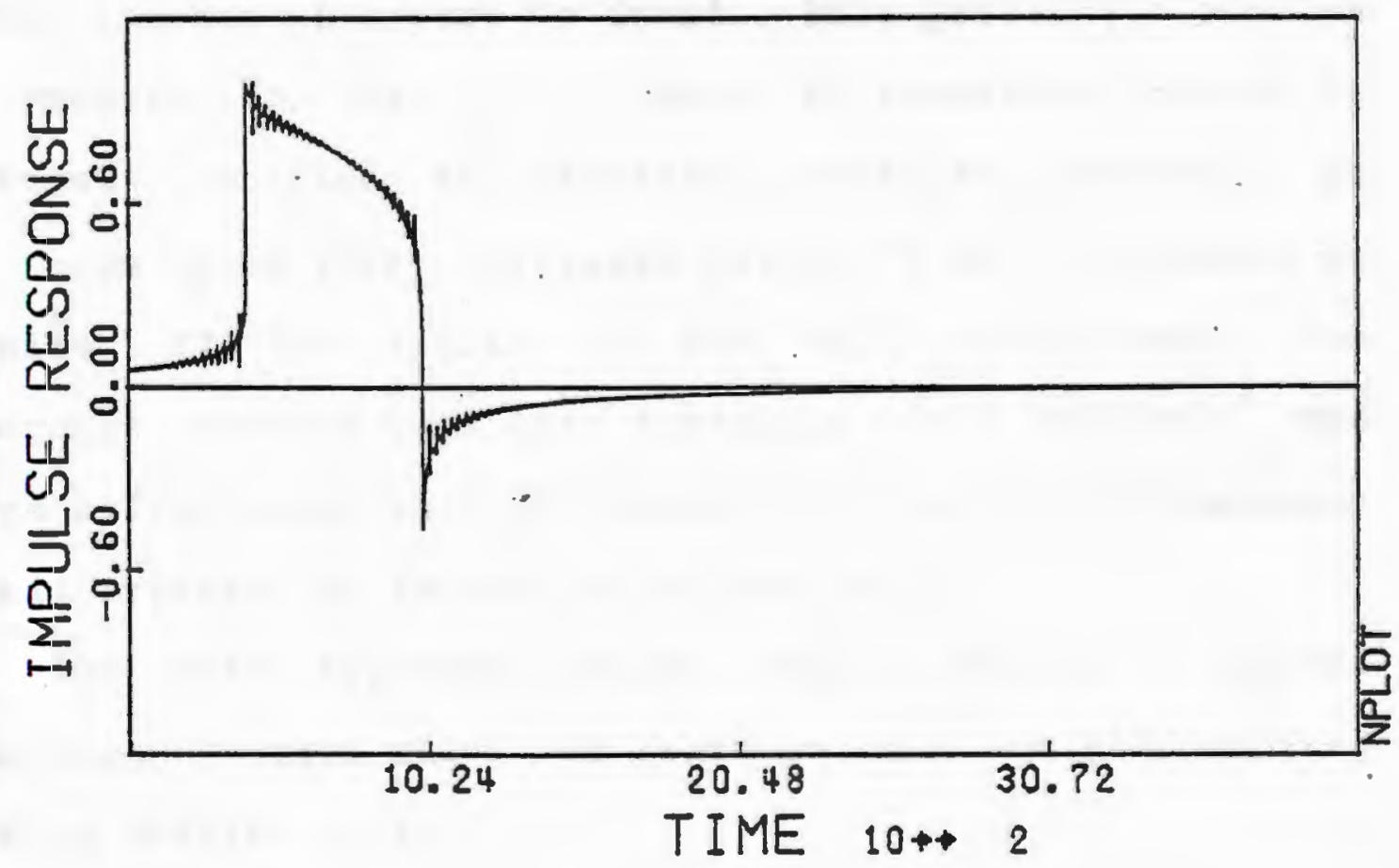

Figure 13. Test Result of Frequency Division Technigue 
Here $B$ is a cross correlation vector, $b$ is the impulse response vector, and a is the autocorrelation matrix which result゙ from the discretizing process.

Mote however that due to the physical size of the transducers involred and the extremelg high sampling rate atilized, the atocorrelation matrix a is of the size of a few thousand elements on a side. To determine h from a and B. the inverse of a must be found. This presents a problem of programing, as first, such an amount of storage is difficult to find and extremely expensive. Secondl, as the size of an array increases beyond 20 or 30 elements on a side, if the matrix is not vell conditioned, the Inversion routine runs into numerical error problems. The above difficulties were sufficient to abandon the freguencI donain approach to deconvolution comfletly.

The nert approach sought was a direct ' number crunching , type which ras based on equation (10) vititen in time sampled form:

$$
\text { - } P_{J}=\Delta t \sum_{k=1}^{J} a_{\jmath} k+1 h_{k} \quad J=1, N
$$

Where $\Delta t$ is the time sampling interval. Equation (16) can be used to develop the following recursion relationship for the sanpled values of the impulse response:

$$
h_{J}=\frac{p_{1}^{\prime \Delta t}-\sum_{k}^{\prime-1} a_{j+1} h_{k}}{a_{1}} \quad J=1, N
$$


a computer program which was based on equation (17) vas dereloped to evaluate the hj's. The program started with p1 and a1 to get $h 1$. Then p1, p2, a1, a2, and h1 yere used to determine h2." This series proceeded, with each iteration using the information previously generated and two more data points. This was the first technigue to jield correct results from simple geometric waveforms and also PUISECघo generated data with no dynaics. Although the method was suitable for certain types of functions which exhibited initial discontinuities, this method is unstable for other classes of functions. This is readily apparent since any error in a data point affects all following points in a geometrically increasing manner. Dhen tested with poIs Ecko data which included transducer aynamics, these instabilities were intolerable. often the program would not be able to finish execution due to overflow caused by widly propagating truncation erIors. A sample of this is presented as figure (14).

The fourth method examined was a gradient search. In this type of analysis, a trial estimate of the impulse response $h(t)$ is conrolved with the input data. The Iesult of this is compared with the output data, and a root mean sguare erIor is calculated. The gradient of the error Eunction is calculated, weighted by an anount deterrined to nnimize the error, and is then added to the previous trial approrimation. This approach yas implenented in a very small number of samples ( 32 ) to determine if a larger 


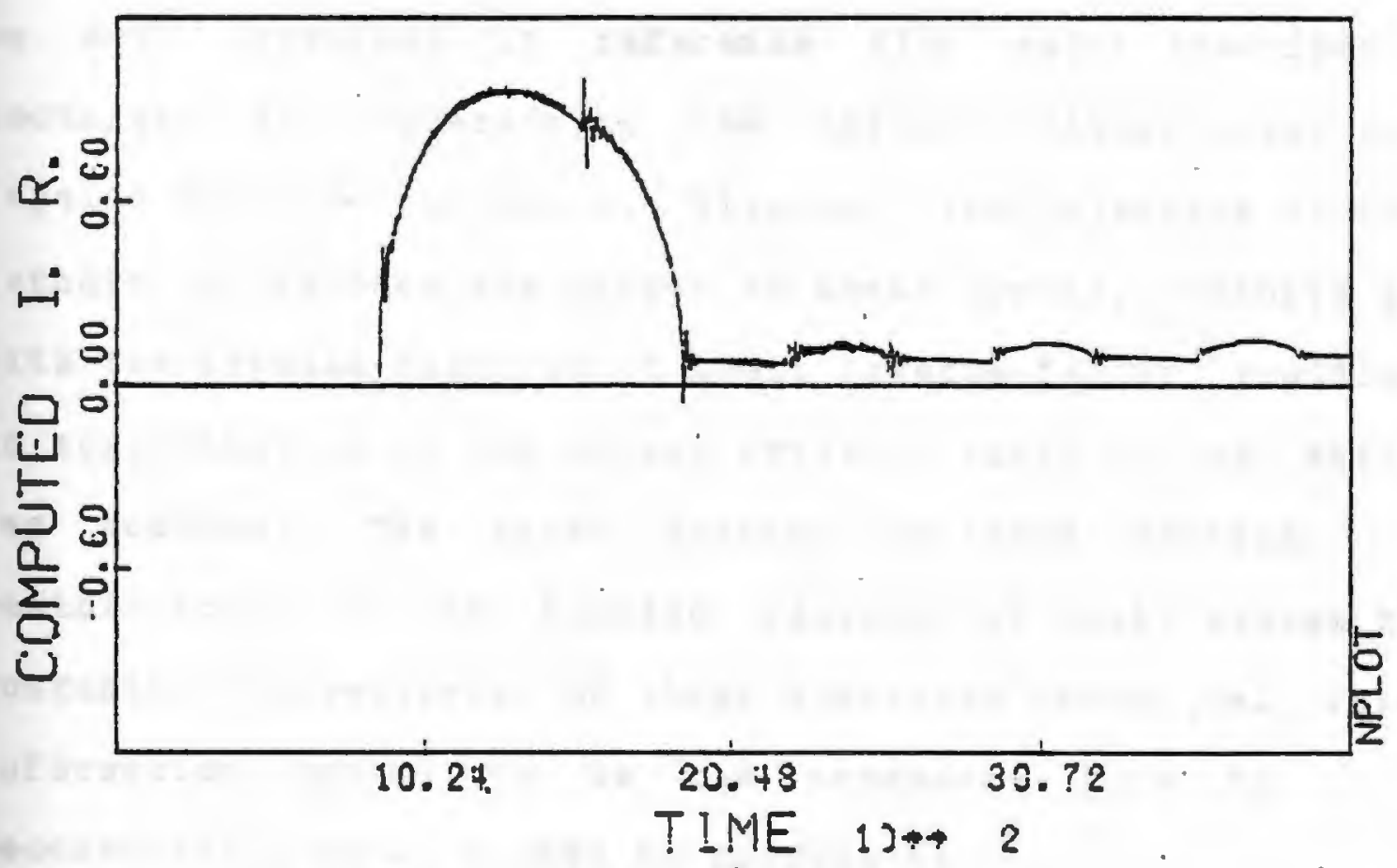

FIgure 14. Test Result of Time Domain Approach 
sanfle size rersion should be tested. This method did show a tendency to converge; howerer, the rate of convergence vas rery slov, and each iteration required at least three En1 convolntions, and sonetimes more, to arrive at the weighting factor needed to mininize the I.m.s. error.

It was during this evaluation that the final deconvolution progran was developed. The program vas based on work contained in Ieference (13) which described a technique for determining the inverse filter given the impnlse response was known. Oltimately the objective of the athors was to take the output of their systen, conrolve it with the impulse response of their inverse filter, yielding an approximation to the actual input to their system, which was unknown. The paper further outlined certain restrictions on the impulse response of their system to guarantee convergence of their iterative technique. This information proved to be the necessary clue to deconrolution as ve wished to perforn it.

DESCRIPTIOI Of IUPLEUERTED METBOD OE DECONVOLUTION

The technigue which finally proved successful is based on an iterative approach. The reference mentioned above outlined a procedure for determining the unknown input of a linear system, given the impulse response and the output. Conditions necessary for convergence of the iterations are discussed. OuI approach was to perform a substitution on their method. The technique iterates, each time comparing 
the conrolution of the latest estimate of $h(t)$ with $a(t)$ to the output of the system, $p(t)$, and adds this difference to the estimate:

$$
h_{1}(t)=h_{0}(t)+\left[p(t) h_{0}(t)+a(t)\right]
$$

or in general:

$$
\left.h_{n}(t)=h_{n-1}(t)+\left[p(t)+h_{n-1}(t)+a c t\right)\right]
$$

The corrections added with each iteration can be vritten as an infinite series:

$$
h_{n}(t)=h_{0}(t)+\epsilon_{1}(t)+\epsilon_{2}(t)+\cdots+\epsilon_{n}(t)+\cdots
$$

here

$$
\begin{aligned}
& \epsilon_{1}(t)=p(t)-h_{0}(t)+a(t) \\
& \epsilon_{2}(t)=p(t)-\left[h_{0}(t)+\epsilon_{1}(t)\right]+\dot{a}(t) \\
& \left.\left.\varepsilon_{s}(t)=p(t)-\left[h_{0}(t)+\epsilon_{1} s t\right)+\epsilon_{2}(t)\right]+ \text { ast }\right)
\end{aligned}
$$

and

$$
\left.\epsilon_{n}(t)=p(t)-\left[h_{0}(t)+\epsilon_{1}(p)+\epsilon_{2}(t)+\cdots+\epsilon_{n-1}(t)\right]+\text { act }\right)
$$


This can be transformed to the frequency domain as follows:

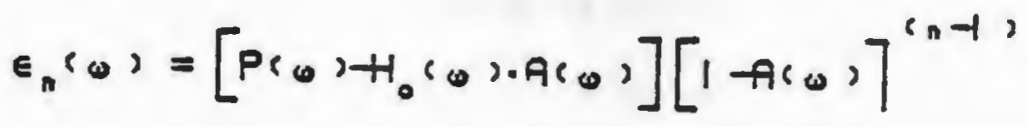

This means that the series of $(20)$ can be written as:

$$
H(0)=H_{0}+a+a r+a r^{2}+\cdots=\frac{a}{(1-p)}|r|-i
$$

vhere

$$
a=P(\omega)-H_{0}(0) \cdot A_{0}(0), r=1-A(\omega)
$$

Therefore the series of (20) converges in the limit as follous:

$$
\left.\left|m_{n \rightarrow-} H_{n}(\omega)=\frac{\left.P_{0}\right)}{\left.1-\left[1+A \theta_{0}\right]\right]} \quad\right| 1 \text { A } \varphi_{0}\right) \mid-1
$$

The abore condition for convergence is too strict to deal with, as it implies that $A(w)$ contains no phase inversions. In vier of this, the abore process is modified by first processing both input and output signals in such a way to allow a less stringent convergence criteria. Eere, both input and output are convolved with the input signal, which has been inverted in time:

$$
\left.g^{c t}\right)=a(t)+a c t,
$$




$$
x(t)=p(t)+a b+,
$$

The method above is again applied, with the result that the series conrerges if:

$$
|1-6(0)|=1
$$

bat

$$
G_{0}(0)=\left|A_{0}()^{2}\right|^{2}
$$

therefore the series converges if

$$
|A r \cdot 2|^{2}<2
$$

which is satisfied by proper scaling of the input signal.

The above analysis has been formulated to allow anI starting estimate at all. Note that as implemented on the computer, the technique is ralid only for impulse resonses which are finite, within the time window of the program, and causal, meaning that $h(t)$ is non-zero only for $t>0$. The general convergence condition makes no restrictions on the first estimate, so any function may be used without fear of biasing the results. Obriously mang more iterations are needed for the sant degree of accuracy in 
the result if the first guess is considerably different from the solution. In viey of this, when applied to real data, the initial estimate used was the theoretical impulse Iesponse computed for the spatial point of interest.

This method was implemented in full size on the Acadenic computer center system. The operation is broken down into two separate programs. Data is first processed in a program called NORM, listed in appendix A. As inplied by its name, this program normalizes both the input and the output time histories so that in terms of actual values, their discrete frequency transforms are always less than 2. It is not necessary for convergence to scale the output time history: this is merely done to keep all the signals at a relatirely constant level. Mert NORM conrolves the input and output signals with the tine inverse of the input. Iastly, vORI calculates the theoretical impulse resfonse, and creates plots of $g(t), x(t)$, and the theoretical $h(t)$. This data is then stored on permanent disk records. MORI does not take an extremely great amount of computer time, but because an input time history is 1024 samples long, and the output bistory is twice that, considerable memory is used. Intermediate data vas stored often throughout the processing to provide backup if the program ran over its alotted time or if the systen crashed. Iert after the data sets have been normalized and pre-processed, a program is run which does the iterations. Several versions of this exist, differing only by the 
number of iterations performed. Each iteration involves only one convolution, which is done by the PFI wethod. One factor of this contolution is always $g(t)$, which instead of being stored in the time domain and transformed every time, is stored as $G(w)$, elininating the need to transform it every iteration. BY this saring, the time for each iteration has been reduced to approximately six seconds of cPo time.

The method was tested as described in the preceeding section, and performed well. With no dymaics present in the simulated data, the deconvolred impulse response tracked almost perfectly, the only deviation being caused by discontinuities in the original trial fit. In testing this program, the first guess impulse response was a simple box, whereas the solution impolse response was known to be a sort of zonaniform semicircle containing discontinuities only at its endpoints. This was done to cause the deconvolution program to require several iterations, to force it to 'work'. The steep rising and falling edges of the box function caused small spikes to appear at the corresponding points of the solution impalse response. A typical output from the program run on this data is shown in figure (15).

Bext the technique was tested with simulated data which included transducer dynamics. The program succesfully deconvolved the correct inpulse re sponse, and the only difference from the previous test was that the 


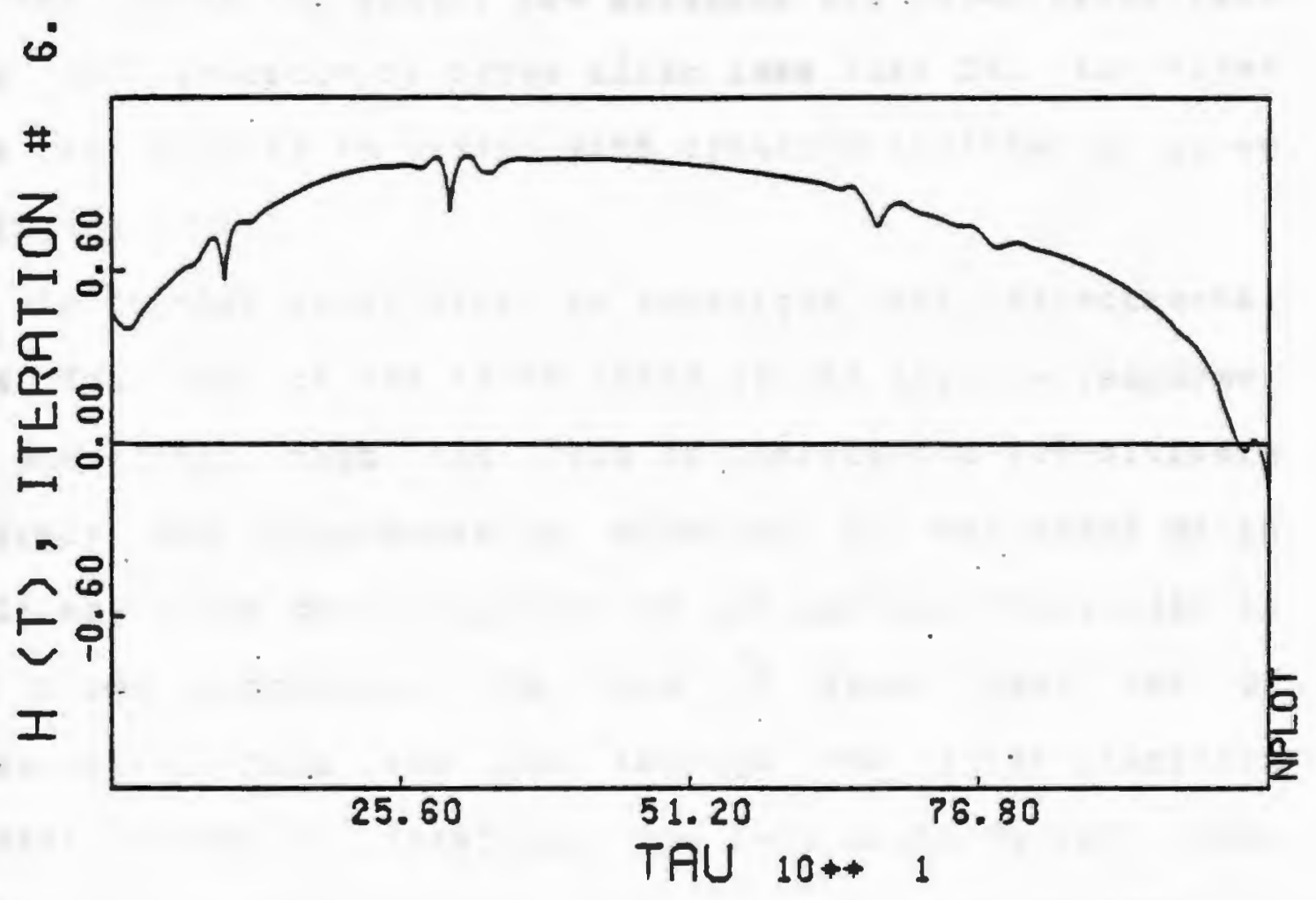

Figure 15. Test Result of Iterative Technique: No Dynamics 
solution had a small amount of high frequency noise present. This was relatively insignificant in terms of the ratio of signal to noise. It has been surmised that the noise is caused by truncation error in the computer. although this is small for ang given iteration, the noise probably accumulates when many iterations are performed. In the abore two tests, the solution was found after less than 100 iterations, often after less than 20. nn output from the program as tested with dynamics included is given in figure (16).

In further study with the technique using experinental data for each of the three cases of the impulse response, it was found that the rate of conrergence and altimate accuracy was significantly affected by the value of an arbitrary scale factor applied to the initial trial $h(t)$ in the first iteration. In view of this, each set of experimental data was run through the first iteration sereral times to determine the best scale factor. This scale factor was adjusted to a value as close as possible to the value where a phase inversion of the first correction occurred at the time corresponding to the first excursion of the impulse response. This significantly improved the rate of convergence and also the ultimate accuracy. The mathematical analysis of the technique shows that convergence is independent of the initial estimate ho; howerer, in actual practice this affects the rate of convergence. The technigue generates a few artifacts of 


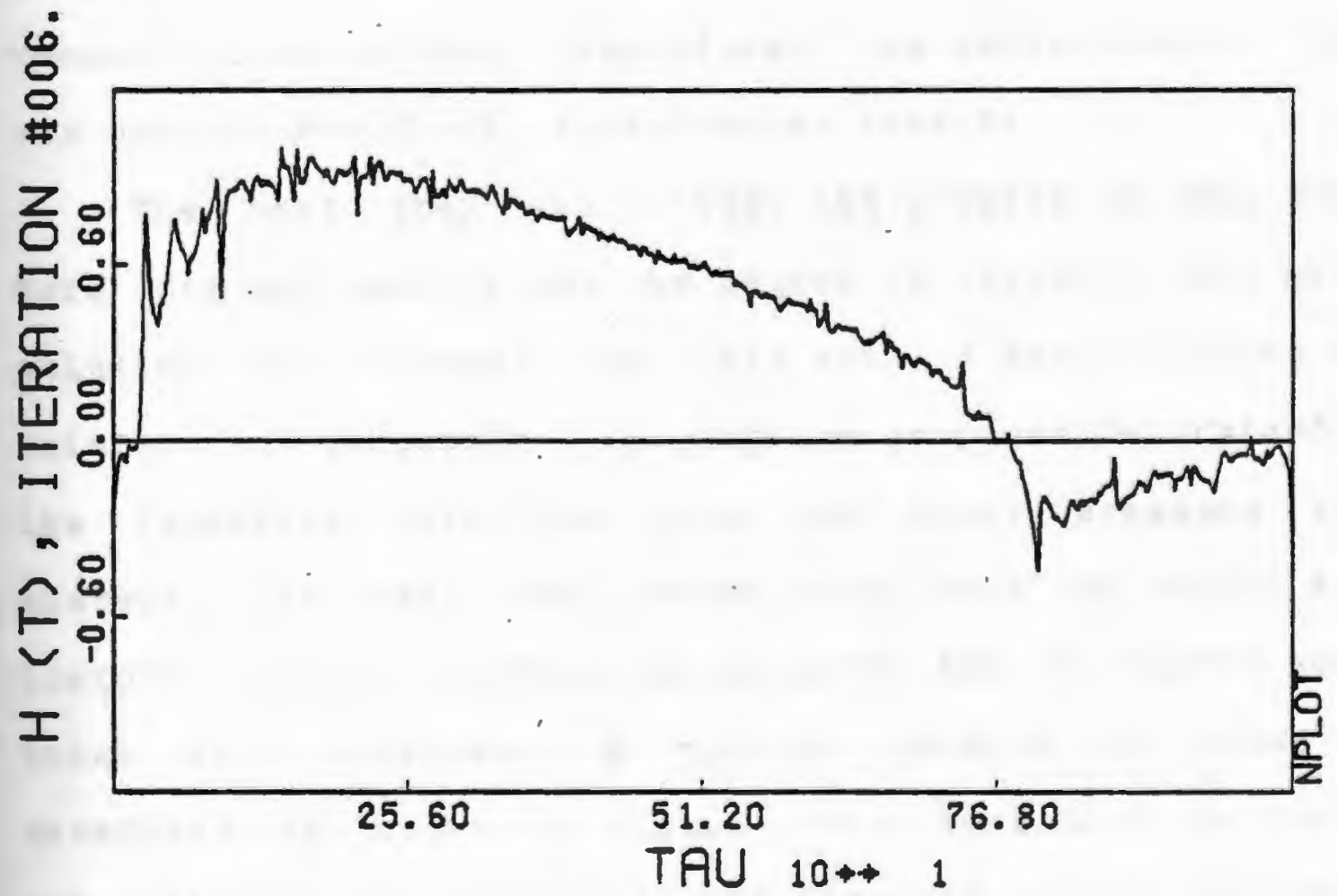

Plgure 16. Test Result of Iterative Technique: Dynamics Included 
processing with many iterations. These artifacts have a fundamental Irequencl were there is little energy in the input signal, and for this reason, these artifacts tend not to affect the reconrolution check. The technique was tested with experimental data such that the initial estimate was yildy in error; in this situation the technique failed to converge in sereral thousand iterations. This failure was clearly indicated in the reconvolution check. Therefore, the reconvolution check vas used to verify all experimental results.

The nert step was to test the program on real data. Bere one may inquire how the degree of accuracy of a given solution was tested. To this end, a small coutine was witten to reconrolve the impulse response determined by the iterative technique with the input pressure time history. The Iesult was plotted along with the output time history. If the solution was correct, the two curres would track well together. a typical erample of these two wareforms is shown in figure (17). Note that the curres are extremely similar until the midpoint, were they cease to track exactiy due to the fact that the input data has been truncated at this point to fit in the time window. 

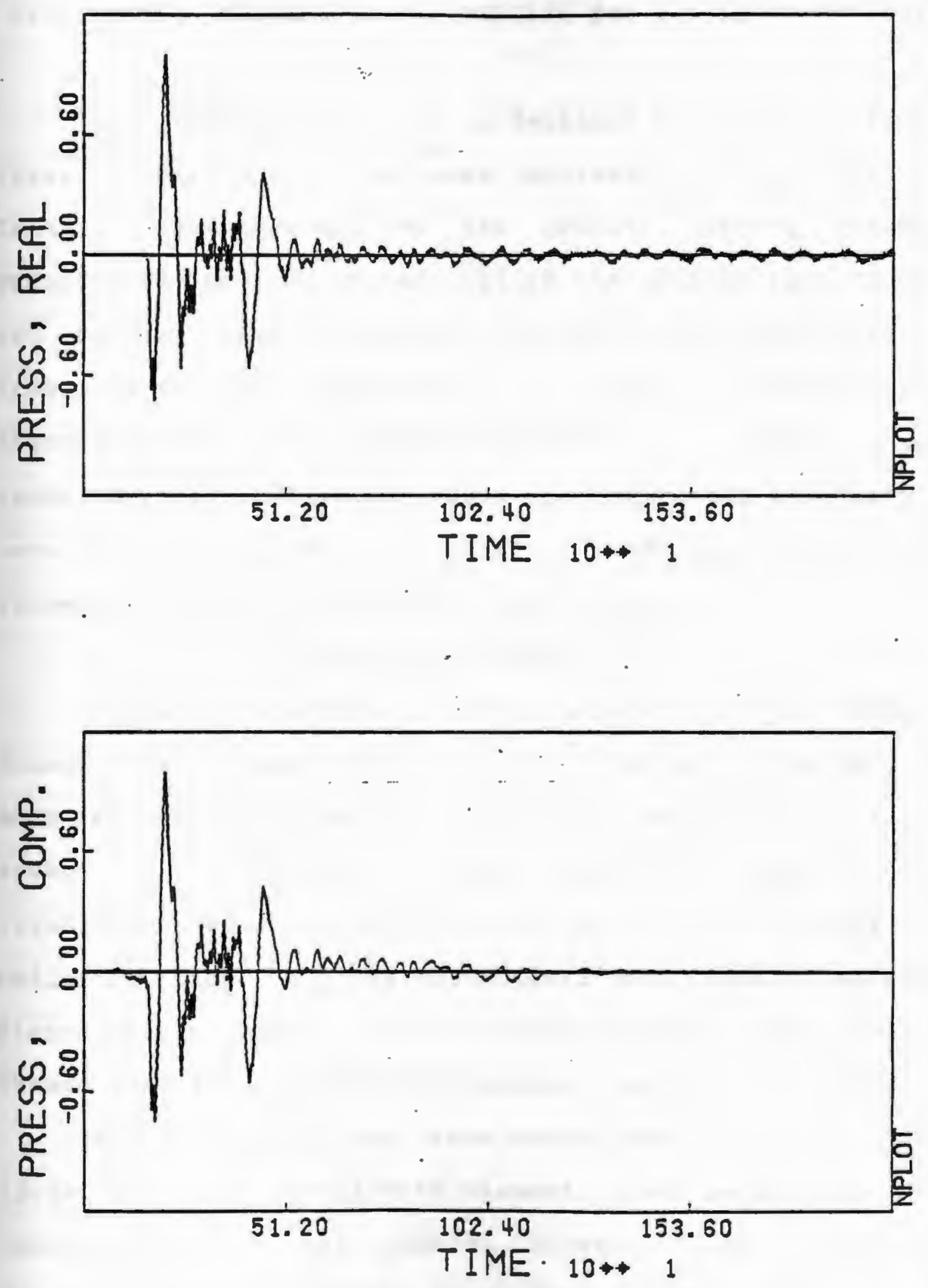

Figure 17. Convolution Check of Iterative Technique 
EXPERIMEATAL PROCEDORES ANA RESOLTS FOI SIMGIE TRANSDUCERS

This section contains a detailed description of the types of transducers which vere analysed in the test setup. Initial investigations of the acoustic fields of these transducers are described, and as the inftial results did not compare with theoretical predictions, subsequent experiments were conducted to discover the cause of the discrepancies. An important observation concerning the experimental procedure was noted and additional experiments were then conducted that jielded results which were in agreenent with the theoretical predictions.

TRAISDUCER CONSTRUCTION

Sereral projectors, which differed as to their construction, were built for this project. Hoverer, in each case the goals behind constraction techniques vere the same, i.e. to derelop a vide bandwidh piezoelectric transducer which exhibited a uniform relocity across its radiating face. All the transducers were constructed froll plezoelectric discs and all were backed with a medinn chosen specifically for it's acoustic impedance or loss.

several transducers vere constructed with a one inch (2.54 mil.) Lead retaniobate element. Lead yetaniobate yas chosen since it has greater internal loss than other materials. The greater loss factor weans that the transducer would tend to be more damped and vould ring for 
a shorter period of time. This was advantageous for two reasons: First the banduidth was increased, giring us more information in the frequency domain concerning the inpulse response. second, the pressure time history tended to be shorter, neaning more of the significant portion would fit in the heavily sampled time vindor of roRE.

Several other researchers $[$ (7), (8) ], have found that the use of a backing material fabricated out of epory and Tungsten porder causes a significant increase in bandwidth, due to the Iesistive loading on the back face. It is interesting to note that fungsten has the highest density of any elemental metal. Some prototype transducers were constructed as a test of construction techniques. at Iist, the amount of Tungsten used ras about one part in six by veight. This was kept in suspension in the epory during the curing time by slowly rotating the sanple. Transducers backed with this compound did not show a considerable difference from those backed on other materials. on comparing construction techniques with a compercial manufacturer, it was found that the amount of Tungsten should be so great that the epory should bare the consistency of cookie batter before curing, obviating the necessity of spinning to keep the particles in solntion. Other investigators have used the centrifuge technigue vith higher concentrations to promote a non-uniform distribution of Tungsten particles.

The first transducer which was constructed vas a Lead 
Metaniobate disc of $25.4 \mathrm{~mm}$. dianeter, mounted on the end of an aluminum bar approximately 10 centimeters in length and 7.5 centimeters in diameter. Aluminun was chosen as the best commonly arailable material to closely match the acoustic impedance of the element. The disc element was $1.0 \mathrm{~mm}$. thick. and was recessed into the end of the Aluminun so that the face of the assembly yas as planar as possible.

The second transducer constructed yas also a Iead Hetaniobate disc, this time mounted on a backing plug polded of araldite epory which vas mixed with a large proportion of Tungsten porder. The elenent was baffled vith a layer of pure araldite formed around the edge of the element. After the epory had set, the baffle was filed Ilat.

The third transducer investigated was a crystal of Iithium sulphate. This was also bonded to a Tungsten and Araldite plug as before, and an epory baffle molded on. The diameter of the Iithium sulphate was only 15 mm. Iithiam sulphate was chosen at the suggestion of a commercial biomedical transducer manufacturer, who bad an intuitive feeling that it vould be less susceptible to vibration in the radial mode because it was a single crystal as opposed to an amorphous ceramic. The thickness of the Iithinm Sulphate cIystal yas only.45 mm., Iesulting in the resonant frequency of betreen 5 and $10 \mathrm{~Hz}$ when nonted on the plug as noted above. 


\section{GEASUBEMENTS and BESULTS}

The time dependent pressures which were radiated frou these transducers under shock excitation were measured in the test setup. Programs vere witten for the Nova to take sereral pressure time histories with the bigh speed $A / D$ converter, average these together, remove any mean value, plot the resulting ensemble average, and store the data on 9-track tape. Another program was run on the rova to read the time histories from the tape and send them ria the telephone link, to the ncademic computer center spstem. Two pressure time histories were obtained for each deconvolution: one pressure time history was measured at an on axis far field point and the other pressure time history was measured at the field point of interest.

Three general areas were concentrated on in the field; on axis at close range ( $z$ less than two radii), off axis but still inside the cylindrical projection of the transducer at close range, and at angles of from 30 to 45 degrees frow the normal to the face of the transducer at ranges from $z$ equal to two to ten radii.

Due to the size of the aquaring and the length of the transducers, the maximum range used for the on axis case was 35 centimeters. This was repeated for the first two transducers described above and for several field points. The results of the deconrolution to obtain the experimental impulse response were at this time disappointing. Although subjected to sometimes as many as 
1400 iterations, the computed impulse response curves were very noisy and high frequency in nature, and did not track at all with the theoretical impulse responses. Pigure (18) is a typical example. Mang suggestions were made as to the cause of this fallure. These included excessive radial node vibrations, insuficient bandwdth throughout the measurement system, and directivity of the receiring probes. The most crucial question at this point was whether the problem was in the transducers themselves or in the measurement system. The deconvolution programs vere not suspected, because the impulse Iesponses, when reconvolved with on axis data, tracked extremely well with the off axis pressures recorded.

lt this point, an experiment was devised to determine the location of the problem. Since the pressure field which emanates from the end of an open pipe or through a circular aperture in an infinite rigid baffe, assuming a plane vare incident, tracks closely with the field of an ideal piston radiator, this field could be used to test the experinental approach. The only significant difference occurs at low frequencies, as characterized by $k d<10$, where $k$ is the ware number and $d$ is the characteristic diameter.

In vies of this information, it was thought that measurements of the acoustic transaission through an aperture in a baffle vould indicate the sonrce of disagrement. Measurements of this type have been done in 
69.

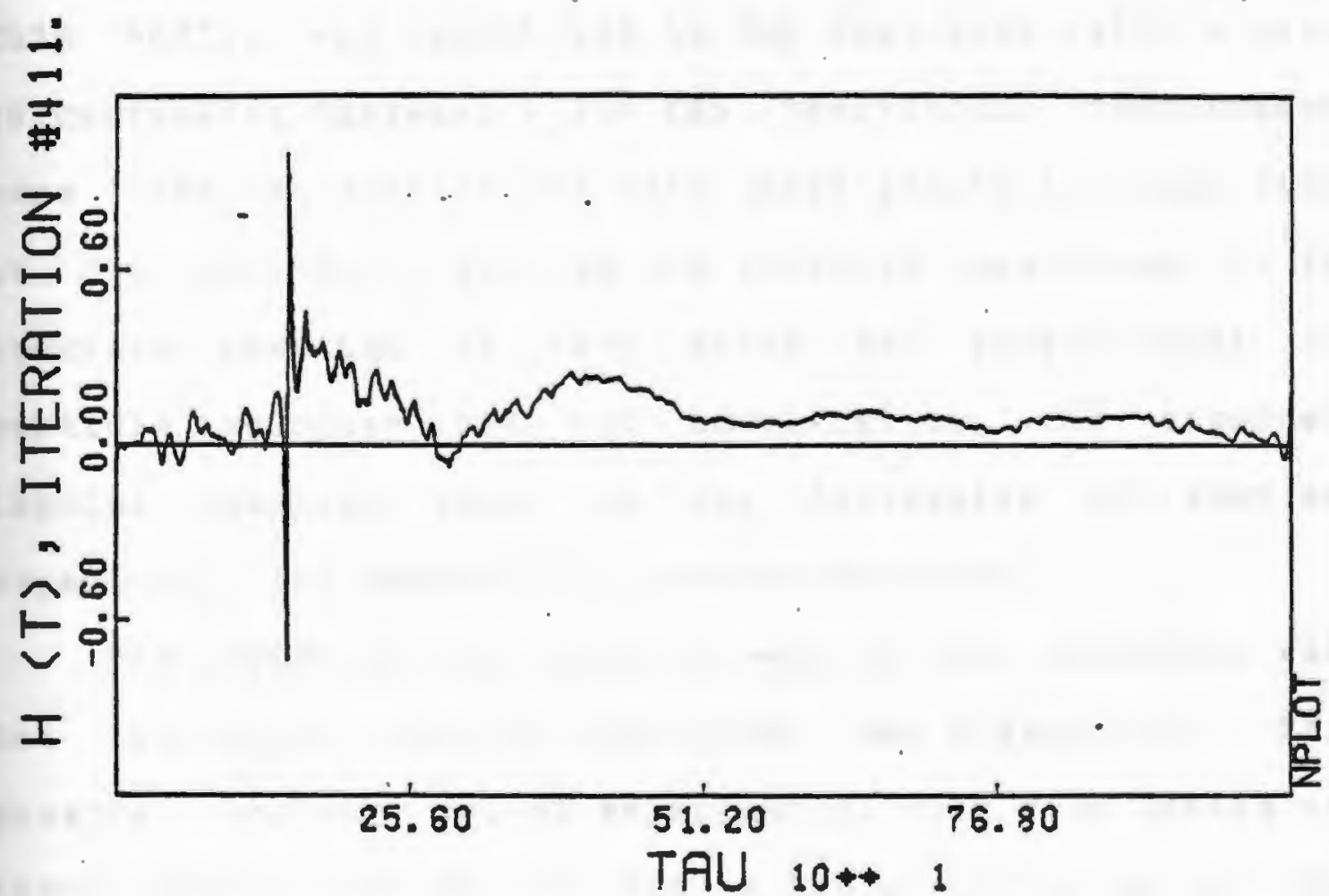

Figure 18. Experimental Impulse Response: Insufficient Range 
air with good Iesults, ref (14). A thin steel sheet was perforated with a one inch diameter aperture, and covered on the back with a pressure release material, a foall rubber layer only a few cells thick. An objective of the construction was to keep the wole assembly as thin as possible, to minimize effects at the edges of the opening. This baffle was insonified in the test setup with a large (6 centimeter diameter ) $200 \mathrm{kBz}$. transducer. Measurements were taken at similar off axis field points and also right at the aperture. Because the pressure measurement in the aperture resolted in data which was proportional to particle velocity and not acceleration, the expected inpulse response would be the derivative of wat was expected in the case of the piston radiators.

The experimental results vere in fair agreement with the theoretical impulse responses, see figure (19).. This prompted another set of experiments, this time taking the input measurement on the axis of the aperture, in it's far field. This should have rielded results identical to those expected for the piston radiators. Basic to this experiment is the reguirement that the acoustic wave at the aperture be planar. Bowever, the aquarium used was not large enough to allow placing the baffle in the far field of the signal source, and also allow the receiving probe to be at sufficient distance from the aperture. To get around this, the entire setup was moved down to the large test tank mentioned before. This tine, to get a shorter 
TI.

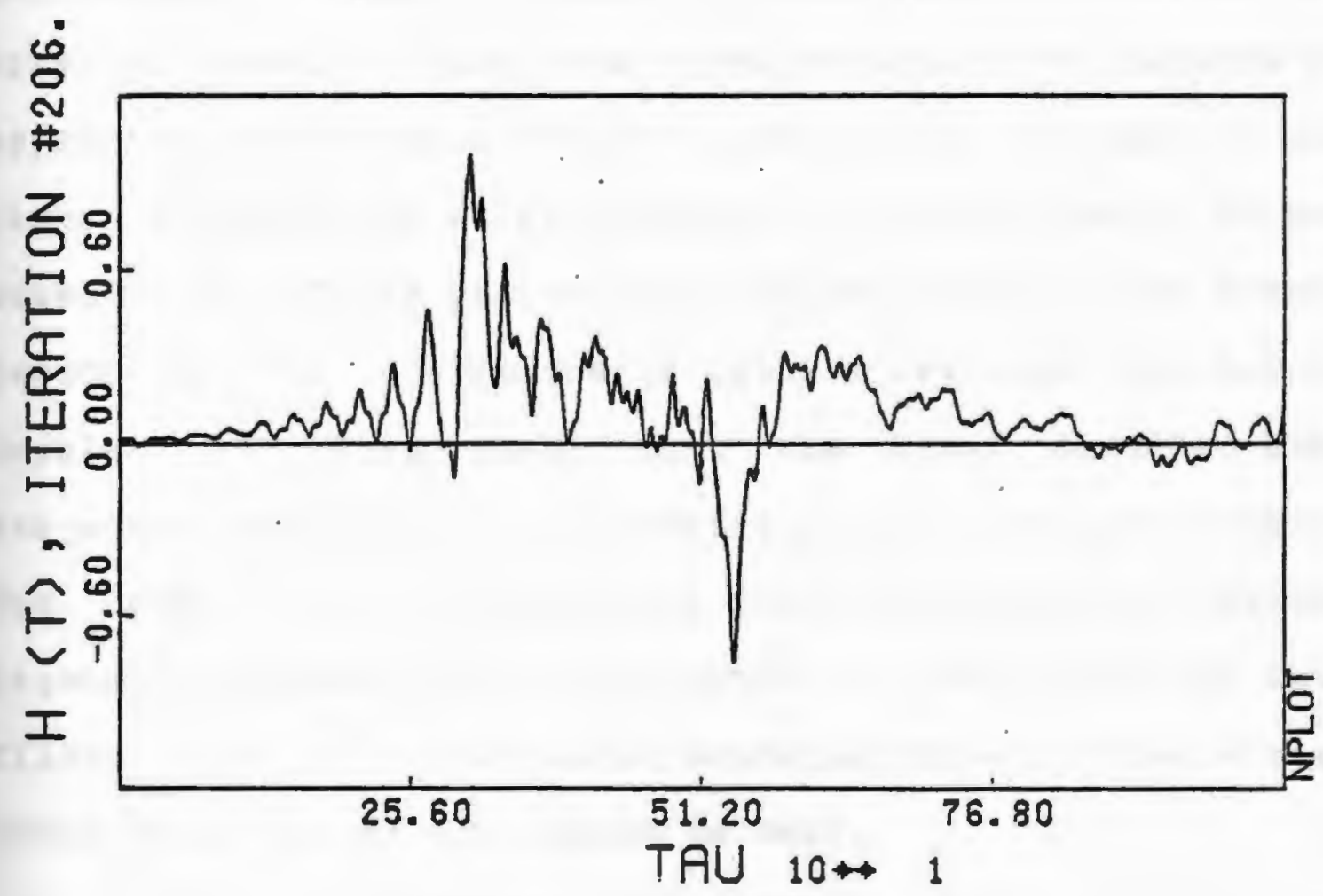

PIgure 19. Experimental Impulse Response: Steel and Foam Baffle 
acoustic pulse, the lead Metaniobate transducer with the Tungsten backing was used as a source.

And here was Divine Inspiration or the accident of science: The pressure field of the source transducer, as measured at a distance of more than two meters, was significantly different from what had been seen a fex moments ago in the aquarium at a distance of 35 centimeters. This was wat had been interfering with the previous results. The data taken on axis at a distance of approrimately 30 radii was not linearly proportional to the piston acceleration at all; Iather it vas the result of the convolution of the piston acceleration and a narroi boxcar (which is the corresponding impulse response, but not an inpulse! 1. This neant that the input data had been subjected to a sin I / I filtering in the frequency domain. The result of this was that the experinentally computed impulse responses had been subjected to the inverse of this filter, i.e.. a filter which contains poles at frequencies where the argument sin $x$ goes to zero.

Dith this stunning information, all the following attempts vere carried out in the large tank, asing the positioning system for the receiving probe and another support for the transducer under test, at a distance of greater than one and one half meters for the on axis measurements. The results from this setup bore an excellent resemblance to the theory as described in the following paragraphs. 
For the three transducers tested, measurements vere ade at points to rield the three types of impulse response outlined in a previous section. The best agreement with the theoretical impolse responses was found for the case where the point was outside the crlinder of projection, which is also the impulse response having the smallest banduidth. Examples of this are given as figure (20) for the alnminum bar transducer, fignre (21) for the Tungsten backed Lead Metaniobate transducer, and figure (22) for the Lithium Sulphate on Tungsten. A reconrolution check of the experimental result for this geometry is presented bere in figure (23).

Aditional agreement between exferiment and theory was obtained with those cases not on axis, but inside the cylinder of projection. Here the falling edge tracks vell, but the sharp leading edge is obscured as indicated in figure (24) for the Tungsten backed lead setaniobate, and Iigure (25) for the Iithinm sulphate. The corresponding reconvolution check for this family of impulse responses is shown in figure (26) .

The least satisfying agreement was obtained in the on aris cases. See figure (27), applying to the alominum bar transacer, figure (28) for the lead lotaniobate on Tungsten, and figure (29) for the Iithinm sulphate. Again, the recontolation check is giren in figure (30).

Note that results obtained frou different transducers agree, an indication that excessive radial modes were not 


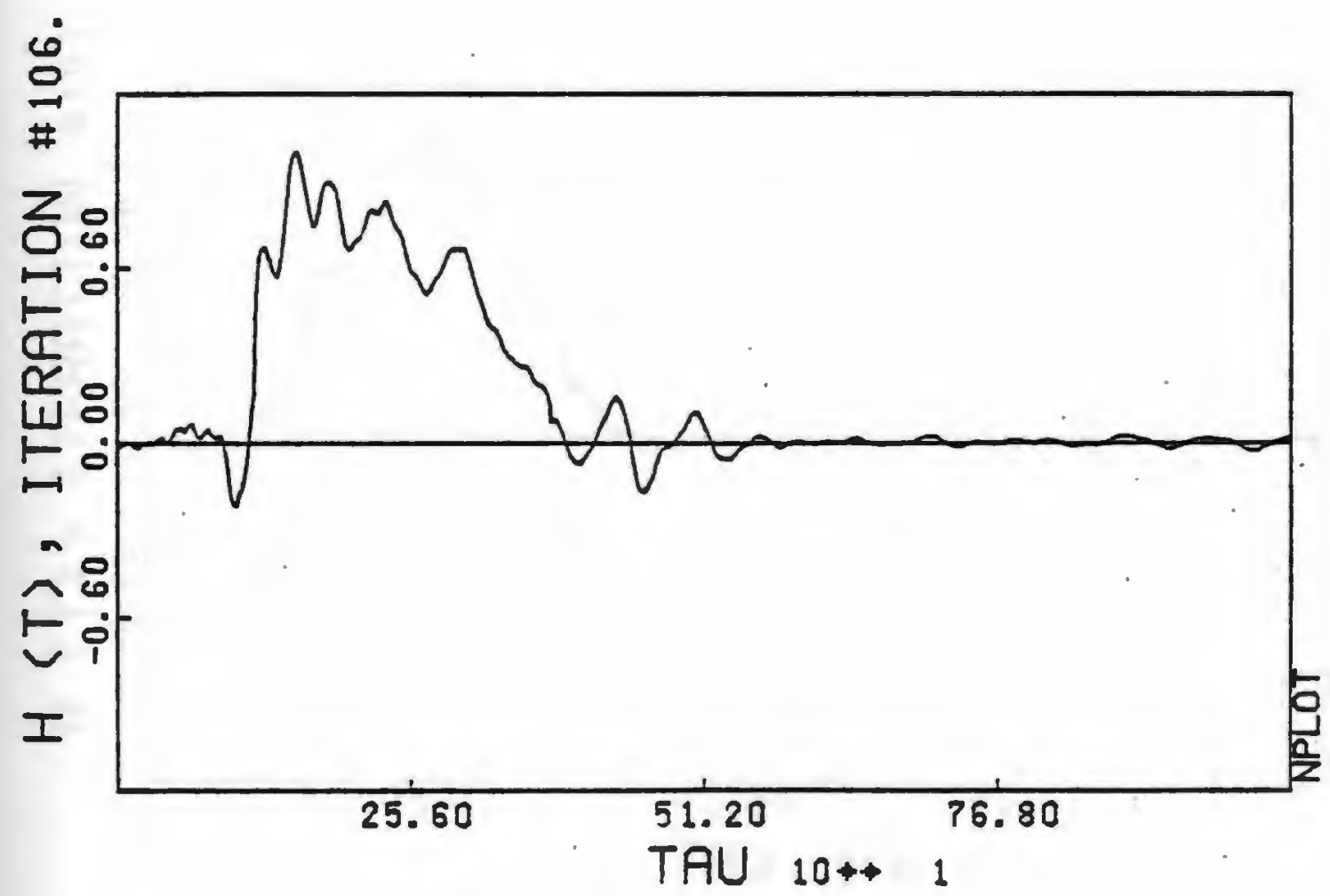

Figure 20. Experimental Imprise Response: Iead Metariobate on Aluminum Bar, Outside Disc

$R=20$. $\mathrm{mm}$. $z=60$. $\mathrm{mm}$. 


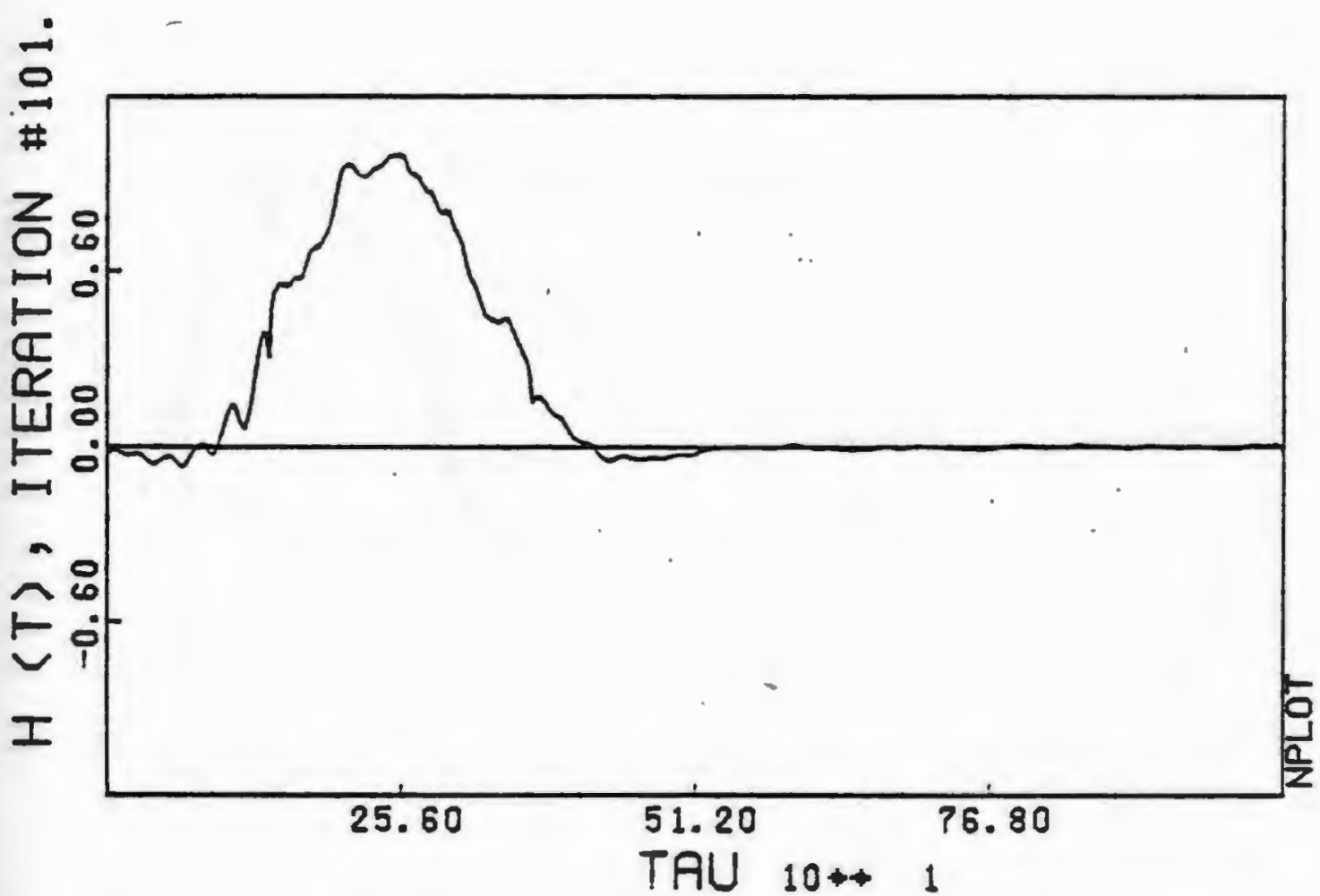

-FIgure 21. Experimental Impulse Response: Iead Metaniabate on Tungsten Backing, Outside Disc $R=40$. m. $Z=140$. Im. 


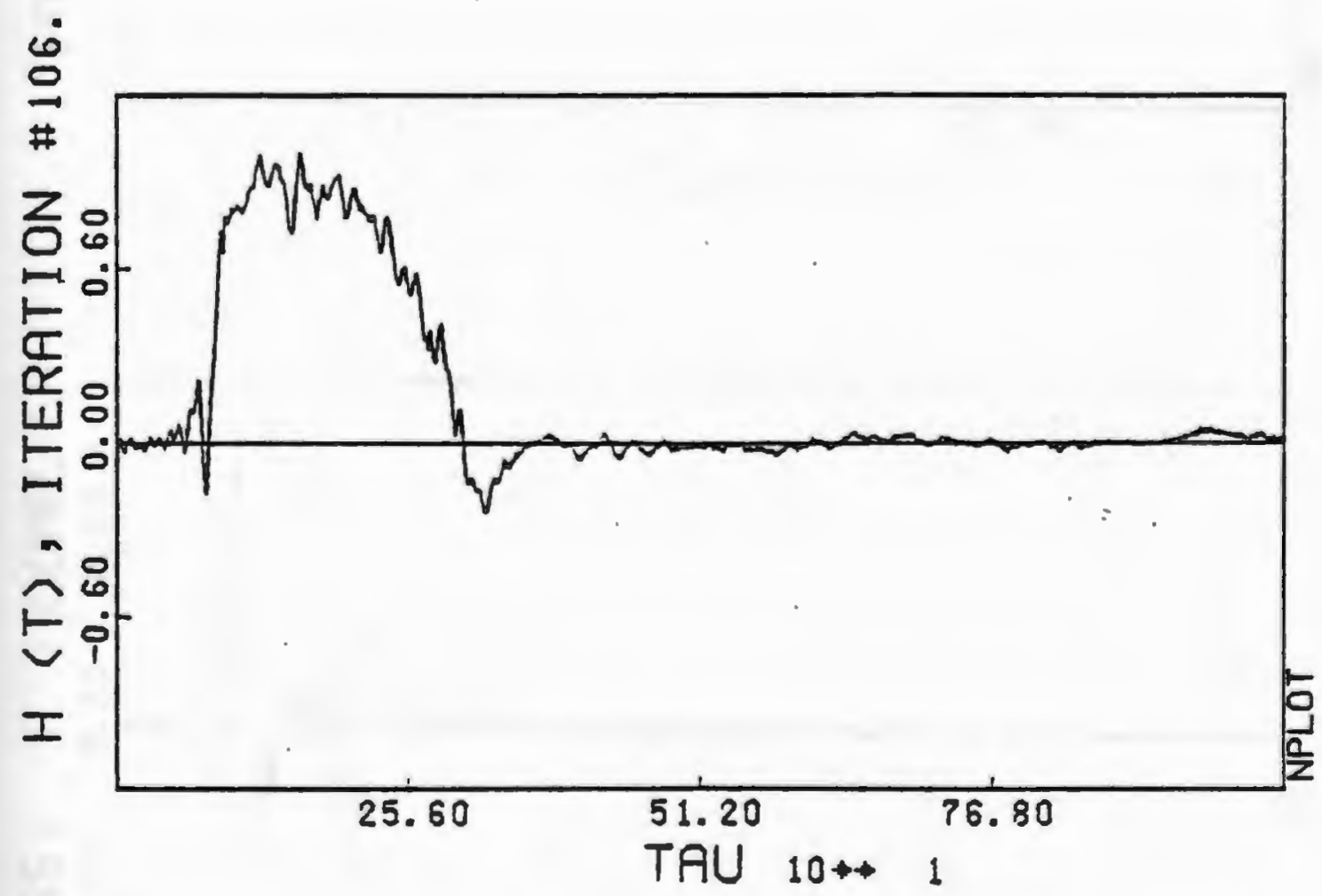

Figure 22. Experimental Impulse Response: Iithium Sulphate on rungsten Backing, Outside Disc

$R=50$. mam. $z=130$. man. 

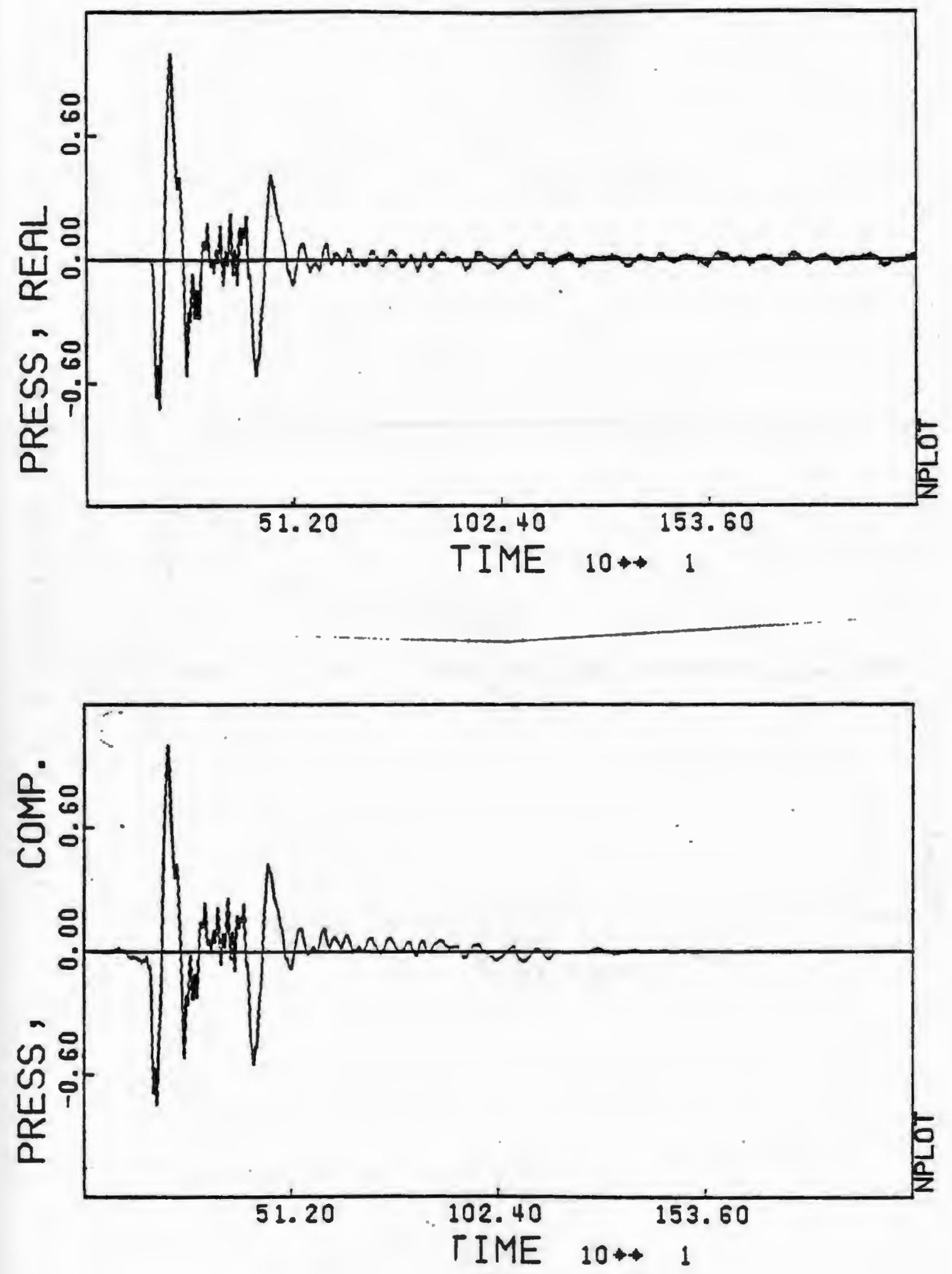

Figure 23. Reconvolution Chenck: Outside Disc 


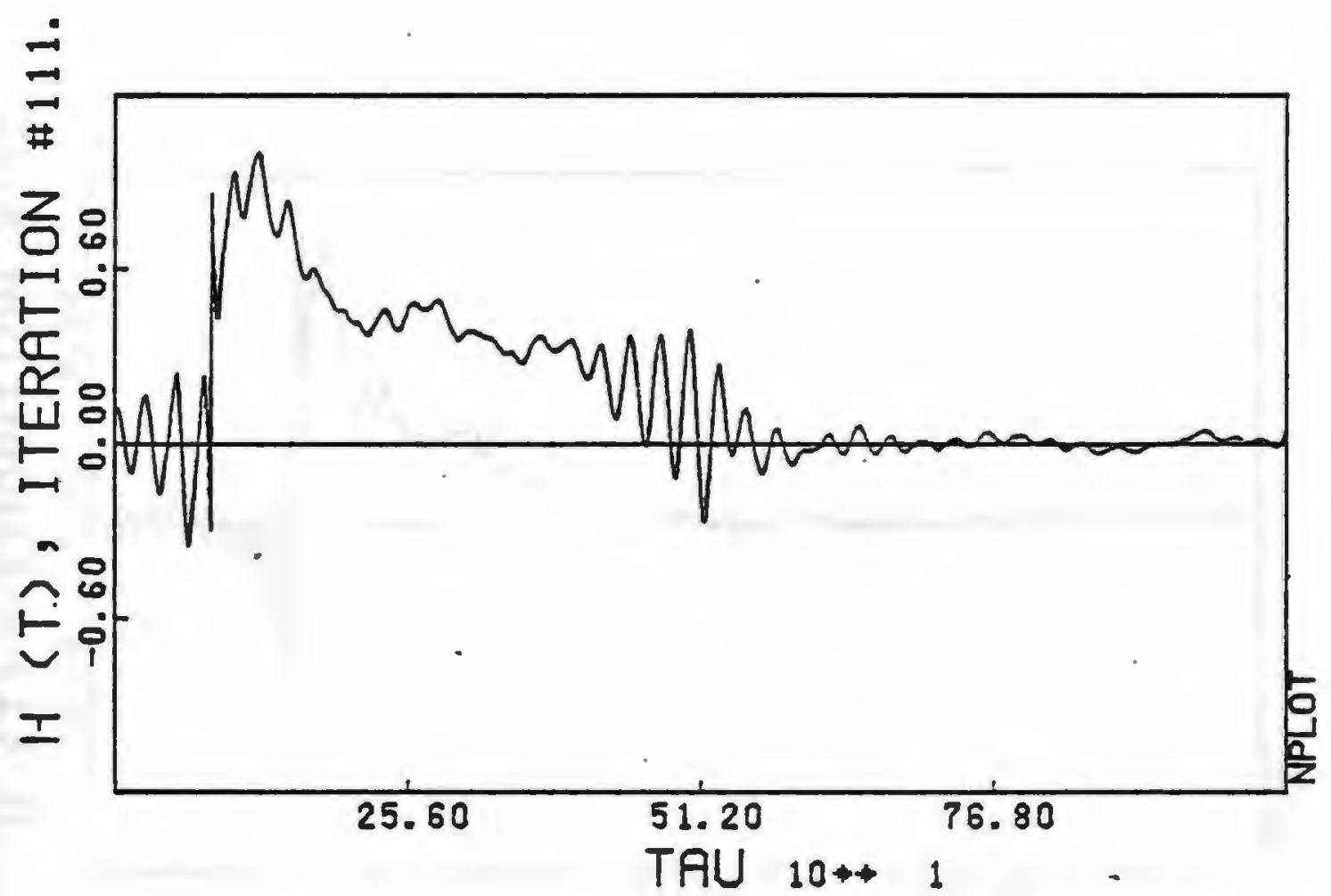

Flgure 24. Experimental Impulse Response: Lead Metaniobate on Tungsten, Inside Disc

$R=10$. Im. $z=12$. $\mathrm{sm}$. 


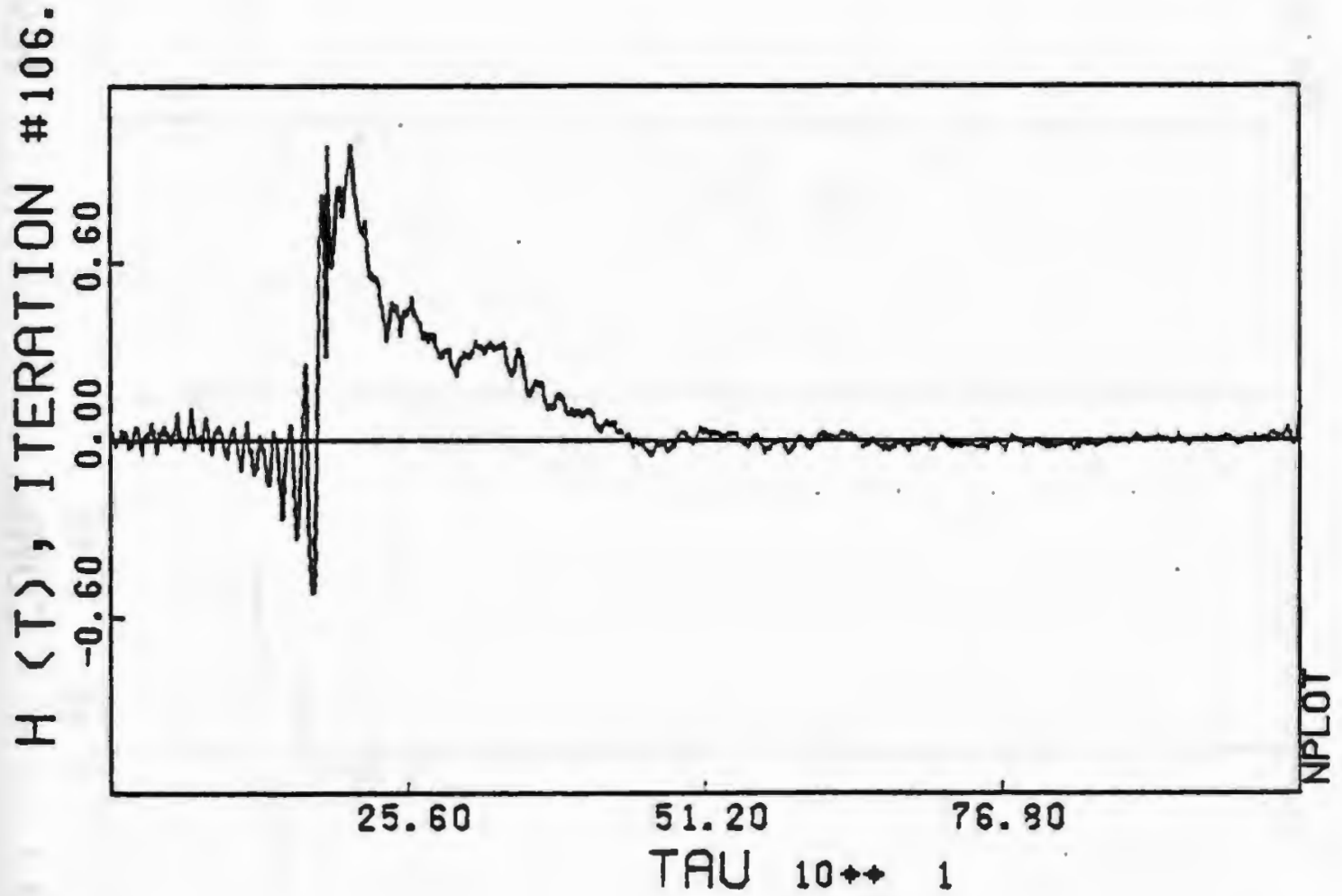

Figure 25. Experimental Impulse Response: Iithium Sulphate on Tungsten Backing, Inside Disc $R=4$. 때. $z=16$. 패. 

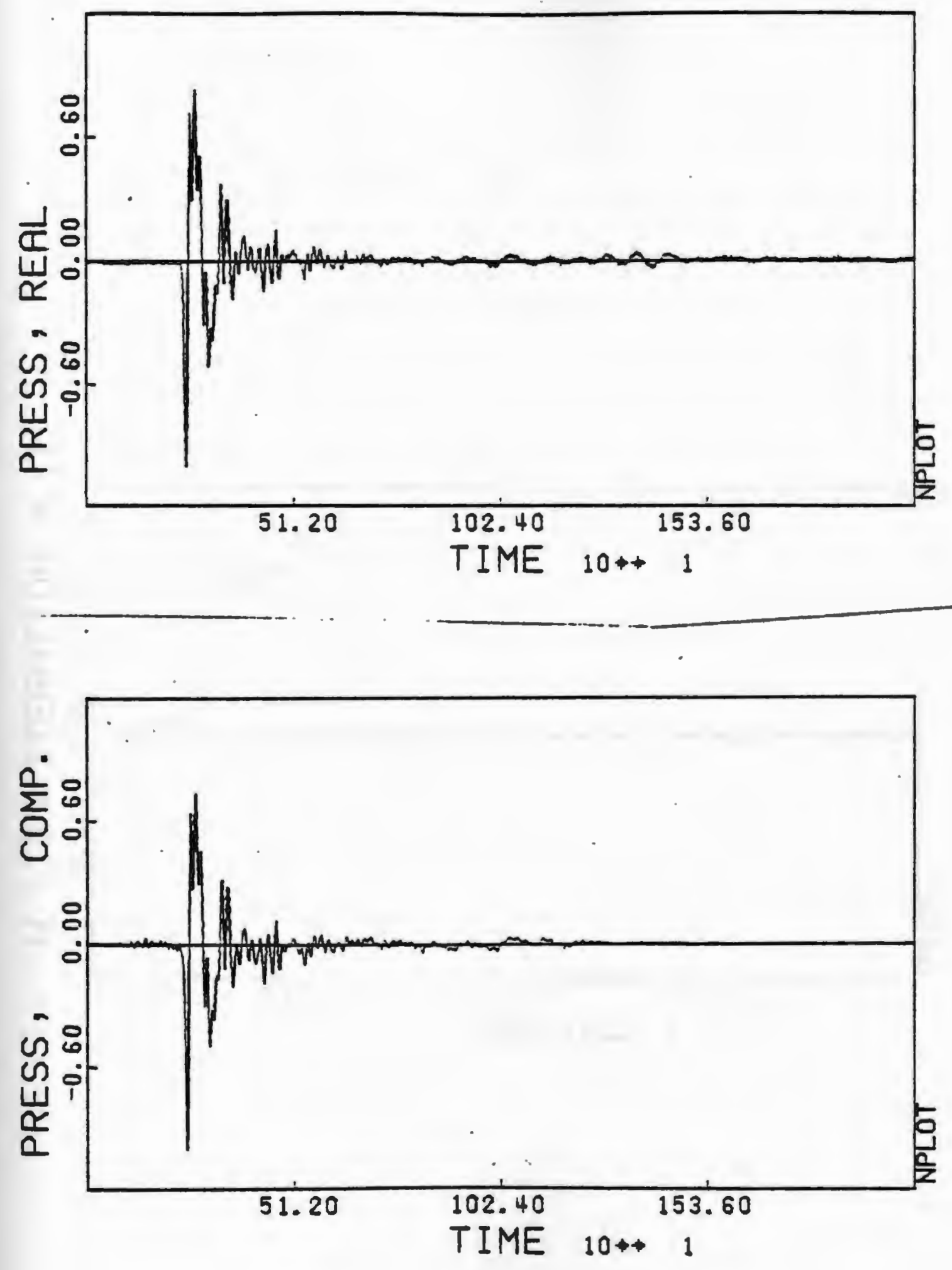

Figure 26. Reconvolution Check: Inside Disc 


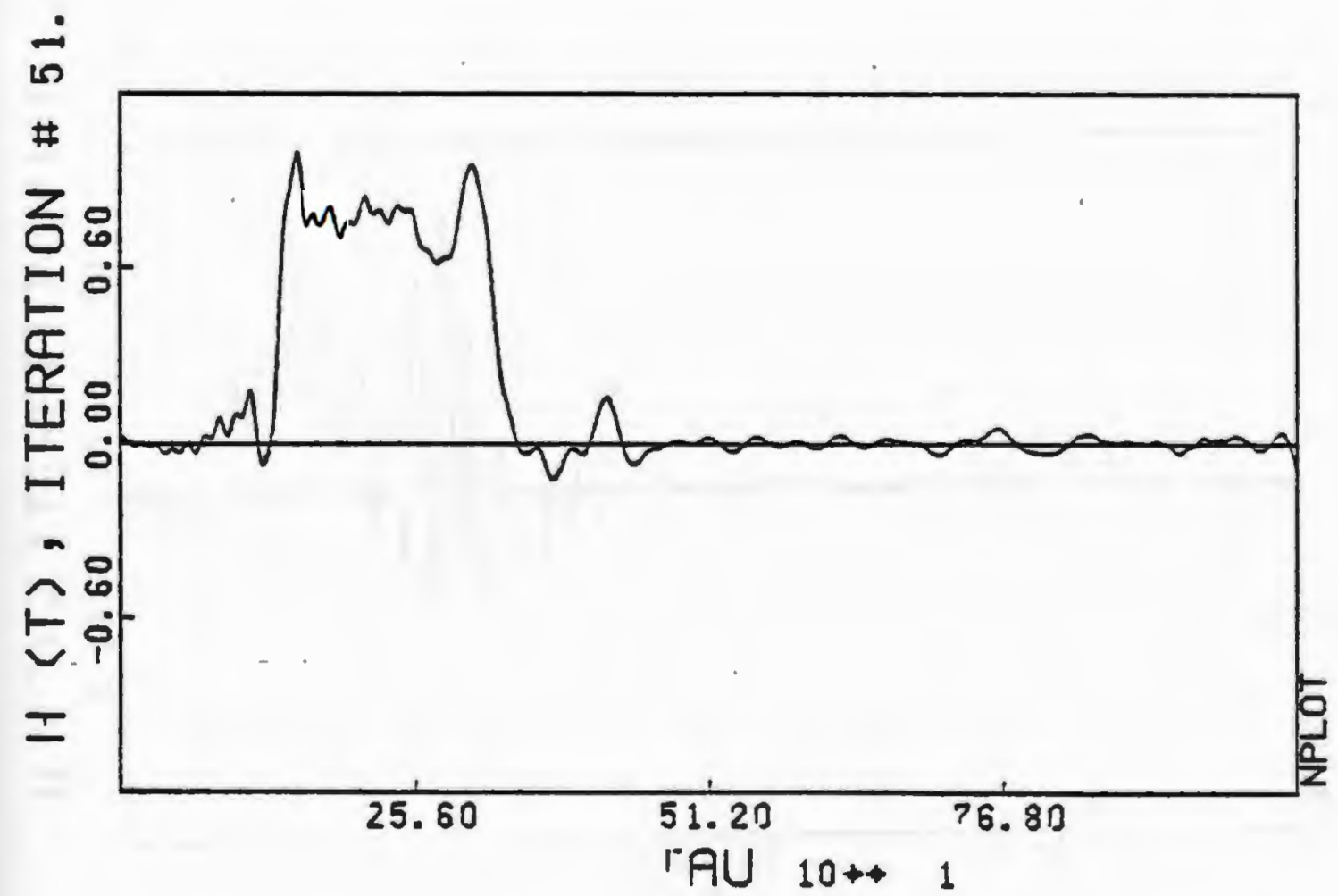

Figure 27. Experimental Impulse Response: Lead Metariobate on Aluminum Bar, On Axis 


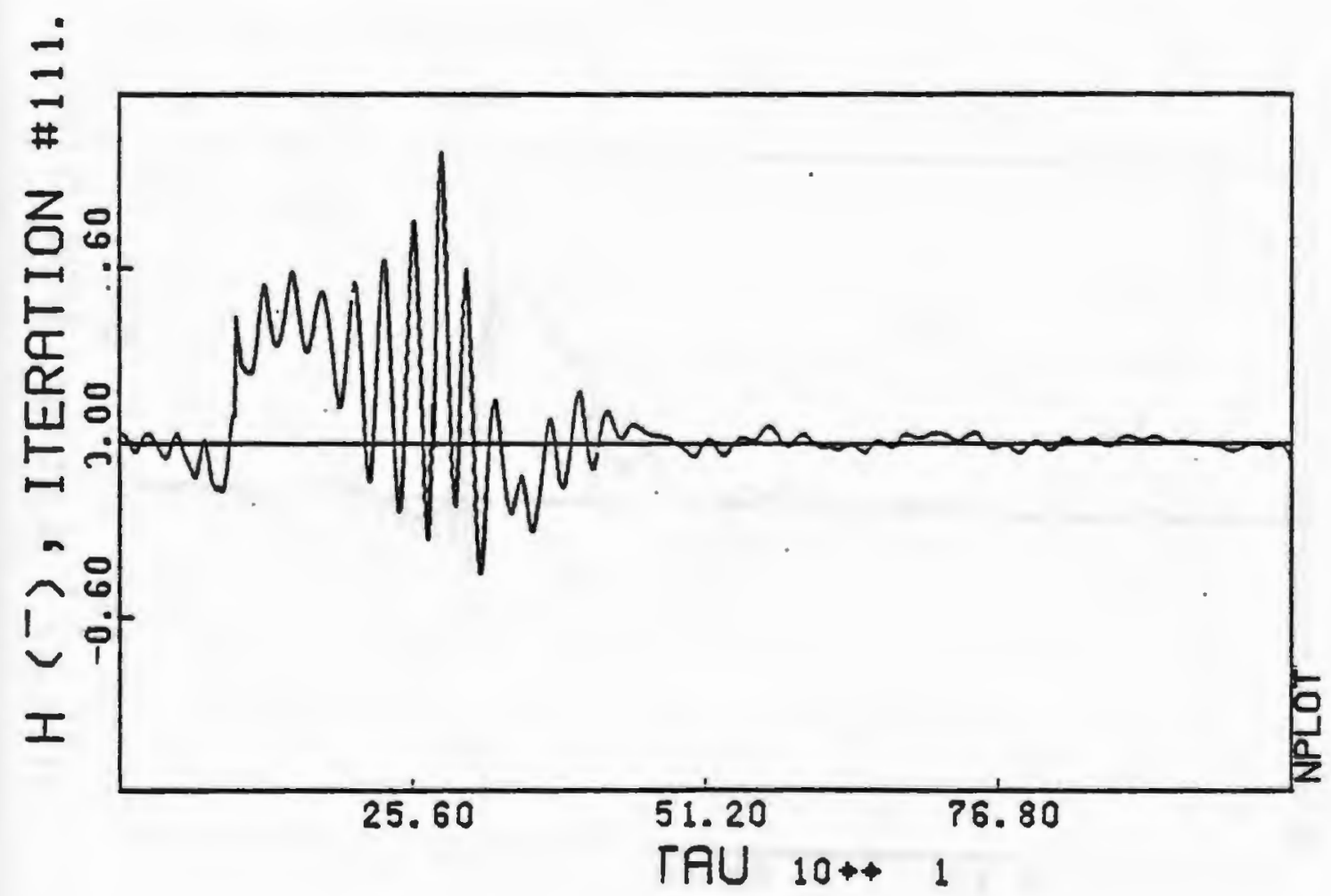

Figure 28. Experimental Impulse Response: Lead Metaniobate on Tungsten Backing, On Axis 


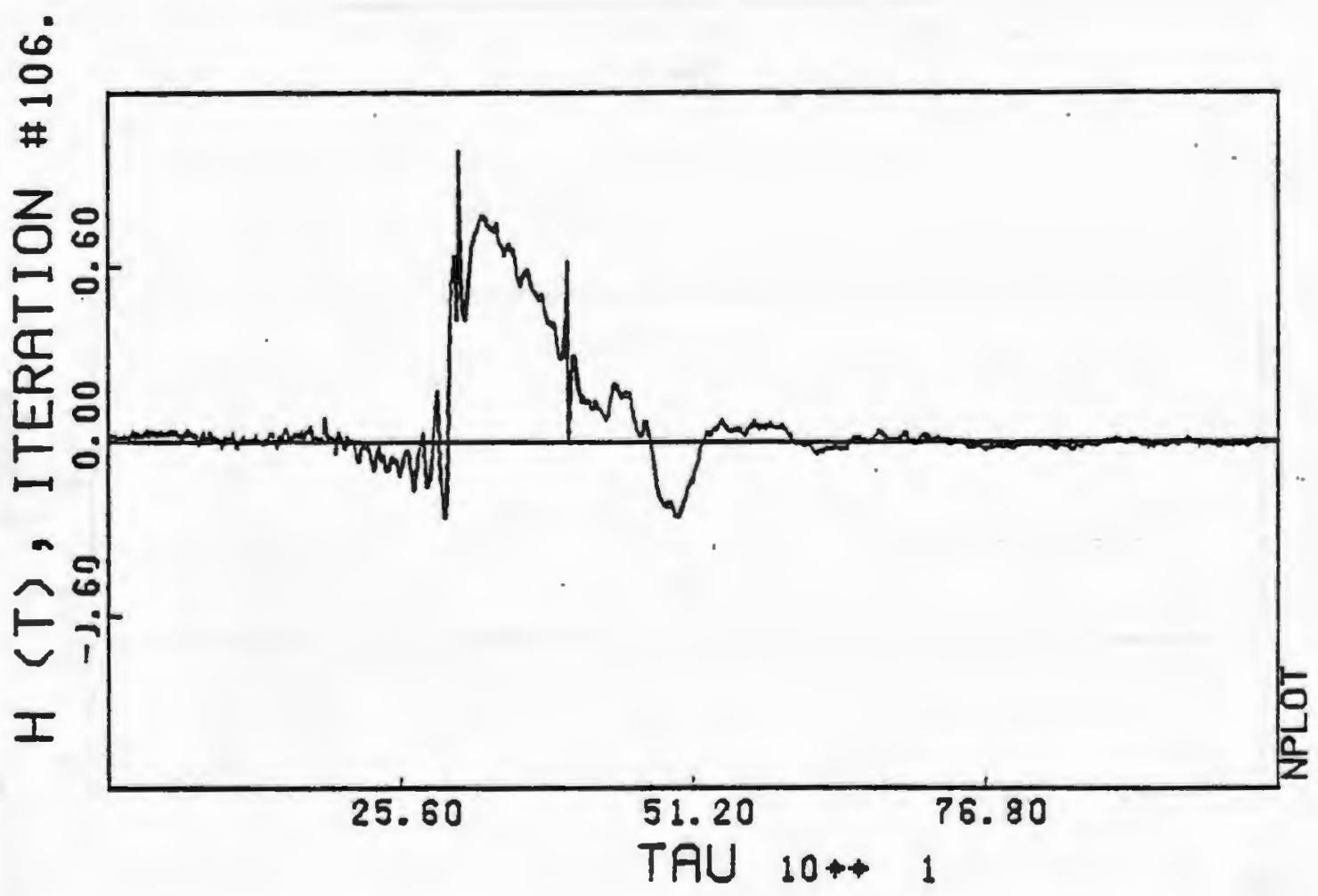

Figure 29. Experimental Impulse Response: Iithium Sulphate on Tungsten Backing, On Axis

$z=18$. $\mathrm{mm}$. 

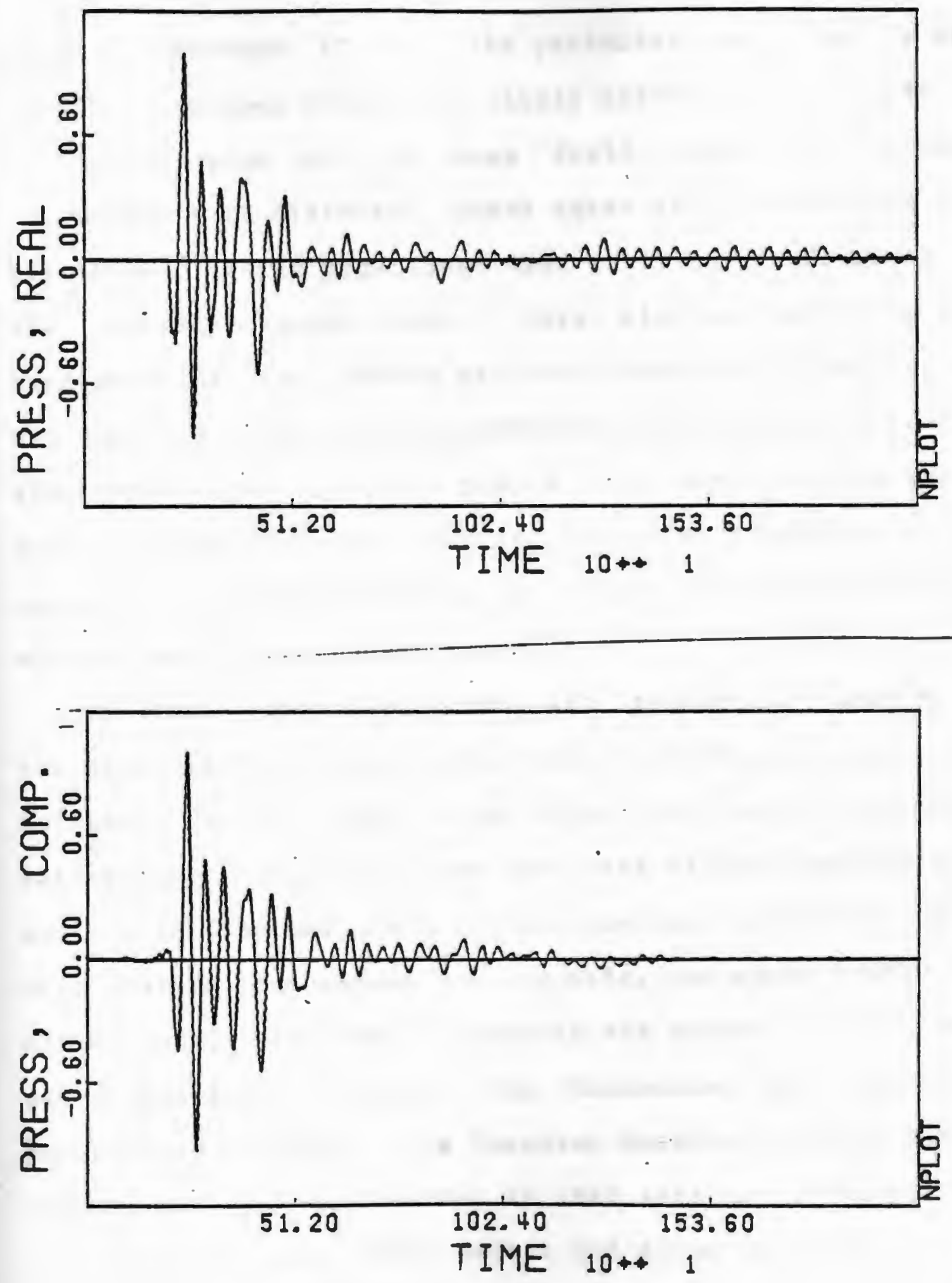

Figure 30. Reconvolution Check: On Axis 
present, because if so, the perturbations caused in the inpulse responses would more likely differ than coincide.

Tests made at the same field point on the same transaucer with different probes agree well, supporting the hypothesis of the experiment that it is affected little by the receiving probe used. This also suggests that the bandwidth of the probes ras not a factor contributing to the smearing of edges. Heasurements made with the Pinducer ained at the center of the piston, when compared with tests made vith the Pinducer aimed awa from the transducer at an angle of about 60 degrees, show that it's directionality effects were also insignificant.

Another comparison made was, intended to discover if the epory baffles were meeting the rigid boundary condition intended, or if the w were supporting wave propagation internally. In this case two sets of measurements were nade with identical test setups, the only difference being that before the second Iun yas made, the epoxy baffle was milled off, and the transaucer yas nounted in the steel plate mentioned before. The transducer was the lead Letaniobate element on a rungsten backing. Bere a slight difference was noticeable, in that with the steel baffle, the negative excursion before and after the endpoints of the ingulse Iesponse was less pronounced. Eoverer the difference is slight: too slight to draw anl solid conclusions. other factors could explain this deriation, such as the fact that any radial mode would certainly be 
affected by the loading presented to the edge of the cIfstal, which changes with the presence or absence of the epory baffle. 
EXPERIMENTAI PROCEDORES AOA RESULTS FOI ARRAYS INTBODUCTION

With the vork of the single element transducers finished, investigation turned toward the area of nulti-element arrays. Arrays of several elements arranged in some sinple geonetric configuration are of particula interest for biomedical systems in view of the fact that under the proper driving conditions, they offer significant gains in terms of directivity and resolution. also, the Iegion of maximum acoustic intensity can be mored electronically.

noIk with acoustic transducer arrays has been in existence for more than thirty years. yost of this information concerns sorar system transducers, where the physical size is large, and the object of interest is in the far field of the array. Onder these conditions, the difection. of maximum response is controlled by proper shading of the amplitude and phase of the driving signals. Expressions have been generated to optimize the directivity of such an array, for certain boundary conditions such as number or maximum allowable level of side lobe structure. These expressions result, for a line array, in a constant phase difference in driving signal from element to element, assuning a constant elemento elenent spacing. Recently, 
work has been done in the area of high frequency arrays; howerer, this was based on a Ch excitation, not pulsed operation. [ See reference (15). ]

The abore information becomes of little importance in the biomedical oriented implementation, as the object of interest in the acoustic field is often no longer in the far field of the array. Also because of the use of transient excitation to the individual transducers, the term phase gives way to the term delay. Beamforming can now be thought of as 'spotforming', because if the point of interest is close to the array in terms of its size, it is possible to concentrate the acoustic pressure to a spot instead of simply confining it to a range of angles as a beam. It was the inrestigation of this phenomena that was of particular interest.

In contrast to the operation of a single transducer, anomalies often appear in the operation of an array of densely packed projectors whose dimensions are small Ielative to the acoustic varelength of interest. [ See Ieferences (16) through (19). I The acoustic radiation inpedance experienced by each element is then no longer simply the self radiation impedance of the isolated element, but becomes a sum of the self radiation impedance and mutual radiation impedances which result from the effects of the acoustic pressures caused by the remaining elements. The degree of interaction is influenced principally by the size of each element in comparison to 
the wavelength of interest. This interaction problem is of great potential inportance, since the increased radiation inpedance seen by an element of an array can cause the phase of the radiated signal to vary fron that of an uncoupled element. The resultant phase perturbations can thus significantly affect the beamforming process.

\section{ARRAI TRANSDCCER CONSTROCTION}

Using the knowledge of construction techniques gained from the single element work, a line array of 13 small rectangular elements was constructed as follows: A rectangular element of lead Metaniobate 25.4 mm. Iong by 9 mn. wide was eporied to a plug backing of Tungsten loaded Araldite. The thickness of this element was such that it had a fundamental resonance at 1.0 Hz. After the epoxy was cured, the element was sawed alnost all the way through with a diamond say. The depth of the cut was such that the back electrode remained intact. The cuts were spaced 2.0 mi apart, meaning that there vere 13 small elements each about $1.5 \mathrm{~mm}$. wide and $9 \mathrm{~mm}$. long, spaced $2 \mathrm{~mm}$. from center to center. a baffle was formed as before, by pouring epory until the surface was flush with the element faces. EaiI fine vires vere attached from one end of the elements to a ribbon cable. The assembly was then waterproofed and tested.

To investigate the possibilities of beamsteering, a multiple pulser systen was needed which would allow a 
precise delay between a comnon trigger pulse and each element's firing. This was implemented with TTI logic devices, which were the only suitable choice in view of the speed involved. The resolution of incremental steering is dependent on the smallest possible delay from element to element. In viey of this, the driver for the array consisted of two four-bit binary counters which were preset to the desired number of counts by the trigger pulse, then proceeded to count down frou the preload value to zero. Then the count was couplete, the counters generated a carIy out pulse wich triggered an SCR pulser circuit, and also reset the counters so no more than one pulse rould be generated. The circuit for the SCR pulser is verY similar to the output section of the betrotek pulsers. Because the counters are rated at a marimum count frequency of 35 ur., the suallest delay, one count, was 28.5 nanoseconds. Being 8-bit binary counters, the maximum delay that could be achiered was 255 counts, or 7.3 microseconds. a circuit diagram of one counter section and its associated pulser is shown in figure (31). Each element of the array was fed by one of these for the focussed cases.

\section{HEASORELENT PROCEDORE}

The objectire of this section of the research was to map the field of the array under certain driving conditions, to determine its behavior. Therefore the vova was programmed to command the satpC 6800 to drive the probe to a point, take a pressure time history, compute the peak 
to peak value of the pressure, and store this data point. The rova then signalled the sRTPC 6800 to drive to an adjacent point, and take another peak pressure measurement. This sampling was continued, resulting in a matrix of data points 100 points long by 51 points wide, corresponding to an area of the same size in millimeters. This data was then sent to the academic computer center via the telephone link.

The peak pressure data vas then processed by a package called "Sruvo ", which was adapted from a program of the same name from larrard Onirersity. [ See reference (29). ] This program produces a unigue display of the three dimensional data in a two dimensional plot.

\section{GEASOREHERTS and RESULTS}

The array was first tested without the phasing network, to gain some background data about the beha fior of the indiridual elements. The center element vas driven with the letrotek pulser at a lov level. As the center element vas driven, the pressure time history was observed on the oscilloscope as the adjacent elements vere electrically shorted intermittently, to see any effects of interaction. one of the adjacent elements did show a considerable effect, which was mach more pronounced than the effect of the other adjacent elenent. The effect of the second element was small, consisting of not more than a net change of ten percent of the instantaneous pressure at any point along the waveforin, which was in agreement with 
the analytical study.

lert the remaining elements vere left open circuited, and the pressure field of the center element in the array was mapped as described above. The SIuro plot of this data is shown figure (32). In this case, note that the pattern is not omni-directional; rather there are lover level side lobes which were not accounted for in terms of the size of element relative to a varelength, both of which vere 1.5 mII. A beam like pattern is clearly seen which is similar to the pattern's from single element transducers whose dimensions are the same as the overall yidth of the array. The existence of these side lobes was surprising, and it vas theorized that they way have been caused by the confling of acoustic or electrical energy from the driven element to the other ondiviven elements.

To inrestigate the possibility of element to element interaction, another measurement was made of the array with only the center element being excited. In this case, the other elements vere shorted to ground at the far end of the cable, to proride a clamping effect. The plot of this data is presented as figure (33). Note that the beall like pattern has been affected by the clamping, and a much more omni-directional field is seen.

Is a final effort to characterize the interaction problem, another field map was made, this time firing the end element of the array, with the remaining elements clamped. the idea here was that due to the non-symetry of 


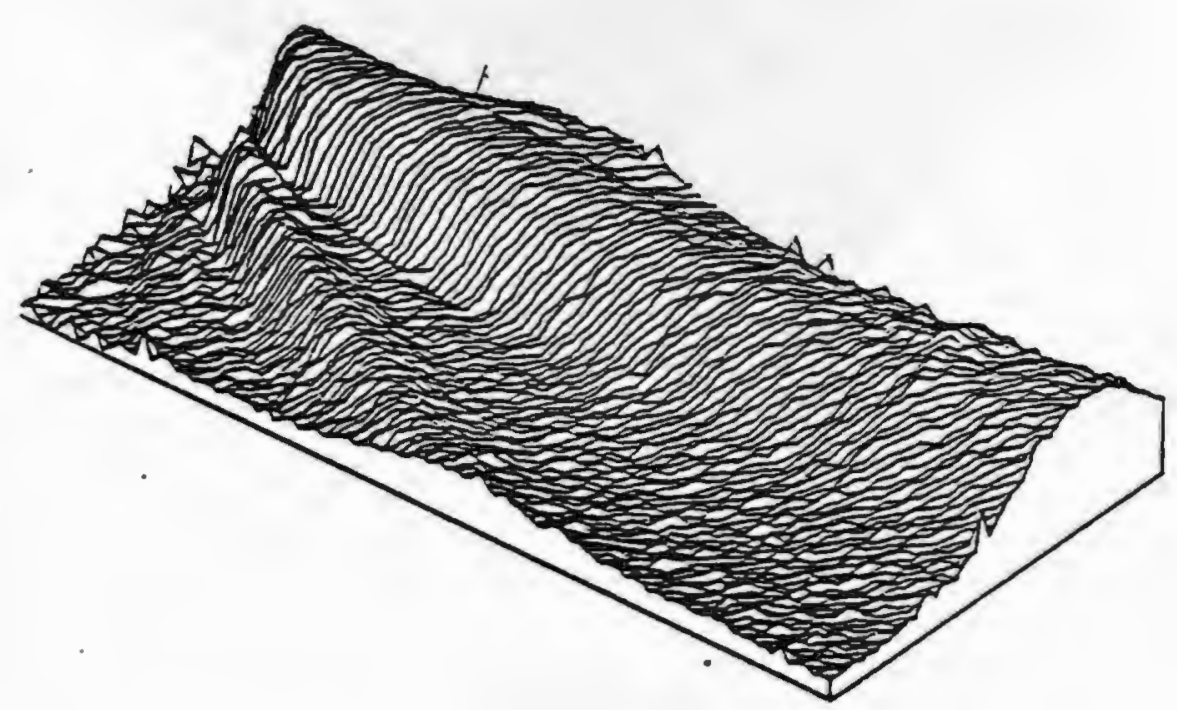

Figure 32.

-IELDMAP PLOT -- CENTER ELEMENT, OTHER ELEMENTS OPEN AZIMUTH $=51.30 \quad$ ALTITUDE $=35.00$

*WIDTH $=2.00 \quad$ *HEIGHT $=1.00$

* = BEFORE FORESHORTENING / FRI.- MAY 5, 1978 / 


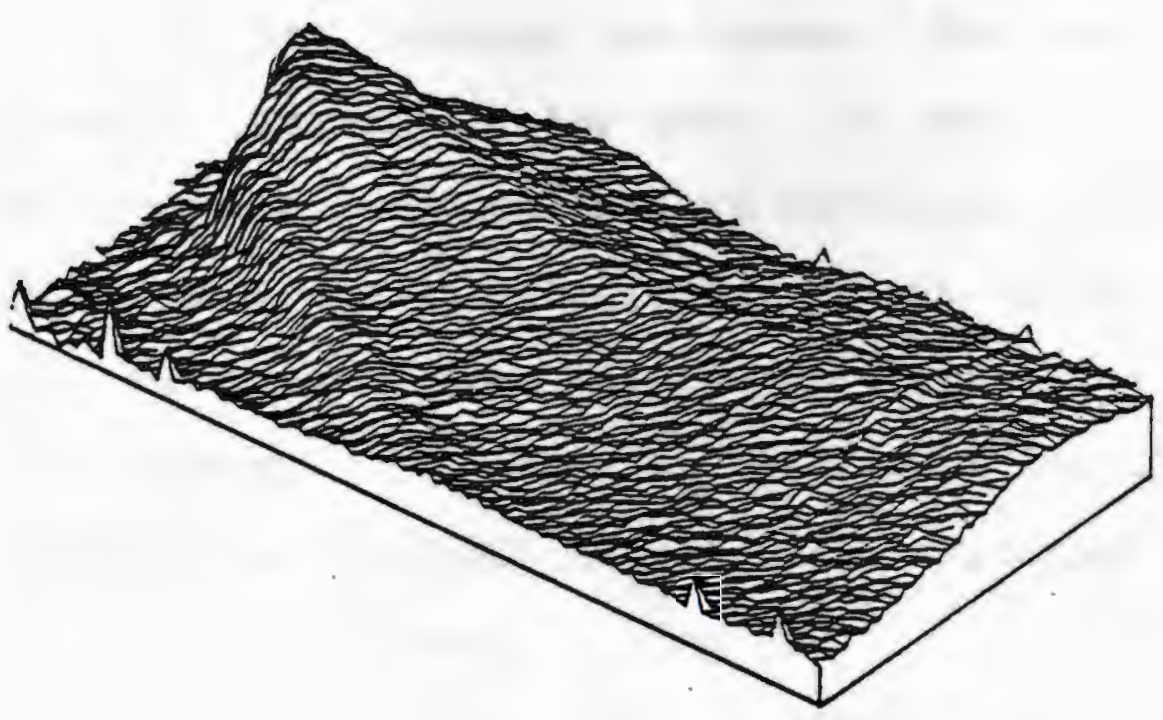

Plgure 33.

- IELDMAP PLOT -- CENTER ELEMENT : OTHER ELEMENTS CLAMPED

$\begin{aligned} \text { RZIMUTH } & =51.30 & \text { ALTITUDE }= & 35.00 \\ * \text { WIDTH } & =2.00 & \text { *HEIGHT }= & 1.00\end{aligned}$

- = BEFORE FORESHORTENING / FRI. - MAY 5, 1978 / 
the undriven elements about the driven one, anj interaction vould shou up as a corresponding non-symmetry in the field. This data is presented in figure (34). The firing element is on the right hand side of the far end of the rectangular area, firing tovards the viever. The remaining unercited elements extend to the left. In this case, the direction of greatest response appears unchanged, however, note that on the side towards the center of the array, the side lobes are fewer and more distinct, indicative of sone interaction. It must be noted that for the geometry and frequencies involred, no side lobe structure should be seen for a single element.

The next test was to drive all the elements in parallel, and the field was again mapped. Theory predicts that the field of sereral elements in parallel is the product of the directivity function for the large array geometry and the directivity function of each individual element. Here, if no interaction was present, the field of the array being fired "broadside " should appear as a composite of 13 elements, weighted by the directivity function of one large rectangular element. The plot of this data is presented in figure (35). Bere the field takes on the appearance of the field from a large circular or rectangular trensducer, in that the width of its main lobe is approximately the same as the transducer width. Bowerer, it is interesting to note the sereral small side lobes, which do not appear in the field of a larger pulsed 


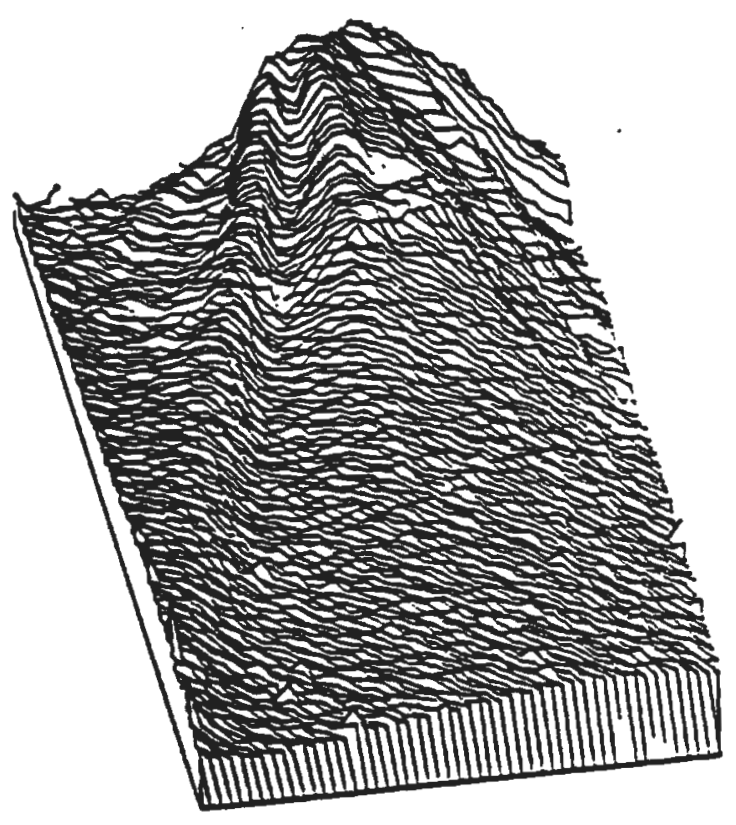

Figure 34.

IELDMAP PLOT -- END ELEMENT, OTHER ELEMENTS CLAMPED

$\begin{aligned} \text { AZIMUTH } & =10.30 & \text { ALTITUDE }= & 35.00 \\ \text { *WIDTH } & =2.00 & \text { HEIGHT }= & 1.00\end{aligned}$

* = BEFORE FORESHORTENING / WED. - MAY 10,1978 / 


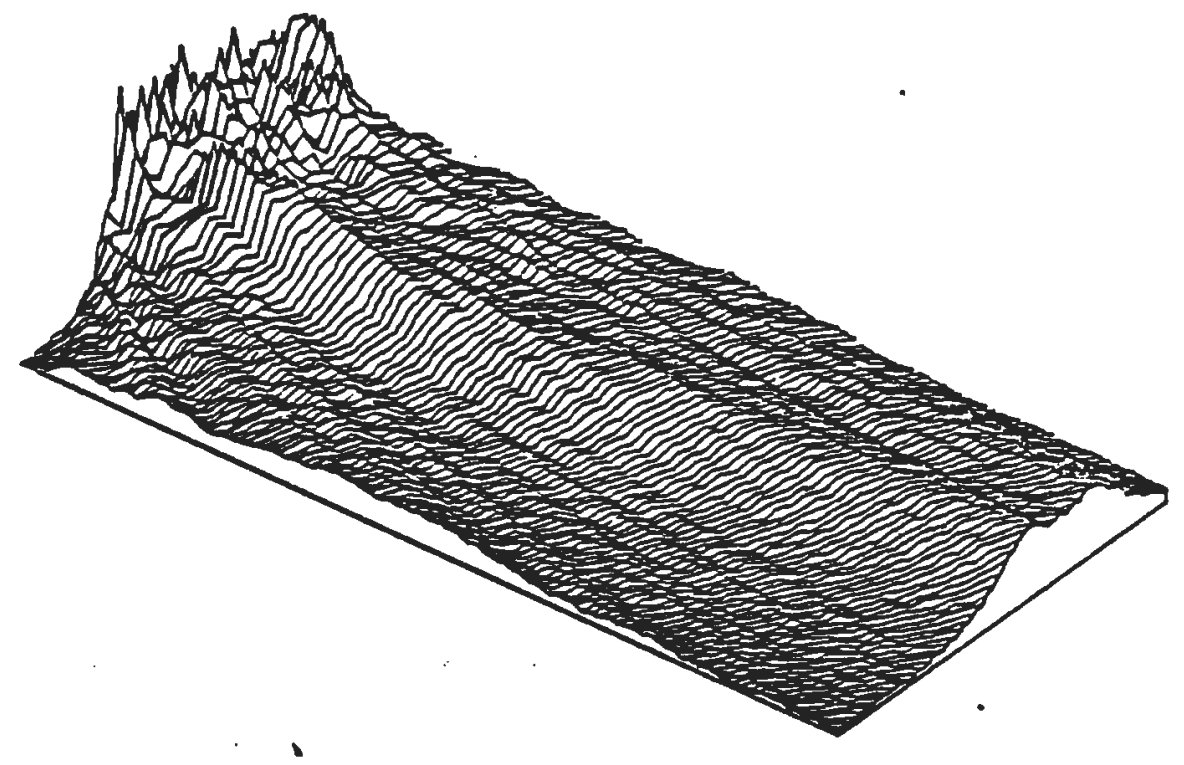

Figure 35.

-IELDMAP PLOT -- RLL ELEMENIS IN PHASE

$\begin{aligned} \text { AZIMUTH } & =51.30 & \text { ALTITUDE }= & 35.00 \\ \text { *WIDTH } & =2.00 & \text { HEIGHT }= & 1.00\end{aligned}$

- = BEFORE FORESHORTENING / MON. - APR. 17:1978 / 
radiator.

Nith background data logged for the array operating in the broadside mode, investigation continued with fieldmaps of the array driven such as to focus the acoustic pressure to a point. This is caused by controlling the driving signals so that the pulses from all of the elements coincide in time at one point in the field. Figure shows the pressure time history of the array taken at a point where the acoustic pulses do not coincide. Figure (37) shows the pressure time history at a focal point. The delays necessary to focus the arrag were calculated on the academic computer center system via the use of a simple algorithm vich calculated the distance and propagation delay from each element to the point of interest.

The difference in propagation time between each element and the farthest element to the point was computed, and converted to an integer number of clock pulses of a certain frequency. A ditgram of the geometry intolved is given as figure (38)

1 few electrical problems were discorered when the array was first Iun by the digital driver. In all our tests, the electrical signal feeding the transducer(s) was introduced into the receive systell by stray coupling. In single element cases this did not cause concern, as the electrical signal is short, and does not overlap the acoustic signal, due to the propagation delap. With the array running under control of the digital delay 


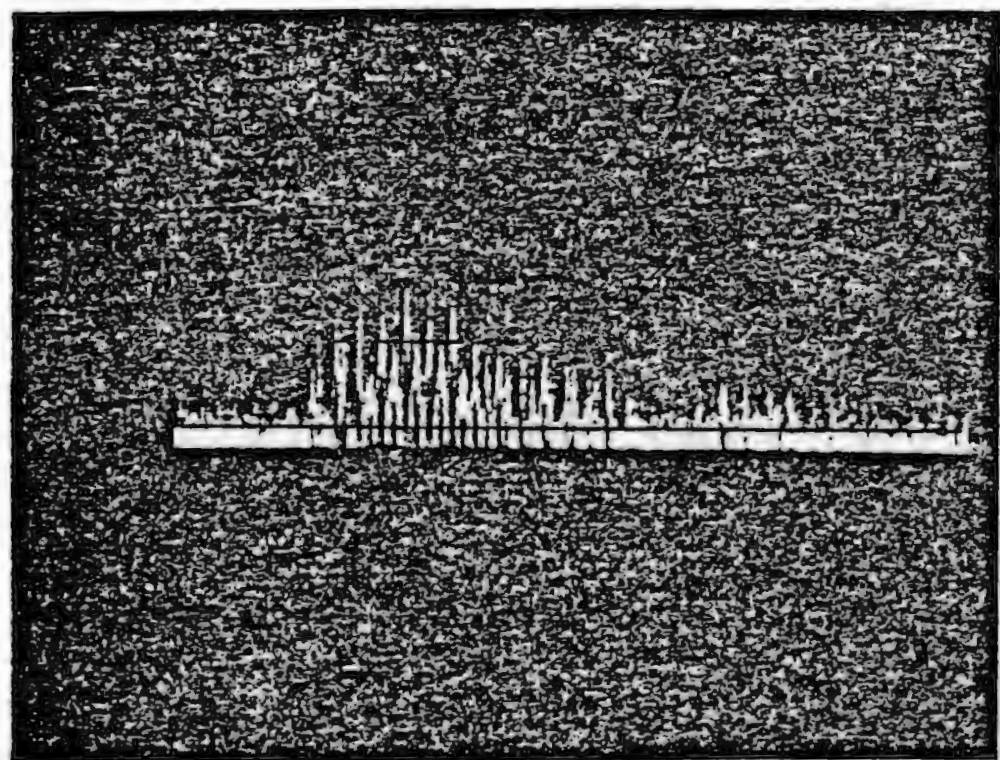

Figure 36. Pressure Time Elstory; Not at Focal Point 


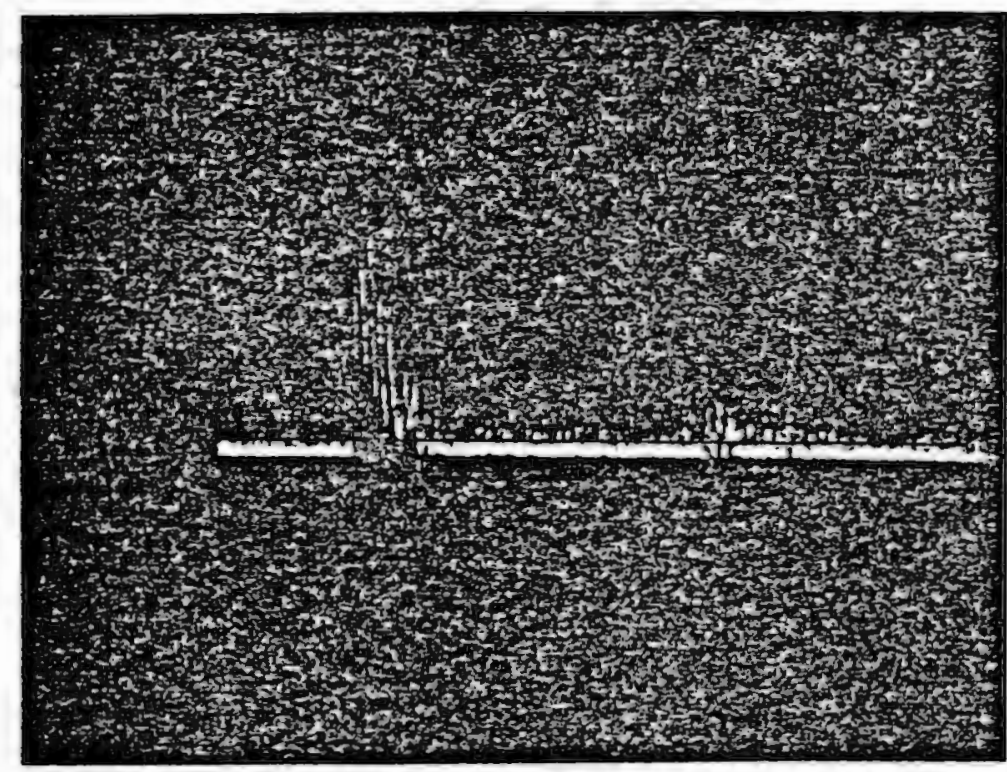

Figure 37. Pressure Time History: Focal Point 


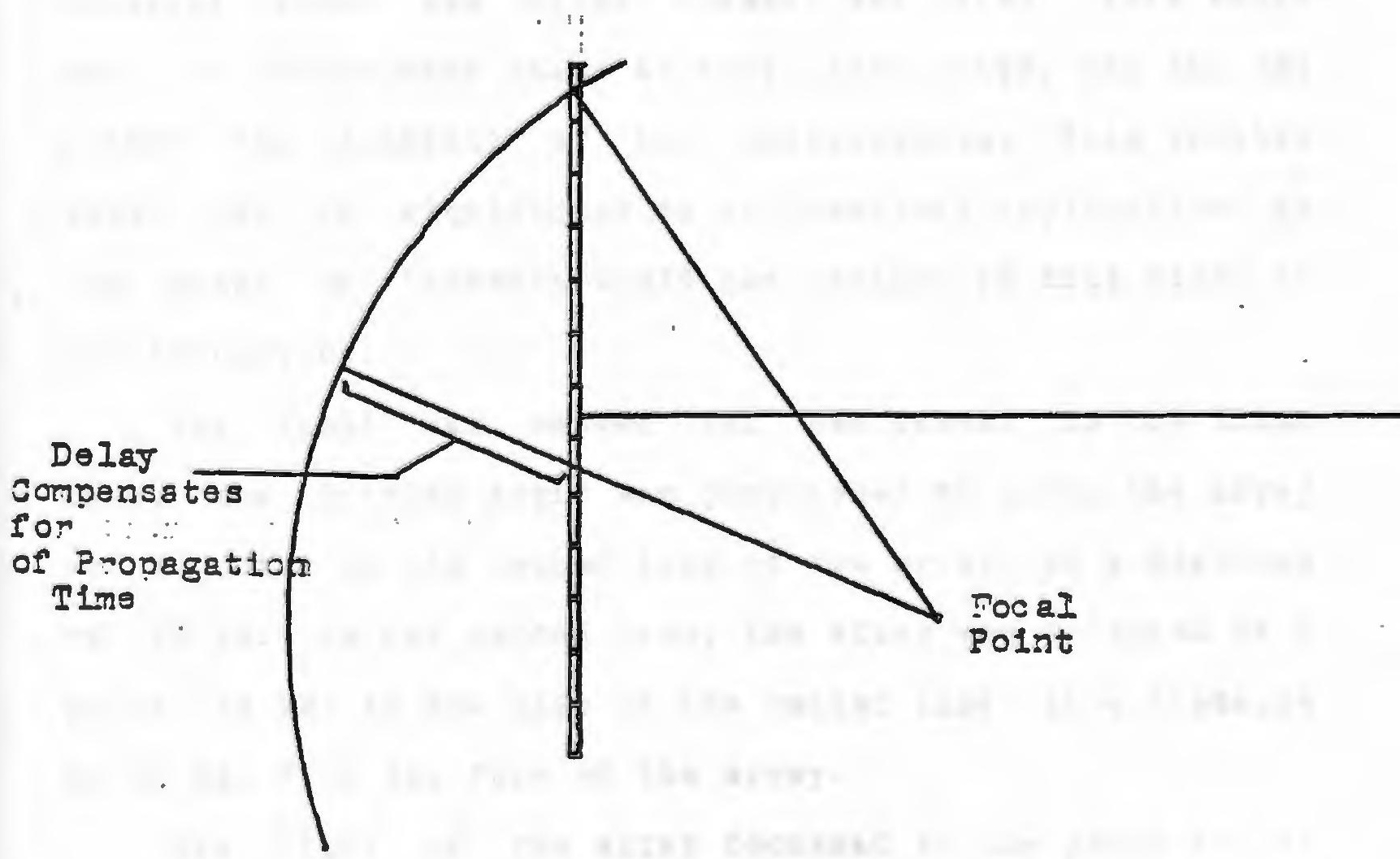

Figure 38. Geometry for Delay Calculation 
controller, the electrical input pulses vere now spread out over more than 2 microseconds. This meant that the electrical pulses orerlapped the acoustic signals at close range. To prevent this from affecting the data, the acoustic signals rere passed through a Metrotek Gate unit nodel 4 G 701, which eliminated all signals for a short interval after the first element vas fired. This vould tend to Ieduce data taken at rery close range, but did not affect the majority of the measurements. This problem yould not be significant in a biomedical application, as the point of interest would not usually be this close to the transducer.

The field was mapped for two cases. In the first case, the driving logic ras programmed to focus the array at a point on the center line of the array, at a distance of $20 \mathrm{~mm}$. In the second case, the array was focussed at a point $10 \mathrm{~mm}$. to one side of the center line, at a distance of $30 \mathrm{~mm}$. Erom the face of the array.

The field of the array focussed at the point $\mathrm{a}=0$. m. and $z=20$. mm. is shown in figure (39). Here the peak pressure is indeed focussed at approrinately the correct point.. The main spot of interest is highly insonified, being greater than ang other characteristic by at least six to ten $d b$. The side lobe structure of this case is surprisingly depressed, in viev of the numer of radiating elements. Jote that there are no aliases, or points other than the main point of interest where the acoustic pulses 


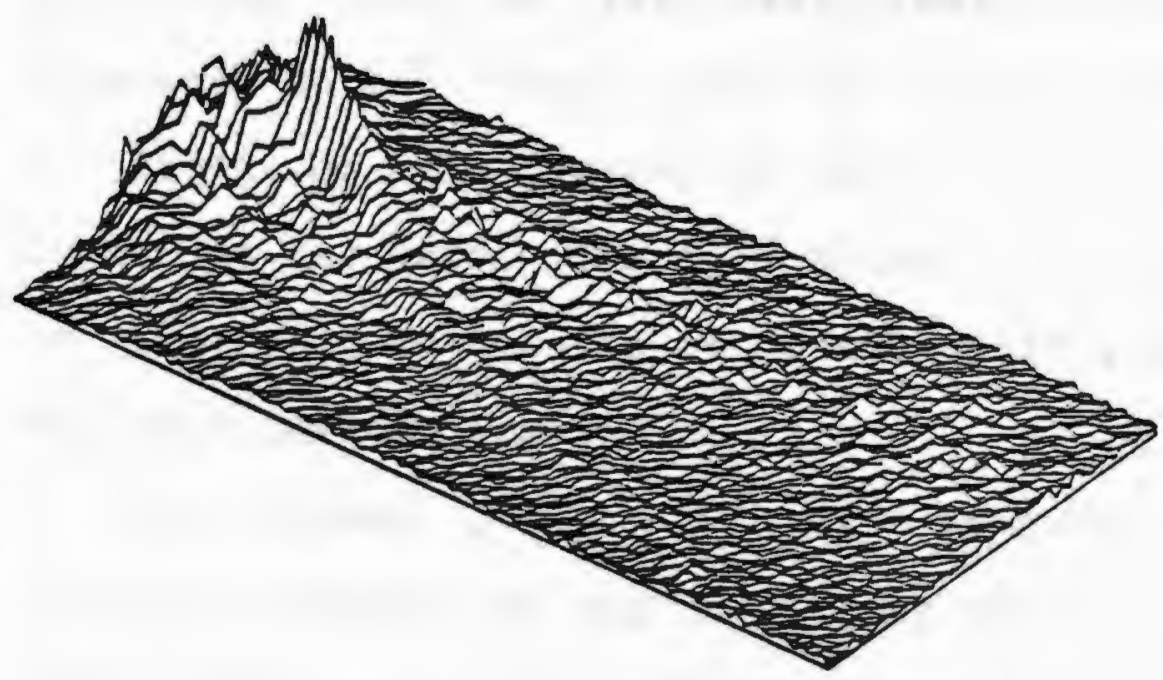

Figure 39.

1 IELDMAP PLOT -- ARRAY FOCUSSED AT $R=0 . Z=20$. MM.

$\begin{array}{rlrl}\text { AZIMUTH } & =51.30 & \text { ALTITUDE }=35.00 \\ \text {-WIDTH } & =2.00 & \text { HHEIGHT }= & 1.00\end{array}$

- = BEFORE FORESHORTENING / MON. - APR. 17,1978 / 
add to form a second peak.

The second focussed field plot is listed as figure (40). Here the array was driven according to the delays generated by the computer routine so as to focus the acoustic energy at the spot $R=10$. mm. and $z=30$. mm. Bere the extraneous side lobe energy is found in two areas, on either side of the main pressure feature. The side structure on the 'near' side of the main feature, that is, in front of the center of the array, is concentrated in close to the face. The side structure on the ' far' side of the main feature is at considerably greater range than the main feature itself.

The above study of arrays provides a small insight into the beharior of high frequency pulsed acoustic arrays. nork must be continued to more fully characterize the acoustic field ander pulsed conditions and to fully realize the usefullness of these arrays. Some areas pertaining to this that could prove informative would be as follows: Experimentally determining the impulse response of the entire array, under various driving conditions, would help to indicate further the extent of element to element interaction. also, more precisely controlled construction techniques, employing smaller elements, would inprove the spatial resolution of the system. raking the elements smaller, i.e., a half ravelength or less, yould decrease the directionality of the individual elements, thereby lessening the pressure variation as the array is focussed 


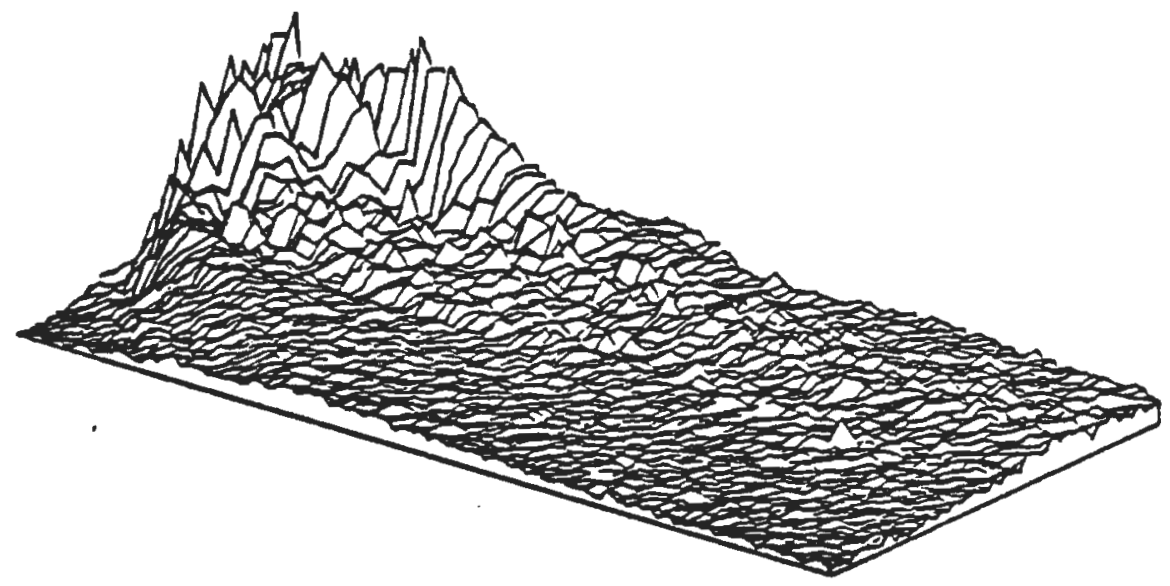

Figure 40.

-IELDMAP PLOT - ARRAY FOCUSSED AT $R=10 . \quad Z=30$. MM.

\begin{tabular}{|c|c|c|}
\hline JTH : & 51.30 & ALTITUDE $=$ \\
\hline -WIDTH $=$ & 2.00 & -HEIGHT $=$ \\
\hline
\end{tabular}

* = BEFORE FORESHORTENING / MON. - APR. 17:1978 / 
toward greater angles from the axis. 


\section{COMCIOSIONS}

This section outlines the results and states the conclusions drawn from the present research. The key acccmplishments, Iesults, and conclusions of each aspect of this research are summarized as fcllows:

In automated measurement system designed for high frequency acoustic research was constructed. This system included a high speed Analog to Digital converter with an effective sampling rate of 100 uHz., and a motorized computer controlled precise positioning systen. Commercially obtained acoustic probes were evaluated and compared to probes constructed in the course of this Iesearch.

a mathematical technique for performing deconvolution on the input and output of a linear systen was inplemented and evaluated on the academic computer system. This procednre was found to be useful in the rerification of the Impulse Response Appoach to evaluate the spatial and temgoral characteristics of the pulsed acoustic field which results from the broadband excitation of medical ultrasonic transducers and arrays.

Three piezoelectric transducers. similar in construction to those presently in bionedical applications were constructed. The use of Tungsten loaded epory as a backing material was found to be helpful in increasing transducer bandwidth. 
These transducers were investigated in the measuring system, and their corresponding inpulse responses yere arrived at via digital signal processing techniques. Several measurements were made for each transducer, to provide data for the computer deconvolution routine. Por each of the transducers tested, and each of the three types of impulse Iesponse, the results of the experimental work were in good agreement vith the theoretical predictions, thereby strengthening the validity of the use of the theoretical approach for unconfirmed analytical simulation.

The impulse Iesponses obtained from the broadband acoustic fields which vere generated by these transducers provided important new experimental verification to the Impulse Response Approach for describing the pressure fields of pulsed piston radiators. The agreement of theoretical and experimental results implied that vibration of the elements in modes other than thickness expansion was not significantly troublesome. Identical results obtained from different acoustic Ieceiving systems shoved that the experimental approach and assumptions were valid.

1 thirteen element array of similar materials chosen for wide bandwidth was constructed. A digital delay driving systen with bigh voltage high speed pulsers was built to drive the array. The background characteristics of the array were measured. The array was successfully dIiven in such a vay as to concentrate the acoustic pressure to a rerg small region. Blement to element 
interaction effects vere examined, and found to be insignificant as far as pressure focussing was conerned. 
REFHRENCES

(1) J. B. L. Manniello et al, "Prospectives for Ultrasonic Imaging is Medical Diagnosis," National Science Foundation Survey Team Report, 1973.

(2) C. Relsey et al, "Interaction of Ultrasonic Energy with Biological Structures," Alliance for Engineering in Medicine and Biology Report of Task Group 1, Apri1, 1974.

(3) J. D. Meindl et al, "Ultrasonic Transducers: Signal Detection and Preprocessing," Alliance for Engineering in Medicine and Biology Report of Task Group 2, April, 1974.

(4) I. I. von Micsky, et al, "Ultrasonic Diagnostic Scanning and Display Systems," Alliance for Engineering in Medicine and Biology, Report of Task Group 3, 1974.

(5) J. H. Busser et al, "Ultrasonic Diagnostic Signal Processing," Alliance for Engineering in Medicine and Biology - Report of Task Group 4, JuIy, 1974.

(6) E. P. Carome et al, "Effects of Diffraction on Stress Pulse Propagation," Office of Naval Research Technical Report FH77-1, July, 1977.

(7) G. Rossoff, "The Effects of Backing and Matching on the Performance of Miezoelectric Ceramic Transducers," IEEE Transactions on Sonics and Dltrasonics, March, 1966.

(8) M. Redwood, "Experiments with the Electrical Analog of a Piezoelectric mansducer," Journal of Acoustical Society of America, October, 1964.

J. P. Weight et al, "Observations of the Propagation of Very Short Oltrasonic Pulses and Their Reflection by Small Targets," Journal of the Acoustical Society of America, February, 1978. 
(10) J. Zemanek, "Beam Behavior within the Nearfield of a Vibrating Piston," Journal of the Acoustical Society of America, August, 1970.

(1I) P. R. Stepanishen, "Acoustic Transients in the Far Field of a Baffled Circular Piston Using the Impulse Response Approach," Journal of Sound and Vibration, May, 1973.

(12) J. S. Bendat, et al, "Random Data: Analysis and Measurement Procedures," wiley Interscience, 1971.

(13) E. O. Brigham et al, "An Iterative Technique for Determining Inverse Filters," IEES Transactions on Geoscience Electronics, May, 1968.

(14) D. T. Blackstock, "Research in High Intensity Sound," Air Force Office of Scientific Research, June, 1976.

(15) M. Pappalardo, "Transducer Iine Arrays in the Eigh Frequency Range," Oltrasonics, March, 1973.

(16) J. S. M. Rusby, "Investigation of an Interactive Effect Between Sound Projectors Mounted in an Array," Journal of British IRE, No. 4. 1963.

(17) J. S. M. Rusby, "Investigation of a Mutual Inpedance Anomaly between Sound Projectors in an Array," Acustics, 14, 1964.

(18) D. I. Carson, "Diagnosis and Cure of Erratic Velocity Distributions in Sonar Projector Arrays," Journal of the Acoustical Society of Amertca, 34, 1963.

(19) C. I. Sherman, "Analysis of Acoustic Interaction in Iransducer Arrays," IEEE Transactions on Sonics and oltrasonics, SD-13, No.1, 1966.

(20) "SYMVO MANUAL", Laboratory for Graphies and Spatial Analysis, Earvard University. 
$10 / /$ IECONULU JOB (LDG100,384,1),' TONY FISHER GSO ,

$20 /$ *FOUTE PFINT REMOTE2

$30 / /$ EXEC FOFTHCLG, FEGION=384K, FAFM, FOFT $=$ 'OF'T=02', LIEI=SSF', LIB2=TFLI

$40 / / F O R T$. SYSIN III *

$50 \mathrm{C}$

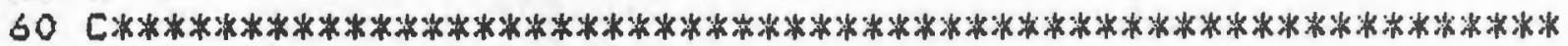

$70 \mathrm{C}$

$80 \mathrm{C}$

$90 \mathrm{C}$

$100 \mathrm{C}$

THIS FFIOGFAM FEFIFORMS THE INITIAL STEFS OF LIECONYOLUTIOI

$110 \mathrm{C}$

$120 \mathrm{C}$

$130 \quad C$

$140 \mathrm{C}$

$150 \mathrm{C}$

$160 \mathrm{C}$

$170 \mathrm{C}$

$180 \mathrm{C}$

$190 \mathrm{C}$

$200 \mathrm{C}$

$210 \mathrm{C}$

$220 \mathrm{C}$

$230 \mathrm{C}$

$240 \quad C$

$250 . \mathrm{C}$

UIA A METHOI OF SUCCESSIVE AFFFOXIMATION. THIS SECTION

INITIALIZES THE DATA SETS, FLOTTING INTEFMEIIATE STEFS.

THE FIECUFSIUE FOFMULA IS AS FOLLOWS:

$$
H_{N}(T)=H_{N-1}(T)+\langle X(T)-G(T): H \underset{N-1}{ }(T)\rangle
$$

WHEFE:

$260 \mathrm{C}$

* STANDS FOF conUOLUTION

$X(T)=F(T): A(-T)$

ANI

$G(T)=\dot{A}(T) * A(-T)$

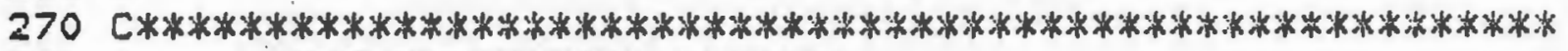

$280 \mathrm{C}$ INITIALIZATION SECTION

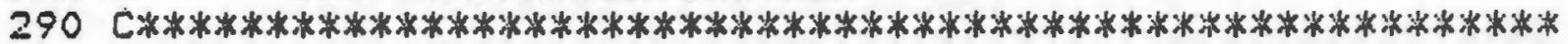

300

310

DIMENSION ACC $(1024), M(3), 5(1024), \operatorname{INU}(1024), X(1024)$

320

IIMENSION FFESS $(2040), H(1024)$

330 COMPLEX AFIRAY1 (4096), AFFAY2 (4096)

340 COMMON $M, I N U, S$, IFEFF

350

$M(1)=12$

$M(2)=0$

360

370

380

$M(3)=0$.

390

IIO $25 \quad I=1,4096$

25 AFIFAY $1(I)=(0.0,0.0)$

CALL HAFIM (AFIFAY 1 ,, , INU, $S, 0$, IFERR)

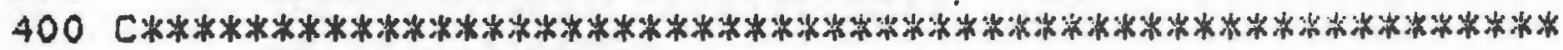

$410 \mathrm{C}$ NORMALIZE $A(T)$ SUCH THAT /A(W)/m2 $<2.0$

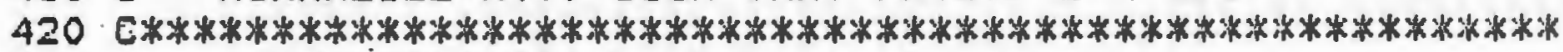

$430 \quad$ FEAD $(8)(A C C(I), I=1,1024)$

440 DO $12 \quad I=1,4095$

$450 \quad$ AFFAY $1(I)=(0,0,0.0)$

$460 \quad$ IF (I.LT. 1025)AFRAYI (I) =CMFLX (ACC (I), 0.0)

$470 \quad 12$ CONTINUE

430 CALL NOFM (AFFAY1)

$490 \quad$ DO $17 \quad I=1,1024$

$500 \quad A C C(I)=R E A L(A F R A Y Y(I))$

51017 CONTINUE

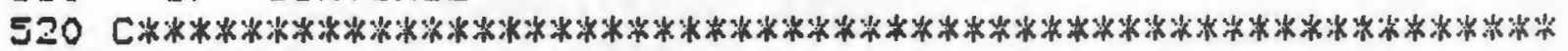

530 C CONUOLVE A(T) WITH A(-T) TO GIVE GiT)

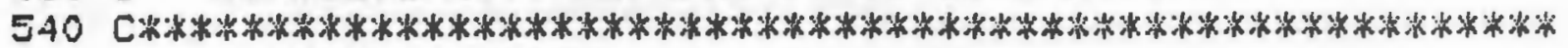

ज50 WRITE $(6,1) A C C$

5301 FORMAT $(10(2 X \dot{X}, E 10.4))$ 
610

620

630

640

550

6ó

670

680

690

700

710

720

730

740

750

760

770

730

790

800

810

820

330

840

850

860

870

880

890

900

910

920

930

940

950

960

970

980

990

1000

1010

1020

1030

1040

1050

1060

1070

1080

1090

1100

no $100 \quad I=1,4096$

IF (I.GT.1024)GO TO 50

ARRAY $1(I)=C M F L X(A C C(I), 0.0)$

ARRAY2 (I ) =CMFLX $(A C C(1025-I), 0.0)$

GO TO 100

50 ARRAY $1(I)=(0,0,0.0)$

AFRAY $2(I)=(0.0,0.0)$

100 CONTINUE

CALL CONUOL (AFRAY1, AFRAY2)

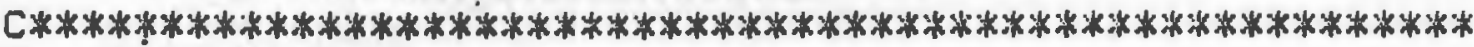
C FLDT G(T)

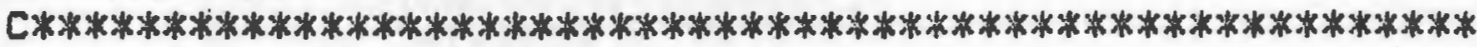
CALL PLTOUT (ARRAY2,'G(T)', 4)

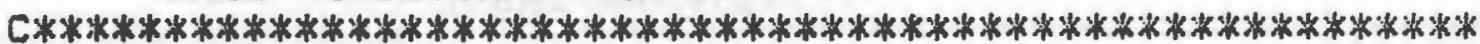

C SPLIT G(T) INTO G1(T) ANI G2(T)

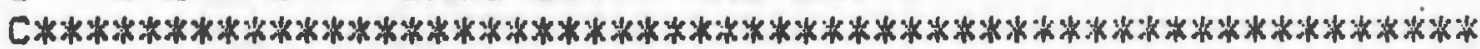

DO $200 \quad I=1,4076$

IF (I.LT.1025) ARRAY1 (I) =CMFLX(REAL (ARFAY2 (I)), 0.0)

IF (I.LT. 1025) AFRAYZ (I) =CMFLX (REAL (ARRAY $2(I+1024)$ ), 0.0)

IF (I.GE, 1025) ARRAY 1 (I) $=(0,0,0.0)$

$I F(I . G E, 1025)$ AFFAYY $(I)=(0.0,0.0)$

200 CONTINUE

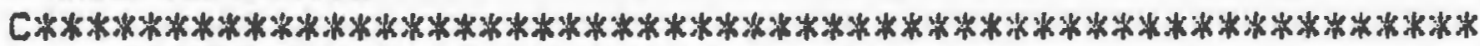

C TRANSFORM G 'S TO FRERUENCY IIOMAIN

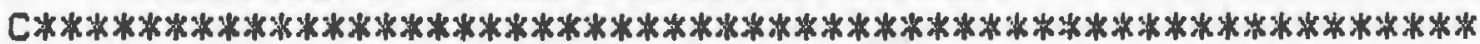

CALL HARM (ARRAY 1 , M, INU, 5,2 , IFERF')

CALL HARM (ARRAY2, M, INU, 5,2, IFEFR')

WRITE (10) (ARRAY1 (I), I=1,4096)

WRITE (11) (ARFAY2 ( $I$ ), I $=1,4096$ )

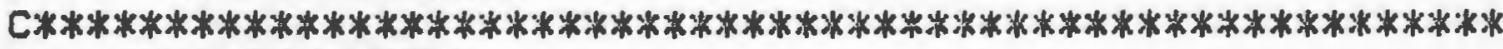

C NORMALIZE FRESS

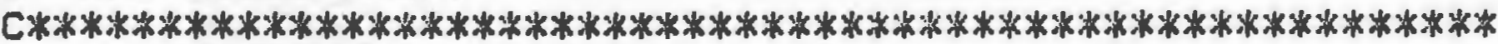

READ(9)FRESS

DO 237 IU $=1,4096$

ARRAY $1($ IU $)=(0.0,0.0)$

IF (IU.LT. 2049) ARRAY1 (IU) =CMFLX (FFESS (IU), 0.)

237 CONTINUE

CALL NOFIM (ARRAY1)

DO 242 IO $=1,2048$

242 FRESS $(I O)=$ REAL (ARFAY $1(I O)$ )

WRITE $(\sigma, 1)$ FRESS

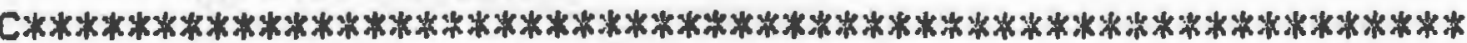

C CONUOLUE $A(-T)$ WITH $F(T)$ TO GIVE $X(T)$

\section{FIFST HALF:}

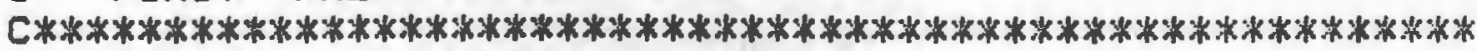
DO $300 \quad I=1,4096$

IF (I.LT.1025) ARFAY 1 (I) =CMFLX (FRESS (I),0.0)

IF (I.LT.1025) ARRAYZ (I) =CMFLX (ACC:1025-I),0.0)

$I F(I . G T .1024)$ ARRAY $1(I)=(0.0,0.0)$

IF (I.GT.1024) AFRAYZ $(I)=(0,0,0.0)$

300 CONTINUE

CALL CONUOL (ARFAY1, ARFAY 2)

DO $400 \quad I=1,1024$

$X(I)=$ REAL $(A R F A Y 2(I+1024)$ ) 


$$
X(I)=R E A L(A R F A Y 2(I+1024))
$$

400 CONT INUE

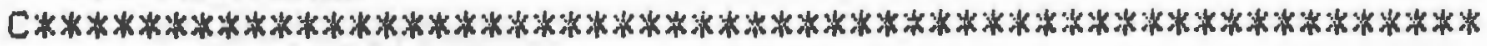
C SECONI HALF:

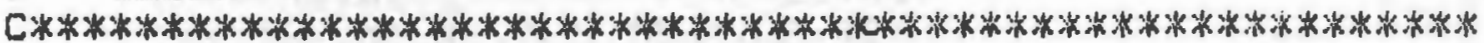

1150

1160

1170

1180

1190

1200

1210

1220

1230

1240

1250

1260

1270

1230

1290

1300

1310

1320

1330

1340

1350

1360

1370

1380

1390

1400

1410

1420

1430

1440

1450

1450

1470

1480

1490

1500

1510

1520

1530

1540

1550

1560

1570

1580

1590

1600

DO $500 \quad I=1,4096$

IF (I.LT.1025)AFFAYI (I) =CMFLX(FFESS $(I+1024), 0.0)$

$I F(I . L T .1025$ ) ARFAY $2(I)=C M F L X(A C C(1025-I), 0.0)$

IF (I.GT, 1024) ARRAYI (I) $=(0.0,0.0)$

IF (I.GT, 1024) ARRAYY $(I)=(0,0,0.0)$

500 CONTINUE

CALL CONUOL (ARRAY1, AFRAYZ)

IIO $600 \quad I=1,1024$

$X(I)=X(I)+F E A L$ (AFRAY $2(I)$ )

600 CONTINUE

WRITE (12)X

CALL RESET

CALL ORIGIN $(0,9,5,0)$

III $700 \quad I=1,4096$

IF (I.LT.1025) ARFAY I (I) $=C M F L X(X(I), 0.0)$

IF (I.GT.1024)ARRAYI (I) $=(0.0,0.0)$

700 CONTINUE

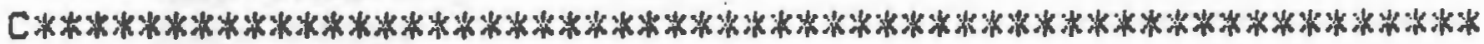

C FLOT $X(T)$

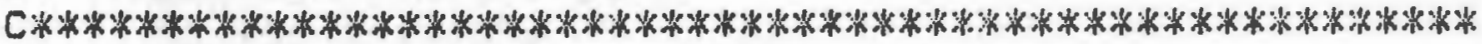
CALL FLTOUT (AFFAY1,' $X(T) ', 4$ )

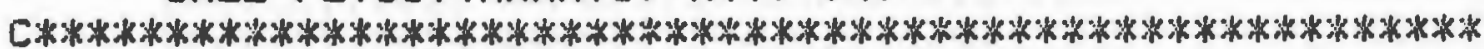

C COMFUTE THEORETICAL H(T)

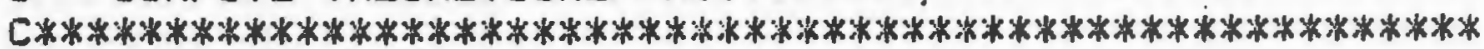

$\mathrm{F}:=20.0 \mathrm{E}-3$

$Z=60,0 E-3$

$A=12 \cdot 5 E-3$

$C=1500$.

$T A U=C / A * 2 . O E-8$

$F 1=((Z / A) * * 2,+A B S((R / A)-1) * * 2) * *,$,

$\mathrm{R} 2=((Z / A) * * 2,+A B S((R / A)+1) * * 2) * *+$,

WFITE $(G, 2)$ FI, FI

2 FORMATSIX;' $F 1=' E 20.8, ' R 2=' E 20.8\rangle$

TAU1 $=R 1$

$I F(R, L T, 1, O E-4) R=1, O E-4$

IF (A/R.GT.1.) GO TO 800

DO $900 \quad I=1,1024$

$H(I)=0$.

TIME $=$ TAU1+TAU*I

IF (TIME, LE, R2, AND, TIME, GE, Fi1)

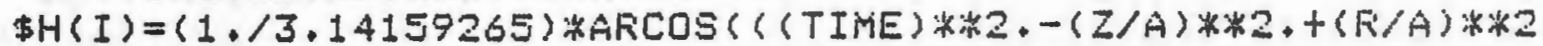
\$, -1,$) /(2 *(R / A) *((T I M E) * * 2,-(Z / A) * * 2) * * * 5)$,

900 CONTINUE

BO TO 1000

800 TAU1 $=2 / A+4$ T TAU

IIO $210 \quad L I=1,1024$ 
1610

1620

1630

1640

1550

1660

1670

1680

1690

1700

1710

1720

1730

1740

1750

1760

1770

1730

1770

1800

1810

1820

1830

1840

1550

1860

1870

1880

1890

1900

1910

1920

1930

1940

1950

1960

1970

1980

19.90

2000

2010

2020

2030

2040

2050

2060

2070

2080

2090

2100

2110

$H(L I)=0$.

TIME $=$ TAU1+TAU*LI

IF (TIME, GE, Z/A,AND, TIME,LE, RI I H $(L I)=1$,

IF (TIYE.GT, RI , AND. TIME. LE, R2)

\$TERM $=(((T I M E) * * 2,-(Z / A) * * 2,+(F / A) * * 2,-$

$\$ 1,) /(2, *(R / A) *($ (TIME) ***2, $-(Z / A) * * 2) * *, 5)$.

IF (TERM.ET . 1.) TERM $=1$.

IF (TIME.GT,R1, AND, TIME, LE, FO)H(LI) $=(1, / 3,14159265)$ *AFCOS D(TERT)

210 CONT INUE

$1000 \quad L=0$

CALL FINDEX (ACC, FRESS, INDEX)

IF (INDEX,LT, 1)GO TQ 7777

I0 $977 I=1,1024$

IF(1025-I-INDEX.LT.1)GO TO 877

$H(1025-I)=H(1025-I-I N I E X)$

GO TO 977

$377 H(1025-I)=0$.

977 CONTINUE

7777 CONTINUE

WRITE $(1 \bar{J}) H, L$

CALL RESET

CALL ORIGIN $(6,,-5,, 0)$

DO $750 \quad I=1,4096$

IF (I.LT.10I5) ARFAYI (I) $=\operatorname{CMFLX(H(I),0.0)~}$

IF (I,GT, 1024) ARRAY $1(I)=(0.0,0.0)$

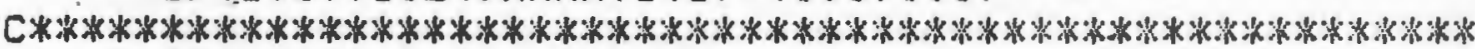

C FLOT H(T)

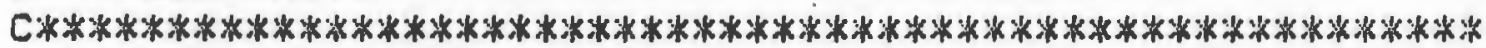

T5O CONTINUE

CALL PLTOUT (ARRAY1, 'H(T)', A)

CALL RESETN

STOF:

END

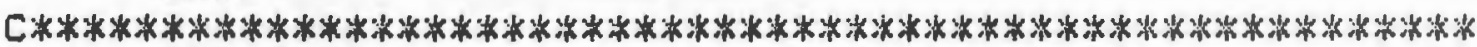

C SUBROUTINE TO FERFOFI CONUOLUTION UIA FFT

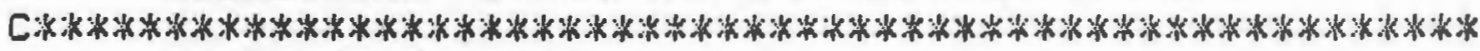

SURROUTINE CONUOL (Y1.,YZ)

COMFLEX Y1(4096), Y2(4096)

COMMON H(3), INU $(1024)$, S $(1024)$, IFEFTi

CALL HAFM $(Y 1, M$, INU, S, 2, IFERFi)

CALL HARM $(Y 2, M, I N U, S, 2$, IFEFFi)

DO $100 \quad I=1,4096$

$Y 2(I)=Y 1(I) * Y 2(I)$

100 CONTINUE

CALL HARYY YY $2, M:$ INU, S, -2, IFEFF')

FETURN

END

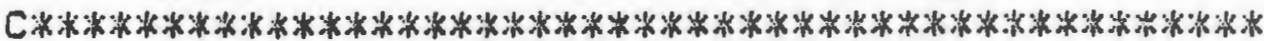

C SUBROUTINE TO FLOT COMFLEX TIME HISTORIES

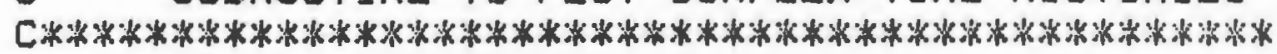


2120

2130

2140

2150

2160

2170

2180

2190

2200

2210

2220

2230

2240

2250

2260

2270

2280

2290

2300

2310

2320

2330

2340

2350

2360

2370

2380

2390

2400

2410

2420

2430

2440

2450

2460

2470

2480

2490

2500

2510

2520

2530

2540

2550

2560

2570

2580

2590

2600
SUURROUTINE FLTOUT $(A, B, C)$

COMFLEX A(4096)

IIIMENSION $X(2048), Y(2048)$

YYMAX $=0$.

YMIN $=0$.

IIO $100 \quad I=1,2043$

$Y(I)=R E A L(A(I))$

$X(I)=F L Q A T(I)$

IF (YMAX,LT, Y (I) ) YMAX Y Y (I)

IF (YMIN,GT, Y(I) YMIN $=Y(I)$

100 CONTINUE

IF (AES (YMAX), GT . AES (YMIN)) FNORYY=ABS (YMAX)

IF (AES (YMIN) , GT . ABS (YHAX)) FNOFM $=A B S$ (YMIN)

I0 $200 \quad I=1,2048$

$Y(I)=Y(I) / F N O F$ II

200 CONTINUE

YMIN $=-1.2$

$Y M A X=1.2$

CALL SETUFN 10,2048, YMITN, YMAX, $300,3.0$, "TIME',

$\$ B, 4, C, 5,5,1)$

CALL NFLOT $(X, Y, 2048,1,0, F)$

RETUR'N

END

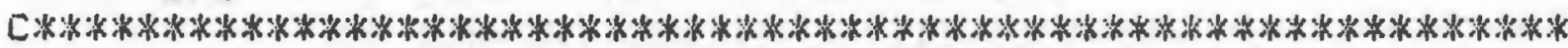

C SUBROUTINE TO NORTHALIZE IATA FOF CONUERGENCE CONIITION

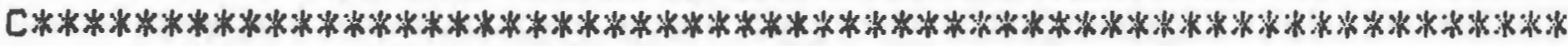

SUBROUTINE NOFM(AFFAY)

COMMON M(3), INU $(1024), S(1024)$, IFERR

COMFLEX ARRAY (4096)

CALL HARM (ARRAY, IY, INU, 5,2 , IFEFR')

FMAX $=0$.

IIO $100 \quad I=1,4096$

FMAG =ARFAY (I) *CONJG (ARRAY (I) )

100 CONTINUE

FMAX $=$ SQRT $(F M A X)$

DO $200 \quad I=1,4096$

200 ARRAY $(I)=($ AFFAY $(I) / F M A X)$ WSQFT $(1.7999)$

CALL HARM (ARRAY, IH, INU, S,-2,IFERR'

WRI ITE $(\sigma, 1)$ FMAX

1 FORIIAT (2X,'IN NORM, FMAX $=$, F30.3)

RETURN

END

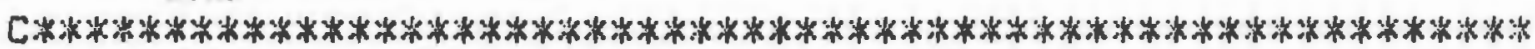

C SUEFOUTINE TO FINI STARTING FOINT DF H (T)

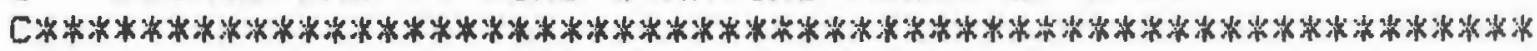

SUBFIUTINE FINUEX (ACC, FRESS, INIEX)

IIMENSION ACC (1024),FRESS(2048)

AMIAX $=0$. 


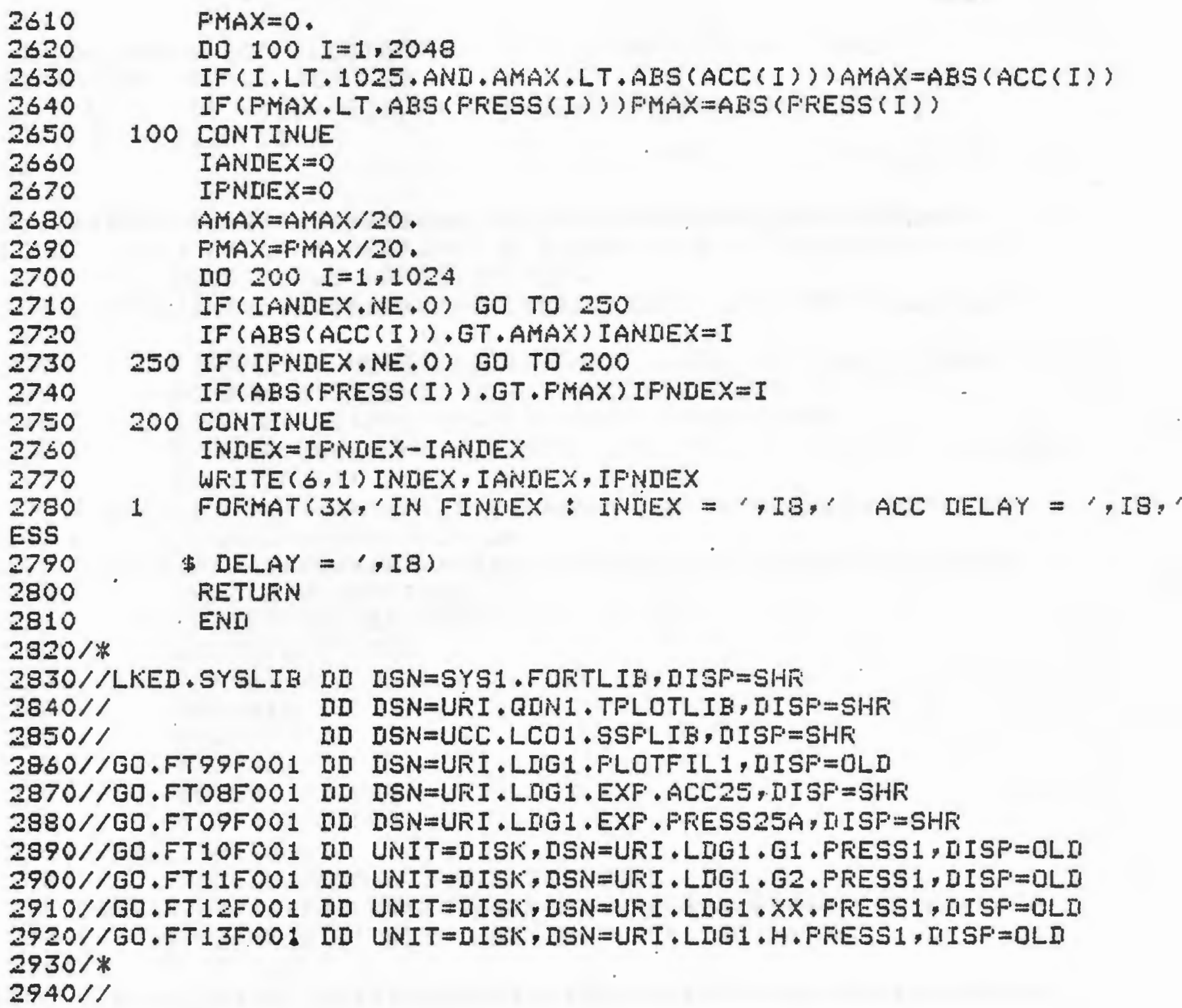


10//DECONITR JOB (LDG100,334,1),' TONY FISHEF GSO , 20/*ROUTE FFINT REMOTE2

$30 / /$ EXEC FOFTHCLG,FEGION=384KK:LIE1=TFLOT, LIE2=SSF

4O/ /FOFT. SYSIN DI *

$50 \mathrm{C}$

60 C

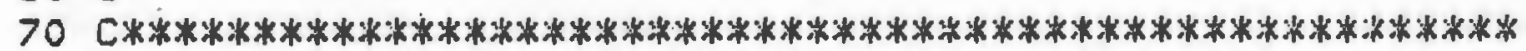

30 C. THIS FFOGFAM FEFFOFMS 5 ITEFATIONS OF DECONUOLUTION

90 C UIA SUCCESSIUE AFFFIOXIMATION

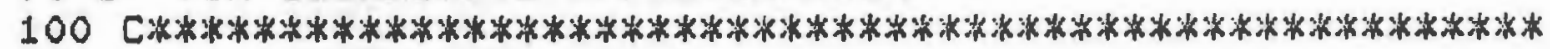

$110 \mathrm{C}$

120

130

140

150

160

170

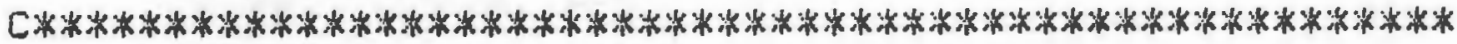

C INITIALIZATION SECTION

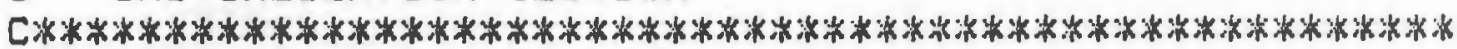

FEAII (B)HLAST, ITEF

WFITE ( 9 ) HLAST, ITEF

WRITE $(6,5)$ ITEF

5 FORMAT (IX,'ITER $=$, I 10)

$M(1)=12$

$M(2)=0$

$M(3)=0$

$11050 \quad I=1,4096$

50 CONTINUE

$G(I)=(0.0,0.0)$

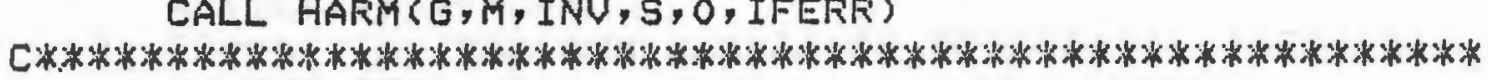

C CONUOLUE G(T) WITH LAST H(T) IN TWO FAFTS

C FIRST HALF;

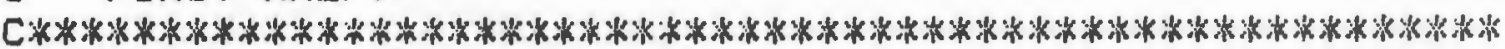

READ (10) G

no $100 \quad I=1,4096$

IF $(I+L T, 1025)$ HFFER $(I)=C M F L X(H L A S T(I), 0,0)$

100 CONTINUE

909 FORMAT (2X, 'CHECKFFOINT')

CALL HAFIMSHFFER, M, INU, $S, 2$, IFERF)

DO $200 \quad I=1,4096$

$A F I A Y(I)=H F F E Q(I) * G(I)$

200 CONTINUE

500

510

520

530

540

550
CALL HARM (AFFAY, M, INU, S, -2, IFEFF)

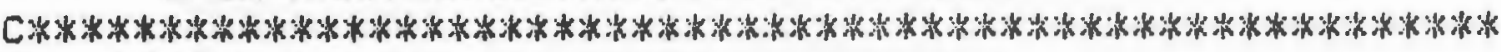
C SECONI HALF;

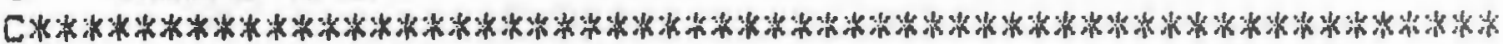

FiEAII (11) G

[II] $300 \quad I=1,4096$

IF II +LT , 1025)HNEXT (I) =FEAL (AFFAY $(I+1024)$ )

300 CONTINUE

$$
\text { AFIFAY }(I)=H F F E Q(I) * K(I)
$$

WFITE (6,909)

CALL HAFM (AFIFAY, M, INU, S,-2, IFEFFI) 
560

570

580

590

600

610

620

630

540

S50

560

670

680

690

700

710

720

730

740

750

760

770

780

790

800

310

820

830

840

850

860

870

880

890

900

910

920

930

940

950

960

970

980

$9 \% 0$

1000

1010

1020

1030

1040

1050

1060

1070

1080

1090

1100

FEAD (12) $X$

IIUMMY =FEAL (AFFAY $(500)$ )

WRITE $(6,77) \times(500), H N E X T(500)$, IUNMYY

77 FORMAT $(2 X, ' X(T)=', E 10,4, ' H 1=' E 10.4, ' H 2=\prime, E 10.4)$

$00 \quad 400 \quad I=1,1024$

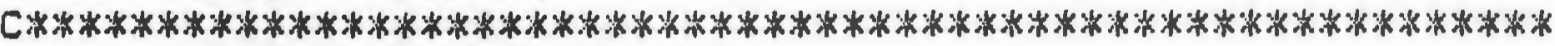
C COMFUTE LATEST CORFECTION

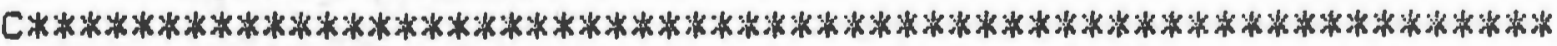
CHANGE $(I)=X(I)-H N E X T(I)-F E A L(A R F A Y(I))$

400. CONT INUE

$I T E R=I T E F+1$

WRITE $(\sigma, 5)$ ITEF

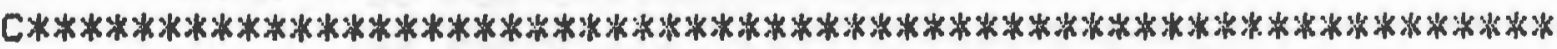
C SAU LATEST ESTIMATE, FLOT RESULTS

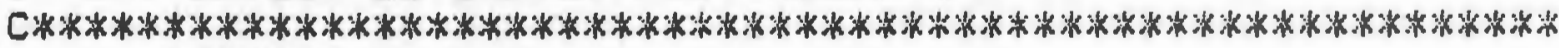

REWIND 8

WRITE (8) HNEXT, ITER

YMAX $=0$

$Y M I N=0$

IIO $500 \quad I=1,1024$

IF (YMAX,LT.HNEXT (I ) ) YMAX:HNEXT (I)

IF (YMIN.GT. HNEXT (I) YMIN=HNEXT (I)

500 CONTINUE

IF (ABS (YMAX) , GT, AES (YMIN) ) FNOFM=ABS (YMAX)

IF (ABS (YMIN) , GE, AES (YMAX)) FNOFM=AES (YMIN)

DO $600 \quad I=1,1024$

HNEXT $(I)=H N E X T(I) / F N O F H$

$X\langle I\rangle=F L O A T(I)$

600 CONTINUE

WRITE $(\sigma, 10)$ FNORM

10 FOFMAT (2X. 'MAXIMUM MAGINITUIIE OF HNEXT = 'E2O.6)

REWINI 97

CALL SETUFN $60 ., 1024,-1,2,1,2,5,0.3,0$, 'TAU',

\$' H (T), ITEFATION $¥, 3,17,5,5,1)$

CALL NFLOT $(X, H N E X T, 1024,1,0, F)$

CALL SLEW $(0,0$,

CALL FESET

CALL NUMFLT $(-, 25,3,3,90,1,125, F L O A T(I T E R), 0)$

CALL OFIGIN $(0,5,5)$

YMAX $=0$.

$Y M I N=0$.

DO $700 \quad I=1,1024$

IF (YHAX.LT.CHANGE (I ) ) YMAX =CHANGE (I)

700 CONTINUE

IF (YMIN,GT.CHANGE (I) ) YMIN=CHANGE (I)

FNORM $=$ YMAX

IF (YMAX.LT . ABS (YMIN) )FNOFM=YMIN

LIFITE $(G, 110)$ FNOFM

FNOFM=ABS (FNORM)

110 FOFMAT (2X, 'MAXIMUM MAGNITUIE OF COFKECTION = "E2O.8) DO $800 \quad I=1,1024$

800 CHANGE (I ) =CHANGE $(I) / F N O F M$

CALL SETUFN $(0,1024,1,-1,2,1,2,5,0,3,0$, 'TAU',

\$'CORRECTION', $3,10,5,5,1)$ 


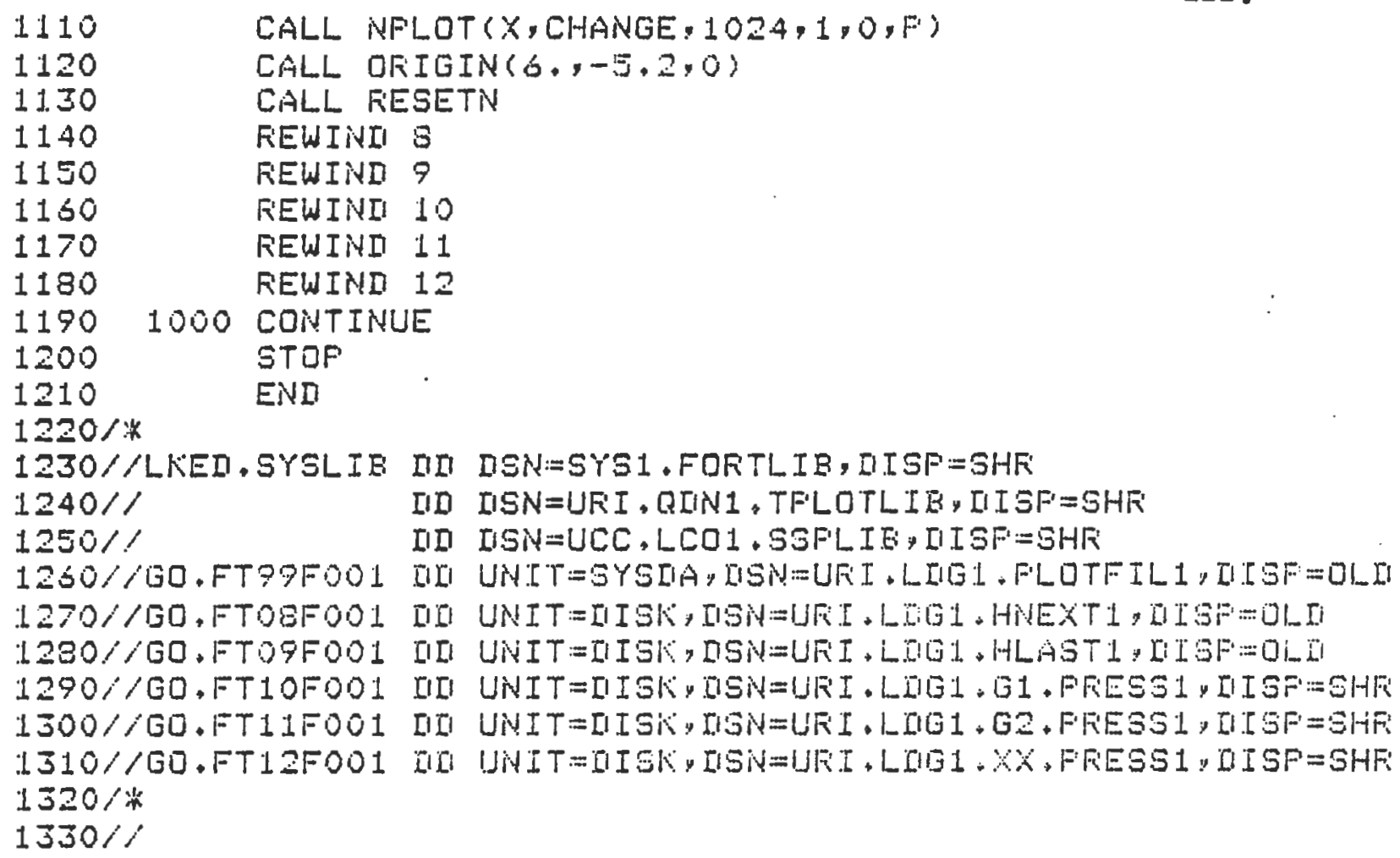

